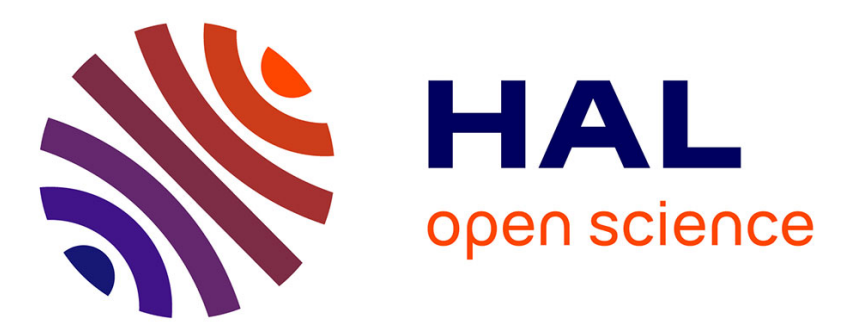

\title{
Nouvelles recherches sur Koh Ker (Chok Gargyar). Jayavarman IV et la maîtrise des mondes \\ Éric Bourdonneau
}

\section{To cite this version:}

Éric Bourdonneau. Nouvelles recherches sur Koh Ker (Chok Gargyar). Jayavarman IV et la maîtrise des mondes. Monuments et mémoires de la Fondation Eugène Piot, 2011, 90 (1), pp.95 - 141. 10.3406/piot.2011.1735. halshs-01885978

\section{HAL Id: halshs-01885978 \\ https://shs.hal.science/halshs-01885978}

Submitted on 2 Oct 2018

HAL is a multi-disciplinary open access archive for the deposit and dissemination of scientific research documents, whether they are published or not. The documents may come from teaching and research institutions in France or abroad, or from public or private research centers.
L'archive ouverte pluridisciplinaire HAL, est destinée au dépôt et à la diffusion de documents scientifiques de niveau recherche, publiés ou non, émanant des établissements d'enseignement et de recherche français ou étrangers, des laboratoires publics ou privés. 


\section{Nouvelles recherches sur Koh Ker (Chok Gargyar). Jayavarman}

IV et la maîtrise des mondes

\section{Éric Bourdonneau}

\section{Citer ce document / Cite this document :}

Bourdonneau Éric. Nouvelles recherches sur Koh Ker (Chok Gargyar). Jayavarman IV et la maîtrise des mondes. In: Monuments et mémoires de la Fondation Eugène Piot, tome 90, 2011. pp. 95-141;

doi : https://doi.org/10.3406/piot.2011.1735

https://www.persee.fr/doc/piot_1148-6023_2011_num_90_1_1735

Fichier pdf généré le 19/07/2018 


\title{
Nouvelles recherches sur Koh Ker (Chok Gargyar). Jayavarman IV et la maîtrise des mondes ${ }^{1}$
}

\author{
Éric Bourdonneau
}

\author{
La recherche du sens livre un développement, \\ la recherche des changements ne livre pas de l'histoire. \\ Louis Dumont, Homo Hierarchicus..., I966, p. 374.
}

$\mathrm{L}^{\prime}$ histoire du Cambodge ancien demeure assez peu ou assez mal périodisée. De la « fondation du Funan » à la « chute d'Angkor », en suivant le cours de plus d'un millénaire d'histoire, il ne manque pas d'évolutions, de césures, de phases de transition qui s'imposent plus ou moins d'elles-mêmes à l'observation, et les tentatives sont nombreuses pour affiner ou assouplir le découpage, évidemment conventionnel et trop lâche, en une période " préangkorienne » et une période " angkorienne ». Mais, si ces cadres chronologiques sont, dans une première approche, aisément affinés en faisant l'inventaire des transformations les plus remarquables propres à telle ou telle époque, on rappellera, en empruntant ici à la formule de Louis Dumont, qu'il peut exister une distance assez considérable entre cette « recherche des changements » et la restitution d'un « développement » que l'on peut désigner à bon droit comme de l'histoire.

Le règne de Jayavarman IV (r. 921-941), marqué par le déplacement de la capitale à Koh Ker, est précisément l'une de ces périodes où la rupture avec ce qui précède et ce qui suit est en apparence si profonde que les innovations observées ont suscité plus de perplexité que d'hypothèses sur le sens historique à leur donner. En ce domaine, une solution commode a consisté à présenter comme une "parenthèse » les deux décennies de l'accès au pouvoir de Jayavarman IV, parenthèse dans laquelle pouvaient être ainsi rangées les créations les plus originales (iconographiques et architecturales en particulier) de son règne.

Il est vrai que le regard que les anciens Khmers ont eux-mêmes porté sur cet épisode, tel qu'il est documenté par l'épigraphie, peut paraître alimenter une lecture en ces termes. Rājendravarman (r. 944-967/968), qui accède au pouvoir à la suite du court règne du fils de Jayavarman IV à Koh Ker (Harșavarman II, r. ca 941-944), est ainsi célébré comme le

1 La présente étude s'inscrit dans le cadre d'une mission archéologique mise en place sur le site de Koh Ker en 2008. Cette dernière constitue, plus largement, l'un des volets d'une réflexion menée sur l'histoire des lieux saints du Cambodge ancien. Mon collègue Arlo Griffiths a bien voulu lire une première version de ce travail et me faire part de ses observations. Je lui exprime ici ma gratitude. 
souverain ayant restauré la splendeur perdue de la capitale Yaśodharapur $\overline{1}^{2}$. En revenant à Angkor, rappelons qu'il choisit par ailleurs d'ériger son " temple aux ancêtres » sur « l'île du bassin de Yaśodhara " (dvīpe tațākasya yaśodharasya), le baray oriental édifié précisément par le fondateur de la cité délaissée, Yaśovarman (r. 889-ca. 910)³. La volonté de Rājendravarman d'inscrire son règne dans la continuité du grand œuvre accompli par son illustre prédécesseur, s'exprime encore, et de façon tout à fait remarquable, dans ce qui s'offre à nous aujourd'hui comme un dialogue établi entre les deux souverains par delà les inscriptions, Rājendravarman semblant répondre à Pre Rup aux supplications formulées par Yaśovarman dans les stances finales des stèles de Lolei et de Thnãl Baray ${ }^{4}$.

Koh Ker : une simple parenthèse donc, ou, à tout le moins, une période de bouleversements à la postérité limitée?

La position défendue dans cette étude sera très différente. S'il existe une réelle singularité des réalisations entreprises sous le règne de Jayavarman IV, celles-ci n'en sont pas moins profondément ancrées dans les grandes évolutions qui nous paraissent traverser un "long $\mathrm{x}^{\mathrm{e}}$ siècle » (c'est-à-dire débordant largement sur les $\mathrm{IX}^{\mathrm{e}}$ et $\mathrm{XI}^{\mathrm{e}}$ siècles). À la fois moment singulier et étape d'un mouvement de plus grande ampleur, l'épisode de Koh Ker se présente comme un véritable tournant dans l'histoire angkorienne. Certes, on ne saurait également donner trop d'emphase à une telle formulation. Les autres règnes majeurs qui ont ponctué l'histoire de ce « long $\mathrm{x}^{\mathrm{e}}$ siècle » (ceux de Indravarman, Yaśovarman, Rājendravarman, Jayavarman V et Sūryavarman I) paraissent offrir chaque fois un visage renouvelé de la société khmère et de ses institutions. Selon la fenêtre chronologique qui est privilégiée, chacun d'entre eux est probablement susceptible de se prêter à une interprétation en terme de «tournant».

C'est là la matière d'une réflexion qui reste à mener sur les rythmes de l'histoire angkorienne et sur les fondements d'une périodisation définie au plus près de la succession des règnes. Une telle périodisation, qui demeure très prégnante dans la littérature, est avant tout, on le sait, le produit d'une historiographie traditionnelle où l'histoire politique étroitement événementielle a imposé sa grille de lecture (ajustée à la chronologie des grands monuments et des styles décoratifs). Notons néanmoins qu'une telle périodisation pourrait aussi offrir quelques vertus heuristiques dans la mesure où elle invite à prendre au sérieux l'un des traits saillants du discours tenu par la royauté la mise en scène du souverain en premier personnage (re-)fondateur du royaume - et à s'interroger ainsi sur la signification de l'acte de « fonder » dans la vision du monde des anciens Khmers.

Il y a donc là un équilibre délicat à trouver. Si le règne de Jayavarman IV représente un tournant, comme nous souhaitons le montrer ici, il n'est assurément pas le seul épisode fondateur de l'histoire angkorienne. Disons surtout, en manière de compromis, que les éléments de rupture revêtent un caractère peut-être plus manifeste, plus immédiatement visible que les éléments de continuité qui apparaissent tout aussi décisifs. L'enjeu demeure, là comme ailleurs, de penser l'articulation des uns et des autres.

2 Cf. la stèle de Pre Rup, K. 806, st. CCLXXIV (Codès, IC I, p. 102) et les inscriptions de Bat Chum, K. 266, st. XIII (Codès 1908, p. 227) et de Prasat Beng Vien, K. 872, st. XIV (Cœè̀s, IC V, p. 99).

3 Cf. inscription de Baksei Chamkrong, K. 286, st. XLIV (Cœè̀s, IC IV, p. 93).
4 Thnãl Baray : K. 282-D st. XXIII (Bergaigne et Barth, ISCC $\mathrm{n}^{\circ}$ LIX, p. 487 et 503) ; Lolei : K. 323 st. XC (Bergaigne et Barth, ISCC $\mathrm{n}^{\circ} \mathrm{LV}$, p. 402 et 411 ) et K. 324 st. II-III (Bergaigne et Barth, ISCC $\mathrm{n}^{\circ}$ XXXIX, p. 325-326). Réponse dans la stèle de Pre Rup : K. 806 st. CCLXXV (Cœè̀s IC I, p. 102 et 139 n. 5). Voir également Cœdès 1940, p. 327-328. 


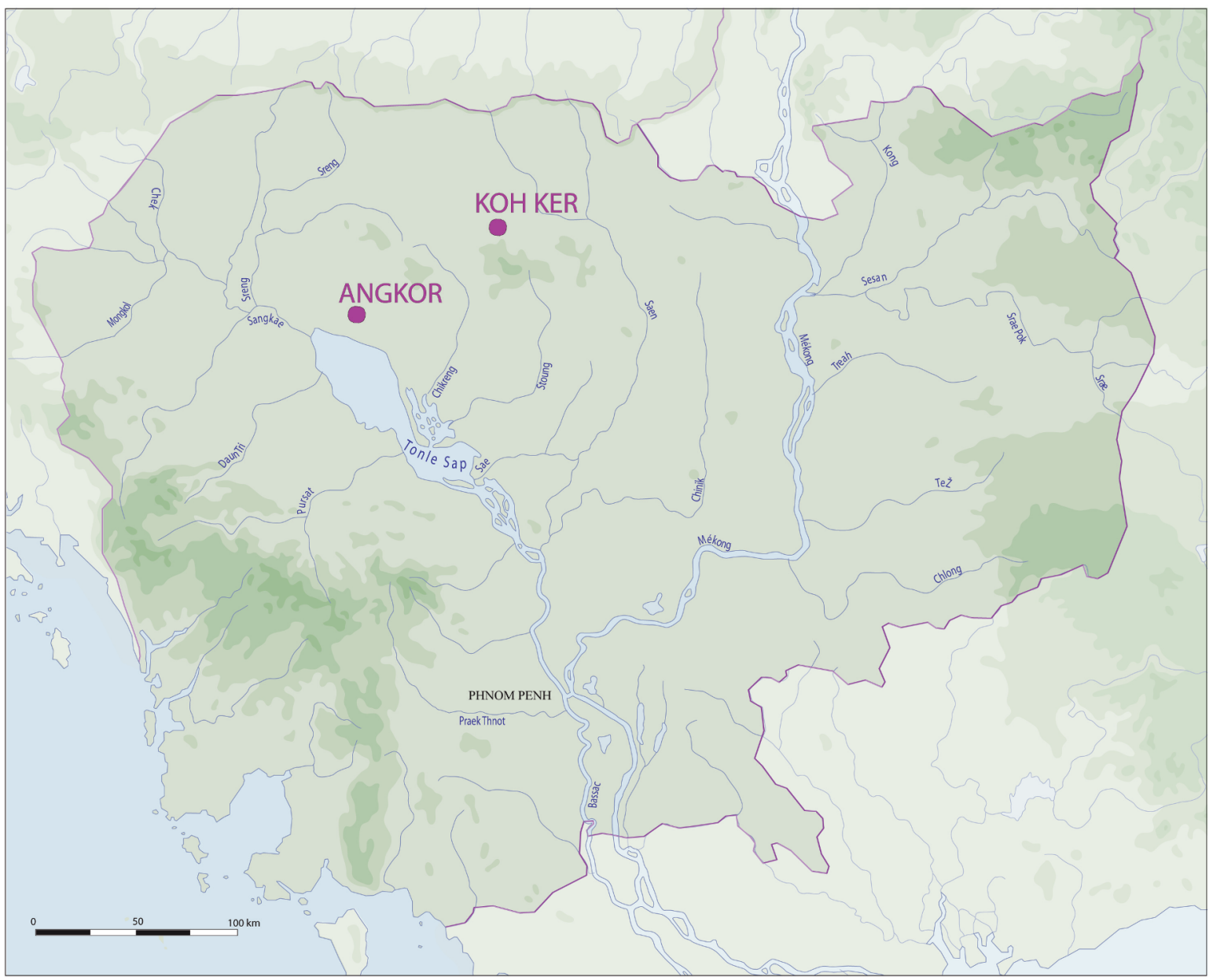

Fig. 1 Localisation du site de Koh Ker (réalisation : Chrin Narong).

\section{Koh Ker / Chok Gargyar, entre rupture et continuité}

Le déplacement de la capitale

Le déplacement de la capitale à $80 \mathrm{~km}$ au nord-est d'Angkor est emblématique de ce statut quelque peu ambigu de Chok Gargyar (le site moderne de Koh Ker, aujourd'hui dans la province de Preah Vihear) dans l'histoire angkorienne (fig. 1).

Au premier abord, il marque une nette rupture avec une tradition sans doute vieille de plus de deux siècles ${ }^{5}$. L'événement n'est certainement pas sans lien avec les luttes de pouvoir qui paraissent marquer la succession de Yaśovarman. Si Jayavarman IV monte sur le trône et installe sa capitale à Chok Gargyar dès 921, les deux fils de Yaśovarman, Harśavarman I ${ }^{\text {er }}$ (r. ca 910-922) et Ísānavarman II (r. 922-928), paraissent assurer la continuité du pouvoir à Angkor 
même, quelques années encore ${ }^{6}$. Cette coexistence est gommée dans les inscriptions plus tardives ; celles-ci réordonnent la succession des rois selon un unique fil chronologique qui ne reconnaît l'accession de Jayavarman IV au pouvoir suprême qu'à la suite du règne de ces deux neveux (Jayavarman IV ayant épousé une sœur, ou une demi-sœur, de Yaśovarman) ${ }^{7}$.

Si ce bref dédoublement de la capitale est bien l'expression de rivalités non résolues entre les différentes branches de la maison royale, et les maisons aristocratiques mobilisées autour de celles-ci, la notion d'usurpation invoquée par Cœdès à l'adresse de Jayavarman IV, mais contestée par Claude Jacques, sans être a priori fausse, est relative ${ }^{8}$. Importent ici ces réseaux complexes d'alliance tissés autour de la royauté.

De tels réseaux interdisent, à notre sens, l'hypothèse d'une scission territoriale du royaume. À ce sujet, on gardera tout d'abord à l'esprit que le $\mathrm{x}^{\mathrm{e}}$ siècle voit l'émergence d'une classification en quatre catégories de quelques-unes des principales charges officielles du royaume, numérotées en sanskrit de un à quatre $(e k a, d o, \operatorname{trin} i$, catvāri). L'une des premières attestations de cette classification est précisément fournie par une inscription datée du règne de Jayavarman IV ${ }^{9}$. Or l'interprétation la plus convaincante d'une telle institution consiste à y reconnaître la préfiguration de la distinction entre quatre "Maisons princières » dans le Cambodge post-angkorien (et jusqu'à l'époque moderne) ${ }^{10}$. À l'époque documentée par Étienne Aymonier, ces « Maisons princières » se partageaient les cinquante-sept provinces du royaume. Comme le souligne cet auteur, il faut naturellement se garder de croire qu'il y avait au Cambodge deux ou plusieurs rois : "l'autorité réelle étant concentrée entre les mains du Souverain chef de la maison $e k$ ou première $»^{11}$. Le principe d'une imbrication des provinces tenues par les différentes maisons de la famille royale n'en retient pas moins l'attention.

Une coïncidence pour le moins troublante s'oppose par ailleurs à l'hypothèse d'une partition du royaume entre 921 et 928. La date de consécration du Prasat Thom de Koh Ker, le grand sanctuaire śivaite bâti par Jayavarman IV au cœur de sa capitale - le mercredi 12 décembre 921, "vers $8 \mathrm{~h} 47$ »-est très exactement celle indiquée, avec le même raffinement de précisions astrologiques, dans deux autres temples situés, non pas à Koh Ker, mais dans la région même d'Angkor : le Prasat Kravan (K. 269-270) et le Kôk O Chrung (K. 260, avec diagramme astrologique ${ }^{12}$. L'hypothèse

6 Sur la date d'accession au pouvoir de Jayavarman IV en 921, voir les inscriptions du Prasat Thom de Koh Ker, K. 184 et K. 682, discutées dans Cœdès 1931. Sur les dates des règnes de Harśavarman I $^{\text {er }}$ et de Ísaānavarman II, voir K. 164 datée de 922 (Cœè̀s, IC VI, p. 96) et, pour le second, K. 872-873 (Cœè̀s, IC V, p. 98) et K. 831 (Codès, IC V, p. 147)

7 e.g. la stèle de Baksei Chamkrong (948/869 śaka) , K. 286 st. XXX-XXXVII (Cœè̀s IC IV, p. 92 et 99). À Koh Ker même, et dès le règne de Jayavarman IV, cf. K. 675 st. X-XX (Cœè̀s IC I, p. 62-63 et 66-67)

8 Cf. Jacques 2009, p. 15.

9 K. 99, 1. 4 : khloñ glāì nā eka (Cœè̀s, IC VI, p. 108).

10 Comme à l'époque angkorienne, les quatre Maisons sont chacune dénommées par un nombre sanskrit (désormais pālinisés $e k$, do, trī, citva) et leurs organisations hiérarchiques sont calquées les unes sur les autres. Le souverain est bien sûr à la tête de la première d'entre elles. Selon Aymonier, les trois autres Maisons princières sont attribuées respectivement aux trois personnages suivants : " le roi qui a abdiqué, appelé upayuvrāj, dont le parasol royal est à six étages ; le premier prince du sang, héritier présomptif, uparāj, au parasol de cinq étages ; la reine-mère Brah varrājjīni ou, à défaut, une reine ou la première princesse du sang, au parasol royal de quatre étages » (Aymonier 1900, p. 61). 11 Le partage se faisait dans les proportions suivantes: quarantedeux, sept, cinq et trois, les quinze dernières étant dispersées (ibid.). 12 Cf. Billard 2006, p. 406-407. Contra Golzio 2006, p. 59, qui introduit un décalage de deux jours entre la fondation du Prasat Kravan, et celle du Prasat Thom. Maxwell (qui cite Golzio et ignore l'article de Billard) commet, à nos yeux, un contresens en proposant d'interpréter la fondation du Prasat Kravan comme une réponse, en forme de défi, à la consécration d'un Śiva "Seigneur des trois mondes" au Prasat Thom de Koh Ker (Maxwell 2010, p. 2). Cf. infra. Sur près de 300 dates (hors IMA, "Inscriptions modernes d'Angkor ") recensées et étudiées par Roger Billard, une telle correspondance ne se retrouve qu'à quatre autres reprises. Dans deux cas au moins, il est très improbable que les acteurs des fondations aient eux-mêmes ignoré cette coïncidence des dates. Cf. K. 286 et K. 180 datées de 948 ; K. 444 , K. 869 et K. 1063 datées de 974 ; K. 292 et K. 467 datées de 1011 ; K. 447 et K. 493 datées de 657. 
d'un simple hasard de calendrier paraît d'autant plus douteuse que les divinités érigées à cette occasion présentent de profondes affinités. Comme nous y reviendrons, ces fondations s'interprètent beaucoup plus probablement comme la partie visible du réseau de pouvoir mobilisé autour de Jayavarman IV.

Le scénario de rivalités exacerbées à la fin d'un règne (et a fortiori d'un long règne), tandis que se pose la question du choix du successeur, n'a certainement rien de spécifique au contexte en apparence troublé qui suit la mort de Yaśovarman. Ce qui l'est davantage est que ces rivalités ne se soient pas résorbées à l'interrègne et qu'une telle situation de blocage ait abouti au déplacement de la capitale.

Il faut néanmoins préciser alors ce qui, dans ce déplacement du lieu de pouvoir, est véritablement inédit. Le centre de gravité du royaume est certes ancré depuis la seconde moitié du $\mathrm{VII}^{\mathrm{e}}$ siècle dans la région d'Angkor, mais la capitale n'a jamais cessé par la suite d'être déplacée à l'intérieur de la plaine de Siem Reap. De ce point de vue, la création d'une nouvelle capitale et le déplacement à Koh Ker s'inscrivent dans une certaine continuité. La rupture n'est pas tant ici dans le déplacement du centre de pouvoir que dans son décentrement, en dehors de la plaine d'Angkor, conséquence de ces rivalités non résolues.

On relèvera que ce décentrement s'accompagne d'une autre pratique inédite : l'adoption d'un toponyme khmer - Chok Gargyar, le « bosquet des koki»-, et non sanskrit comme c'est pourtant le cas pour les autres capitales connues (e.g. Bhavapura, Ísānapura, Yaśodharapura, Jayendranagarī). Là encore, le fait est exceptionnel mais n'est certainement pas incongru à la lueur des évolutions qui se dessinent plus en profondeur. N'est-il pas à comprendre en effet comme l'une des manifestations du rapport nouveau entre le vieux khmer et le sanskrit qui s'affirme progressivement dans l'épigraphie des $\mathrm{X}^{\mathrm{e}}$ et $\mathrm{XI}^{\mathrm{e}}$ siècles ${ }^{13}$ ? Ce développement de l'usage du vieux khmer nous semble lui-même devoir être rangé parmi les signes d'une vision du monde renouvelée qui accorde toujours plus de poids à la «surface d'en-bas» (phdai karoṃ), pour utiliser une expression bien attestée dans les inscriptions.

Il est remarquable, à nos yeux, que les panégyriques célébrant l'œuvre de restauration de l'ancienne capitale par Rājendravarman soient susceptibles d'une lecture assez semblable. En première analyse, ils témoignent de la volonté du souverain de prolonger ce qui a été interrompu. Mais l'accent mis sur la continuité (avec ce qui fut avant Koh Ker), s'exprime à travers un discours lui-même inédit : un «discours de la capitale » dans lequel Yaśodharapura, en devenant cette ville d'un passé glorieux, que l'on abandonne puis que l'on restaure, prend le statut d'un objet d'histoire ${ }^{14}$. On relèvera qu'au même moment, l'épigraphie de Rājendravarman met l'accent sur l'autochtonie de la royauté khmère en faisant remonter celle-ci à un nouveau couple d'ancêtres mythiques, Kambu (svāambhuva) et Merâ ${ }^{-15}$. Attacher les ancêtres à la terre, inscrire

13 Sur cette évolution de la relation entre langue vernaculaire et langue savante dans le Cambodge ancien, et plus largement le monde indianisé, voir la thèse désormais fameuse développée dans Pollock 2006. Nous renvoyons également aux observations de Saveros Pou sur la « qualité " grandissante, à partir du $\mathrm{x}^{\mathrm{e}}$ siècle, des textes épigraphiques rédigés en vieux khmer (Pou 2001, p. 130). 14 Nous empruntons la notion de "discours de la capitale " à Mahoko Kyōraku («Le discours de la capitale, le cas de Heian », traduit par Anne Bouchy, Kyōraku 2001).
15 Si la figure de Kambu est bien attestée ailleurs, celle de Merā (qui n'est pas sans évoquer, comme Arlo Griffiths et Emmanuel Francis nous le font observer, l'apsaras Menakā des généalogies mythiques pallava) fait une apparition beaucoup plus ponctuelle dans le corpus épigraphique. Voir l'inscription de Baksei Chamkrong K. 286 st. XI et XII (Cœedès, IC IV, p. 90). 
la capitale dans la géographie et l'histoire vécues, ou encore la fixer une fois pour toutes en un lieu ${ }^{16}$, tout cela participe de ce même mouvement d'« affermissement » de la « surface d'en-bas », sur lequel nous aurons à revenir.

\section{Jayavarman IV et le culte du devarāja}

Rendre compte des éléments de rupture et de continuité dans le règne de Jayavarman IV revient pour une large part à s'interroger sur les raisons pour lesquelles les luttes de pouvoir entre les prétendants au trône ne se sont pas résorbées à ce moment précis de l'histoire angkorienne. Sauf à réduire l'épisode à une simple anecdote de l'« histoire traités-et-batailles » dénoncée ces dernières années par Michael Vickery, une telle réflexion peut difficilement se passer de l'examen du champ évolutif des rapports de force qui traversent l'ensemble de la société khmère du $\mathrm{X}^{\mathrm{e}}$ siècle (bien au-delà du cercle restreint de la royauté) ${ }^{17}$. Cet examen nécessite d'engager une histoire sociale qui fait aujourd'hui cruellement défaut et dépasse naturellement de beaucoup l'horizon de la présente étude.

À titre d'hypothèse de travail, esquissée ici à très grands traits, nous nous contenterons d'une première observation, faite à nouveau sur le temps long et qui, a priori, ne souffre pas de contestations. À considérer l'évolution du profil social des auteurs des inscriptions (et des dignitaires qui y sont mentionnés), le « long $\mathrm{x}^{\mathrm{e}}$ siècle » que nous avons évoqué semble correspondre à une phase de complexification de la hiérarchie sociale qui se traduit par un étalement et une densification de la gradation des rangs et des statuts (en particulier dans les espaces « intermédiaires » de la société). Par contraste, les périodes précédentes et suivantes se caractérisent par une sorte de resserrement ou de contraction, selon des modalités d'ailleurs très différentes, de la hiérarchie sociale à ses extrêmes, de sorte que se devine alors une sorte de césure entre le pouvoir central au sommet de l'État et le reste de la société.

Dans ce «monde plein » socialement qui émerge à partir du $\mathrm{IX}^{\mathrm{e}}$ siècle, les rivalités de pouvoir entre les grandes maisons aristocratiques se seraient, suggérons-nous, exacerbées, et de cette tension nouvelle a pu naître la situation de blocage observée à la succession de Yaśovarman, aboutissant à ce dédoublement de la capitale. Il va de soi que cette observation sur l'évolution globale de la société est, à nos yeux, solidaire du constat fait précédemment d'un « affermissement » progressif de la «surface d'en-bas ». Pour l'heure, tout en gardant à l'esprit ces processus de plus grande ampleur, nous insisterons surtout sur le fait que, dans ce contexte de rivalités accrues, les discours de légitimation accompagnant la transmission du pouvoir royal ont pu ne plus offrir la même valeur opératoire. Le point est d'importance car il offre une première mise en perspective de ce qui constitue l'une des grandes innovations institutionnelles de l'accession au trône de Jayavarman IV : le culte du vrah kamraten añ jagat ta räjya, le kamraten் jagat ta räja ou, en sanskrit, devarāja des inscriptions plus tardives.

16 De retour à Angkor, la capitale ne montrera plus la même mobilité qu'avant l'épisode de Koh Ker. La construction d'une enceinte et de pavillons d'entrée en pierre, tout d'abord pour le palais royal, puis pour la ville elle-même, concrétisera dans le paysage une telle évolution, en contribuant également à la fixation de la capitale. De ce point de vue également, l'épisode de Koh Ker constitue moins une parenthèse qu'un tournant fondateur ou, tout au moins, un événement déclencheur (comme pourra l'être également le contexte dramatique de l'accession au pouvoir de Sūryavaman $\mathrm{I}^{\mathrm{er}}$ au début du $\mathrm{XI}^{\mathrm{e}}$ siècle ou de Jayavarman VII à la fin du XII ${ }^{\mathrm{e}}$ siècle).

17 Cf. Bourdonneau 2003 pour une discussion de la critique historiographique proposée par Vickery (et de l'opposition tranchée, et problématique, entre histoires événementielle et non événementielle que celui-ci retient). 
Rappelons que la nature exacte de ce culte qui associe de façon inédite la royauté et la sphère divine, est l'un des sujets qui a le plus fait couler d'encre dans la littérature. Sa date même de création est matière à débat. De façon un peu surprenante, une large part de l'historiographie récente a suivi, sans plus d'examen critique, le contenu de la célèbre stèle de Sdok Kak Thom (K. 235), attribuant à Jayavarman II (dont le parcours singulier s'échelonne entre la fin du viII ${ }^{\mathrm{e}}$ siècle et le début $\mathrm{du} \mathrm{Ix}^{\mathrm{e}}$ ) la fondation de ce culte. Il existe pourtant de nombreuses objections à cette attribution par une inscription tardive, gravée deux siècles et demi après les faits rapportés. Cœè̀s ne manqua pas, en son temps, de formuler certaines d'entre elles mais les intuitions de l'auteur n'ont guère été suivies ${ }^{18}$.

Le sujet, riche d'implications pour l'histoire politique et culturelle d'Angkor, exige de prendre le temps de l'argumentation et nous renvoyons là à une étude ultérieure pour un réexamen des données disponibles et une pleine discussion des travaux qui se sont succédés depuis un siècle sur le thème du devarāja ${ }^{19}$. En anticipant sur une telle étude, nous ferons dès à présent nôtre la (seconde) thèse de Coedès, attribuant à Jayavarman IV et non Jayavarman II la création de ce culte. La première mention de celui-ci apparaît bien dans le corpus épigraphique du Prasat Thom de Koh Ker et, comme le suggère Coedès, il n'est de fait aucune raison sérieuse de lui assigner une date plus haute. Dès lors, sa création peut être raisonnablement interprétée comme l'une des tentatives majeures du pouvoir royal de renouveler les discours de légitimation existants dans ce contexte spécifique au $\mathrm{x}^{\mathrm{e}}$ siècle.

De façon provisoire, nous laisserons là en suspens l'examen du devarāja, en ajoutant cependant une dernière remarque. L'une des réflexions récurrentes de l'historiographie sur la question est de souligner la pauvreté des sources disponibles pour nous renseigner sur l'histoire de ce culte, de sorte que l'on a pu même douter de son importance véritable, après en avoir fait l'une des institutions centrales du Cambodge angkorien.

À en juger par le très faible nombre d'occurrences du terme même de devarāja dans les inscriptions, le constat n'est pas douteux. À nos yeux pourtant, il ne vaut que pour le corpus épigraphique ou, plus exactement, il ne vaut qu'en opérant une nette séparation entre l'analyse des inscriptions et celle des dispositifs iconographiques et architecturaux. La thèse défendue ici est que les unes ne vont pas sans les autres et qu'on ne saurait rouvrir le dossier sur le devarāja sans considérer ce que les images et les monuments nous disent sur la scène rituelle où celui-ci apparaît pour la première fois.

L'exposé qui suit propose donc une analyse renouvelée des caractéristiques les plus significatives du programme architectural et surtout iconographique des temples du groupe de Koh Ker. En raison de leur position excentrée, depuis les travaux pionniers d'Henri Parmentier dans les années 1930, l'examen de ce programme d'une très grande richesse a été quelques peu négligé2 ${ }^{20}$. Nous n'en proposerons ici qu'un premier survol, offrant un aperçu des premiers résultats des recherches en cours. Il sera suivi d'une seconde étude consacrée plus spécifiquement au grand

18 Coedès 1965 et 1970 (ce second article portant un titre évocateur désignant Jayavarman IV comme « Le véritable fondateur de la royauté divine au Cambodge »). Dès 1931, Codès exprima des doutes sur le récit proposé par la stèle de Sdok Kak Thom : cf. Codès 1931, p. 14 n. 2
19 Parmi les plus récents en date, voir Jacques 2009.

20 Parmentier 1939, chap. I, « Le groupe de Koh Ker », p. 15-117. 
temple royal du Prasat Thom. La perspective adoptée dépassera néanmoins de beaucoup le seul cadre d'une monographie sur Koh Ker ; elle est plus largement une introduction à la cartographie divine du pays khmer sous le règne de Jayavarman IV, à Koh Ker et au-delà.

\section{La sainte famille de Śiva et les ganeśvara. Pillage et réseaux d'images}

La meilleure approche du groupe archéologique de Koh Ker consiste certainement à l'aborder comme un tout. Si l'on sait aujourd'hui que l'ancienne ville de Chok Gargyar n'a pas été créée ex nihilo, s'il existe bien des témoignages d'une occupation nettement postérieure, il demeure qu'une large part des douzaines de temples distribués sur les $50 \mathrm{~km}^{2}$ du site peut être attribuée au règne de Jayavarman IV (fig. 2 ) $^{21}$. Une semblable unité de temps et de lieu demeure exceptionnelle. Elle dit combien un tel ensemble monumental est marqué de l'empreinte du roi et de son règne. La chronologie interne à la période de construction a pu être relativement complexe et tous les temples connus de Koh Ker ne sont pas des fondations strictement royales. Il fait pourtant assez peu de doutes qu'un nombre important d'entre eux obéit à une même conception d'ensemble, même si celle-ci ne s'est certes pas décidée en un jour et bien qu'elle ait pu connaître de nombreux ajustements au cours de sa réalisation, ou bien encore que de nombreux temples soient à l'évidence restés inachevés.

Koh Ker se présente ainsi comme un vaste complexe rituel dont la construction s'est échelonnée sur les deux décennies du règne de Jayavarman IV. La conception unitaire de ce complexe se manifeste tout d'abord dans l'orientation des temples. Le site s'organise autour d'un axe sud-sud-est/nord-nord-ouest, qui suit la pente du terrain et détermine en particulier le tracé du Rahal, le baray de Koh Ker. Les temples situés à proximité de celui-ci et dans la partie ouest de l'ancienne ville sont orientés vers l'est ou le nord-est, tandis que ceux situés dans la partie est le sont vers l'ouest ou le sud-ouest. Dans le premier groupe, on rencontre avant tout le Prasat Thom et, au sud de celui-ci, à Andong Preng, ce qui fut probablement le site du palais royal, l'un et l'autre isoclines avec le Rahal ${ }^{22}$. Dans le second groupe, nous retiendrons en particulier le dispositif formé par quatre petits temples (sans superstructure) localisés au nord-est du Rahal ${ }^{23}$. Ils forment un alignement de quatre linga atteignant des dimensions colossales (fig. 3), implantés sur un axe là encore isocline avec le Rahal et qui, surtout, fait face au Prasat Thom dont il semble avoir été séparé simplement par un bassin ${ }^{24}$. Nous avons là une composition grandiose qui s'étire

21 Le récent inventaire dressé par l'université de Waseda recense 116 sites archéologiques, dont 74 vestiges de temples (Nakagawa et Mizoguchi 2009, p. 7, 13-18). Cf. Evans 2009, p. 59-61 pour un aperçu des données attestant d'une occupation antérieure et postérieure au règne de Jayavarman IV. Cet auteur est amené, ce faisant, à douter de l'attribution traditionnelle de la majorité des temples de Koh Ker au second quart du $x^{e}$ siècle. Ni l'évocation d'un improbable archaïsme des artisans locaux, ni celle de la diversité des plans des édifices, ne sont en mesure de remettre en cause, comme le propose pourtant l'auteur, ce que l'épigraphie et l'analyse stylistique démontrent massivement.

22 Les prospections récentes menées en 2009 et 2010 par l'équipe hongroise de la Royal Angkor Foundation confirment cette hypothèse déjà ancienne (communication personnelle József Laszlovszky). 23 Il s'agit des sites inventoriés sous les numéros IK suivants 278, 279 et 279.02, 280. Ce sont les monuments G, H et I ainsi que le Prasat Balang (intercalé entre les temples $\mathrm{G}$ et $\mathrm{H}$ ). Notons toutefois que leur désignation dans la littérature et sur les cartes publiées (dont celle reproduite ici, fig. 2) est relativement fluctuante. À ces quatre linga monumentaux s'ajoutait un cinquième linga érigé à quelques centaines de mètres plus au nord-ouest (monument K ou IK 281). De façon quelque peu aventureuse, Evans a récemment émis l'hypothèse que ce temple avait été initialement construit à proximité des quatre autres, avant d'être déplacé lors de la construction du Prasat Andong Kuk, attribué au règne de Jayavarman VII (Evans 2009, p. 59). Sans le suivre sur ce point, nous pouvons au moins retenir l'hypothèse qu'il y a pu effectivement avoir un cinquième linga aligné avec les autres, dont les matériaux auraient été remployés dans la construction du Prasat Andong Kuk.

24 L'existence de bassin a été récemment restituée par Damien Evans. Sur la carte publiée par celui-ci, une langue de terre s'avancerait vers l'intérieur du bassin, dans le prolongement de l'axe central du Prasat Thom (Evans 2009, p. 43, fig. 8). 


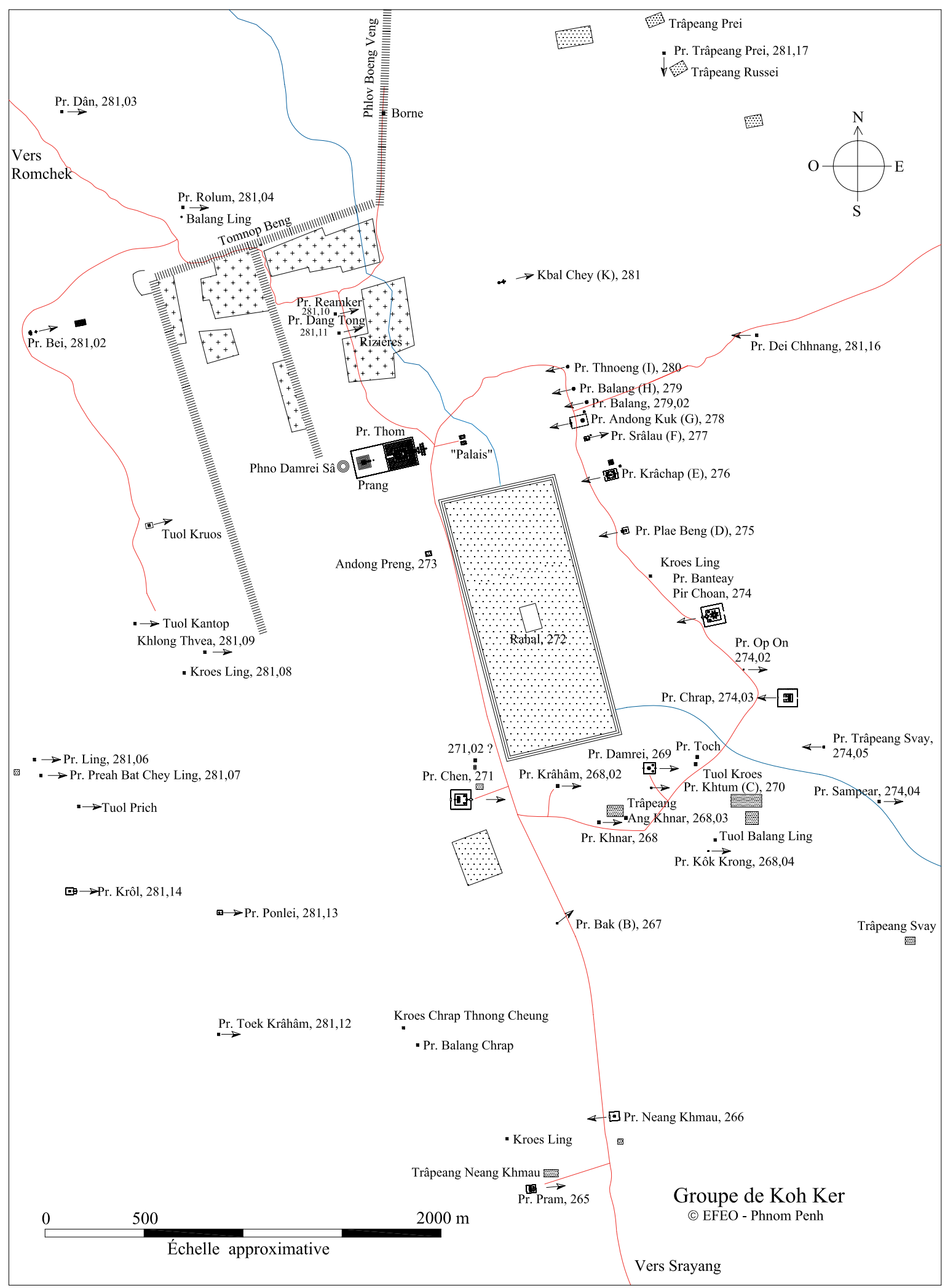

Fig. 2 Le groupe archéologique de Koh Ker (réalisation : Chrin Narong sous la direction de Bruno Bruguier). 


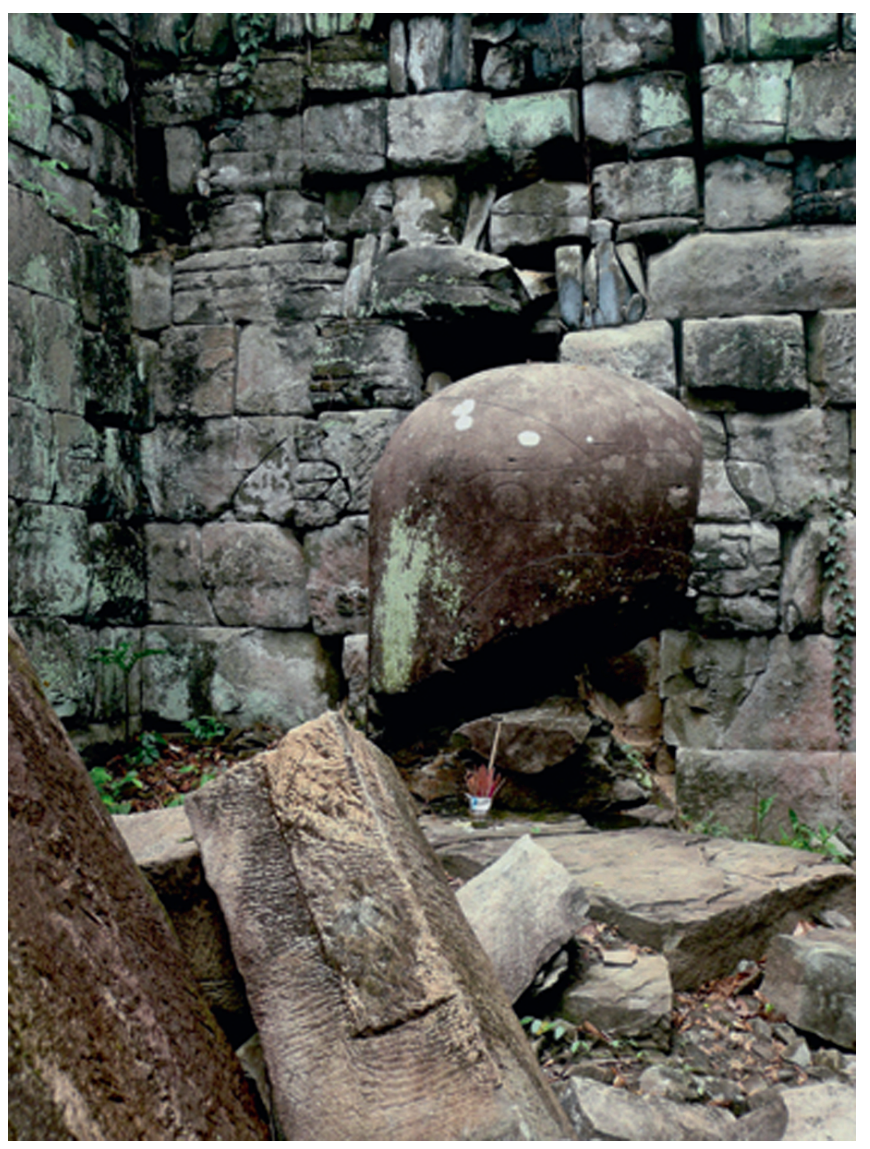

Fig. 3 Linga monumental du monument I (ph. auteur, 2008).

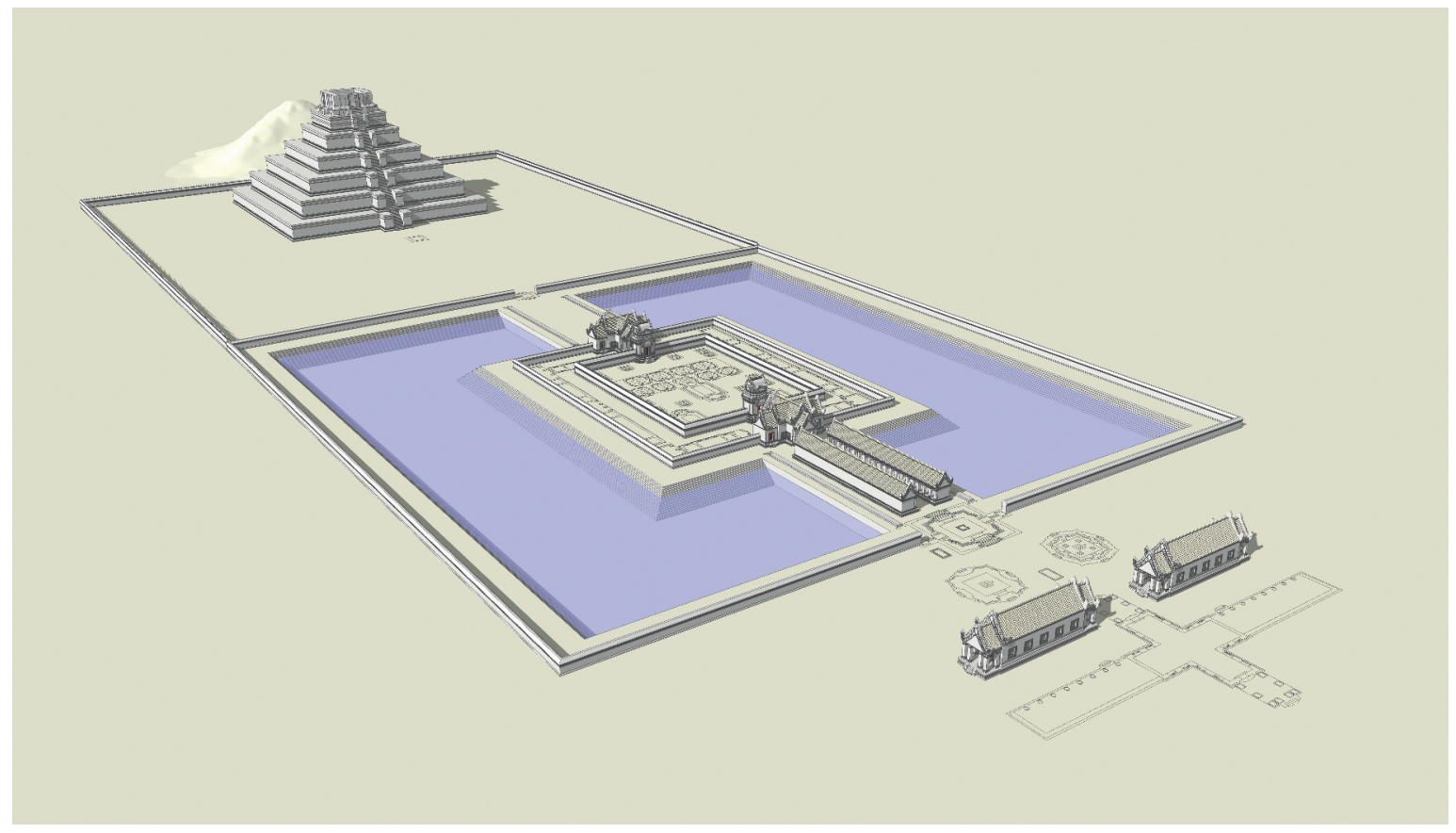

Fig. 4 Restitution du Prasat Thom (travail en cours de O. Cunin). 
d'est en ouest sur plus d'un kilomètre, ces quatre linga faisant écho au linga (aujourd'hui détruit) érigé au sommet de la pyramide du Prang et dominant la silhouette du Prasat Thom (fig. 4). Exposé probablement lui aussi à l'air libre, ce linga montrait des dimensions plus colossales encore, auxquelles il est fait allusion dans les inscriptions et dont le piédestal hors norme, avec une largeur supérieure à cinq mètres, donne une idée assez précise (cf. infra ${ }^{25}$.

D’autres temples venaient compléter le réseau cultuel tissé autour du Prasat Thom qui formait logiquement le cœur du complexe rituel de l'ancienne capitale. Le Prasat Bak, situé au sud du Rahal, est l'un d'entre eux. Composé d'une tour unique, il abritait une statue de Ganeśa, montrant là encore ces proportions imposantes qui sont l'une des marques distinctives de la statuaire et de l'architecture de Koh Ker. Brisée à une époque ancienne, cette pièce exceptionnelle a été restaurée et redressée à son emplacement d'origine par Parmentier dans les années 1930 (fig. 5). Aujourd'hui, ne subsistent plus sur le site que les fragments du piédestal autrefois monolithe avec l'image divine. La partie supérieure du piédestal a été décapitée afin de pouvoir transporter plus aisément la statue du dieu. Après avoir subi une seconde restauration, assez maladroite, qui s'apparente à une opération de maquillage, celle-ci est réapparue à la communauté scientifique en 2004, à l'occasion de la parution de l'ouvrage de Emma Bunker et Douglas Latchford Adoration and Glory, The Golden Age of Khmer Art ${ }^{26}$. Selon les auteurs, elle est désormais conservée dans une collection privée américaine ${ }^{27}$.

Si nous nous attardons ainsi sur le parcours du Ganeśa du Prasat Bak, c'est qu'il n'est nullement un cas isolé. Le pillage du groupe archéologique de Koh Ker s'est sans doute échelonné tout au long du $\mathrm{Xx}^{\mathrm{e}}$ siècle mais paraît s'être intensifié dans le sillage des événements tragiques de la fin du siècle dernier. Opiniâtres et extrêmement bien renseignés, les pilleurs ont à l'évidence quadrillé de façon systématique l'ensemble de la zone archéologique. C’est là le revers dramatique de ce qui, initialement, était une chance pour l'archéologue. Une phase de construction et d'intense occupation relativement courte, une localisation excentrée dans une région devenue désertique à la fin du XIX ${ }^{e}$ siècle, avaient permis d'observer lors de la redécouverte du site ce que l'on rencontre rarement ailleurs sur une telle échelle : des images (abondantes comme nous allons voir) conservées in situ et, dans de nombreux cas, retrouvées très précisément à leur emplacement d'origine. L'isolement du site a, par la suite, joué en sa défaveur, de deux façons : Koh Ker n'a guère fait l'objet d'études approfondies au-delà des travaux pionniers de Parmentier ; il fut particulièrement exposé aux pilleurs.

25 Ce linga n'est plus visible aujourd'hui au sommet du Prang. Une telle absence peut surprendre étant données les dimensions supposées de celui-ci. Elle se comprend plus aisément, toutefois, si l'on suppose qu'il était formé de blocs assemblés, comme c'est le cas, à Koh Ker même, du linga du Prasat Khna dont le diamètre avoisinait les 4 mètres. Ce dernier n'est qu'un gigantesque piédestal à l'air libre, lui aussi maçonné (voir la restitution proposée par l'université Waseda dans Nakagawa et Mizoguchi 2009 , p. 87, fig. 5/13-14-15). Il donne une première idée du profil et de la taille du linga érigé au sommet du Prang, dont il a pu être d'ailleurs conçu ou perçu comme une reproduction. Les blocs du linga du Prang seraient alors à chercher, pour une part, dans le large puits de fondation de la pyramide et, pour une autre part, parmi les éboulis visibles sur la façade ouest de celle-ci (éboulis constitués des blocs provenant des murs ouest de la tour-sanctuaire et du piédestal).

26 Cf. Baptiste et Zéphir 2004 pour un compte-rendu critique qui souligne bien les nombreuses réserves que suscite l'ouvrage. 27 Bunker et Latchord 2004, p. 168-170. L'identification de cette pièce avec le Ganeśa du Prasat Bak ne fait bien, à nos yeux, aucun doute. Nous joignons donc ici notre voix à celles de Pierre Baptiste, Thierry Zéphir et Bertrand Porte (Baptiste et Zéphir 2004, p. 184 ; Porte 2004, p. 177). 


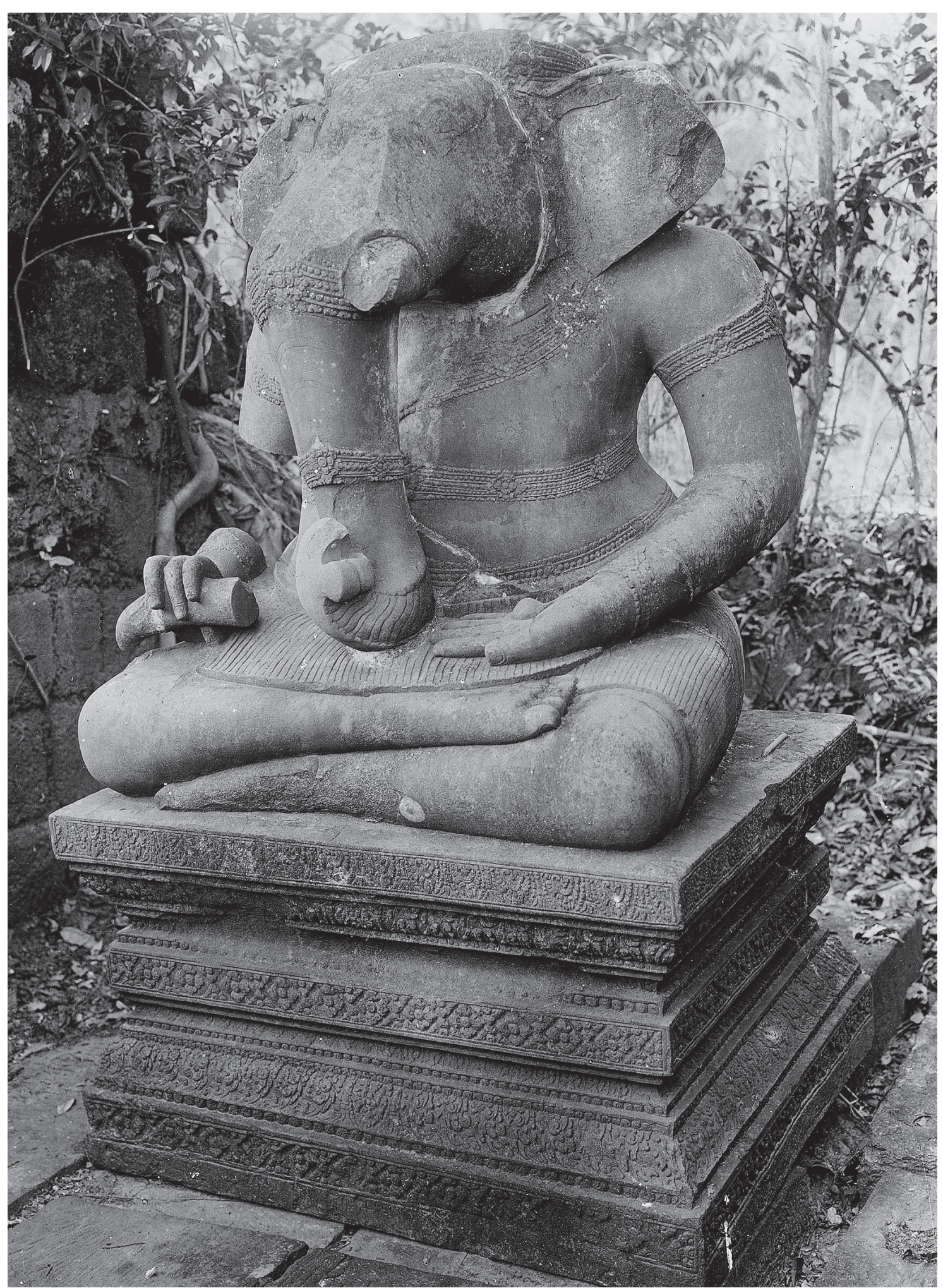

Fig. 5 Ganeśa du Prasat Bak (Archives photographiques de l’EFEO [11291]). 
Le Ganeśa du Prasat Bak offre un exemple assez peu contestable d'identification parmi les pièces de Koh Ker ayant été pillées, dans la mesure où il réunit trois critères particulièrement favorables : la statue est bien documentée par les archives photographiques disponibles (et conservées, pour une part, par l'École française d'Extrême-Orient à Paris) ; elle présente des caractéristiques stylistiques et iconographiques très spécifiques ; sa localisation d'origine était connue avec précision dès les premiers travaux menés sur le site. Bien d'autres pièces réunissent cependant, en tout ou en partie, ces mêmes critères. C'est ainsi le cas du lion atlante (fig. 6-7) acquis par le Dallas Museum of Art et qui ornait à l'origine le piédestal du Śiva dansant érigé dans le pavillon d'entrée oriental de la troisième enceinte du Prasat Thom (gopura III Est, cf. infra ${ }^{28}$. Provenant de ce même temple (et de son gopura II Est), c'est le cas encore du bossu issu de la collection de Latchford et restitué au musée national de Phnom Penh en 2002 (inv. 2943, fig. 8-9 $)^{29}$.

Deux autres statues exceptionnelles méritent également d'être citées. Il s'agit tout d'abord de l'image dite de $d v \bar{a} r a p a \bar{l} a$, acquise en 1980 par la Norton Simon Art Foundation (fig. 10) ${ }^{30}$. Nous ne disposons d'aucun document d'archives à son sujet mais ses proportions, ses caractéristiques stylistiques et iconographiques et surtout le profil des cassures au niveau des chevilles ne laissent aucun doute sur son emplacement d'origine. Elle provient du Prasat Chen de Koh Ker, construit non loin de l'angle sud-ouest du Rahal (fig. 11). Affleurant des décombres à l'intérieur du gopura I Ouest, subsistent là deux piédestaux (fig. 12) sur lesquels sont encore visibles les pieds des images (originellement monolithes avec ces piédestaux). Le socle le plus à l'ouest, où l'extrémité d'un drapé est également conservée entre les pieds du personnage, correspond très exactement à l'image de la Norton Simon Art Foundation ${ }^{31}$. Disons tout de suite, avant d'y revenir, que celle-ci doit être interprétée non comme un dvārapāla mais comme l'image de Bhīma luttant contre Duryodhana.

La statue de ce Duryodhana, également absente de la documentation existante sur Koh Ker, a fait tout récemment son apparition sur le marché de l'art (fig. 13) ${ }^{32}$. Conservée dans une collection privée européenne, elle a été proposée à la vente en mars 2011 par Sotheby’s à New York ${ }^{33}$. Là encore, l'ensemble des caractéristiques de cette image ne laisse aucun doute sur sa provenance. Faisant face à la statue de Bhīma, elle se dressait sur le socle situé à l'est dans le gopura I Ouest du Prasat Chen ${ }^{34}$.

28 Bunker et Latchford 2004, p. 166-167. Sur cette identification, cf. Baptiste et Zéphir 2008, p. 140-141. Pierre Baptiste y dresse un inventaire des lions atlantes connus à ce jour provenant, selon toute vraisemblance, de ce piédestal : outre celui de Dallas, deux autres exemples sont conservés, l'un au musée Guimet, l'autre au Musée national de Phnom Penh. Deux autres lions ont été vendus en 2003 chez Christie's et Sotheby's.

29 Bunker et Latchford 2003 et Bunker et Latchford 2004, p. $164-165$.

30 Inv. : M.1980.15.S (Ht. : 156, $8 \mathrm{~cm}$ ). Elle est également identifiée comme un dvārapāla, dans Bunker et Latchford 2004, p. 149-151.

31 Comme nous le signale Christian Fischer (UCLA, Costen Institute of Archaeology), l'hypothèse de localisation de la statue de la Norton Simon Art Foundation a été formulée une première fois en 2007 dans une note adressée par Simon Warrack (GACP) à l'autorité APSARA et à l'Unesco.

32 Nous devons à Pierre Baptiste et Thierry Zéphir d'avoir pris connaissance en décembre 2010 de l'existence de cette statue dont le musée Guimet conservait une photographie.

33 Lot 27 de la vente N08727 de Sotheby's New-York (24 mars 2011). À la date de rédaction de cet article, la vente a été annulée suite à une mobilisation de la communauté scientifique et des autorités cambodgiennes, coordonnée par l'Unesco.

$34 \mathrm{Ht} .158,4 \mathrm{~cm}$. La statue a fait très certainement l'objet de restaurations (en particulier à la tête), comme la grande majorité des pièces évoquées ici et conservées aujourd'hui dans les musées et les collections privées. Une série de mesures a été prise en 2009 sur les deux piédestaux pour contribuer, si nécessaire, à faire la preuve de telles provenances. 


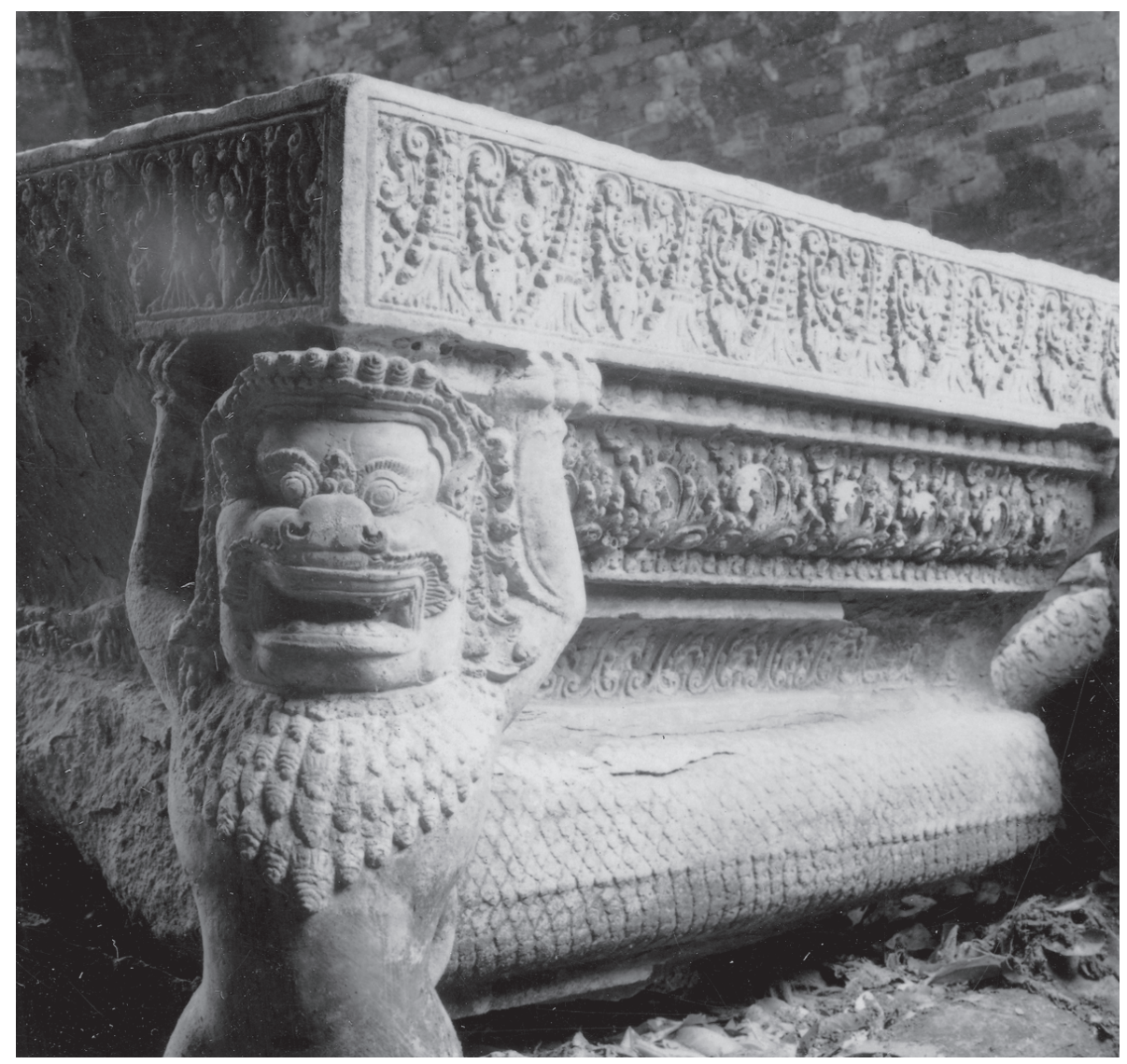

Fig. 6 Lion atlante du piédestal du Siva dansant, gopura III Est du Prasat Thom (Archives photographiques de l'EFEO [11341-2]).

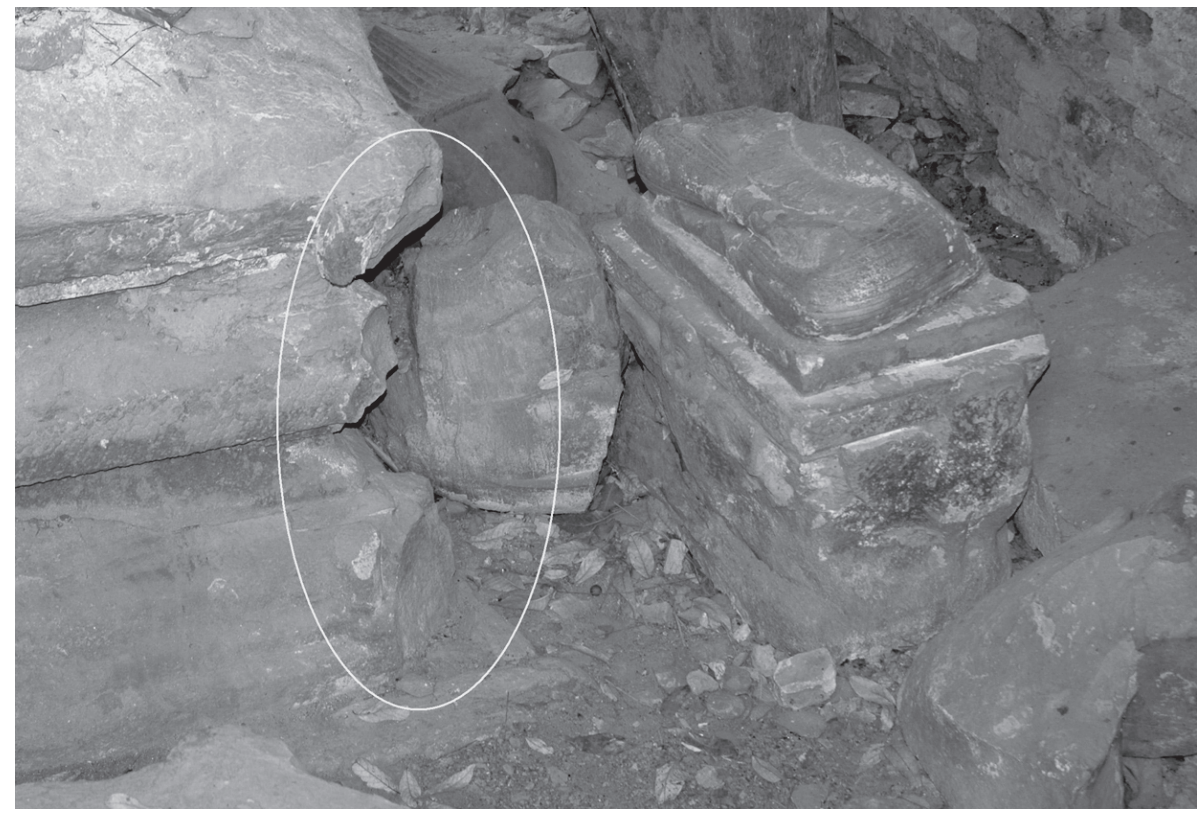

Fig. 7 Piédestal du Śiva dansant, gopura III Est du Prasat Thom (ph. auteur, 2009). 


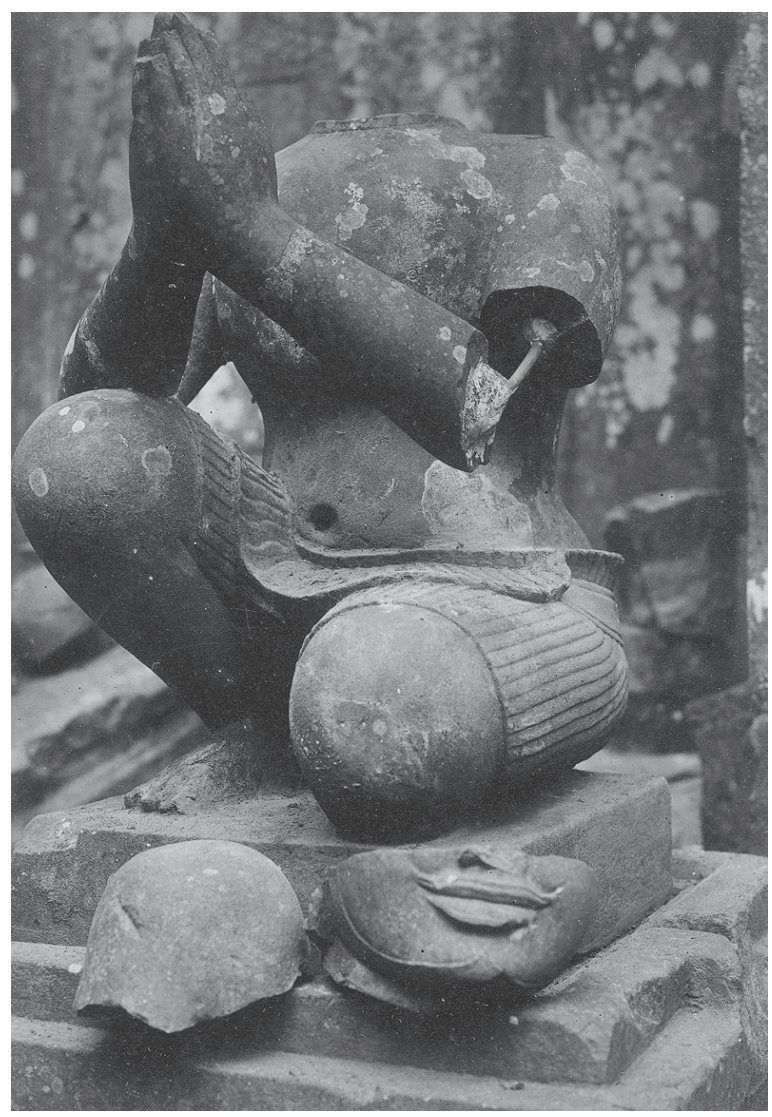

Fig. 8 Bossu, gopura II Est du Prasat Thom (Archives photographiques de l'EFEO [11277]).

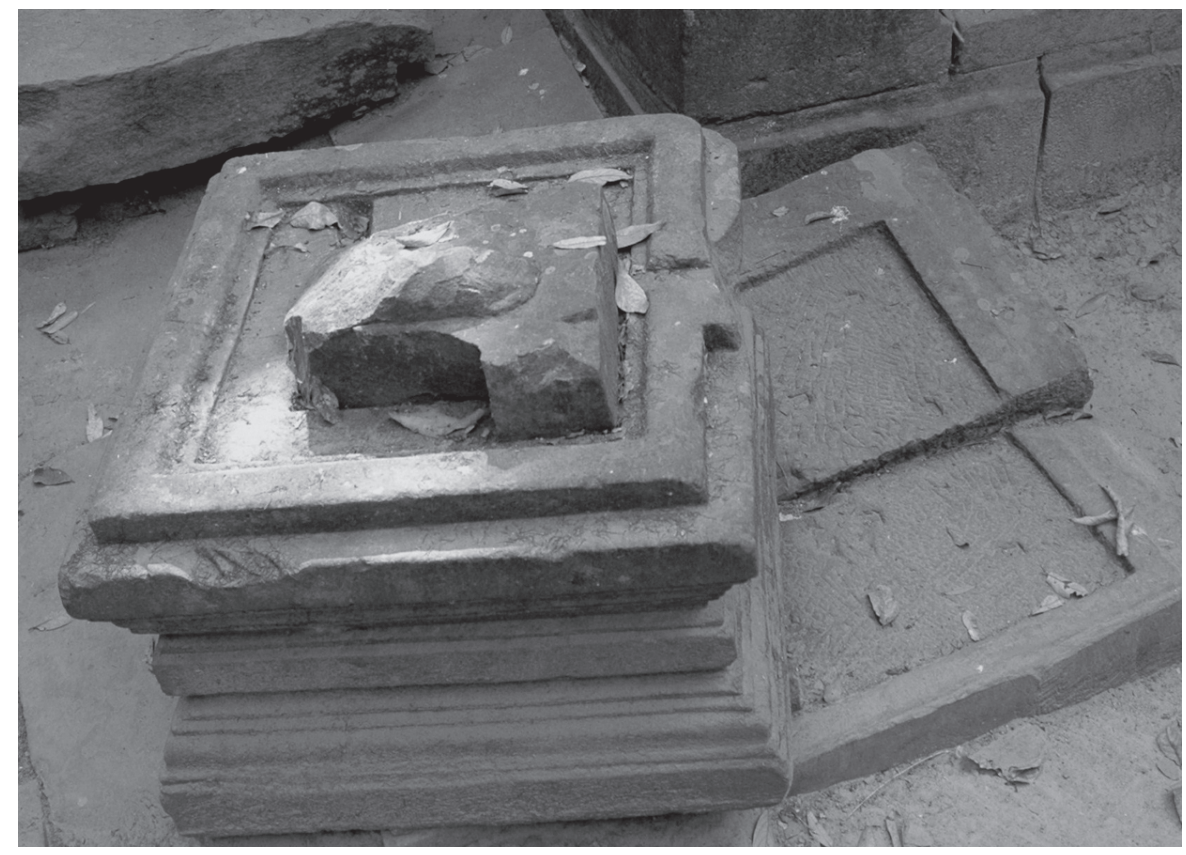

Fig. 9 Piédestal du bossu, gopura II Est du Prasat Thom (ph. auteur, 2009). 


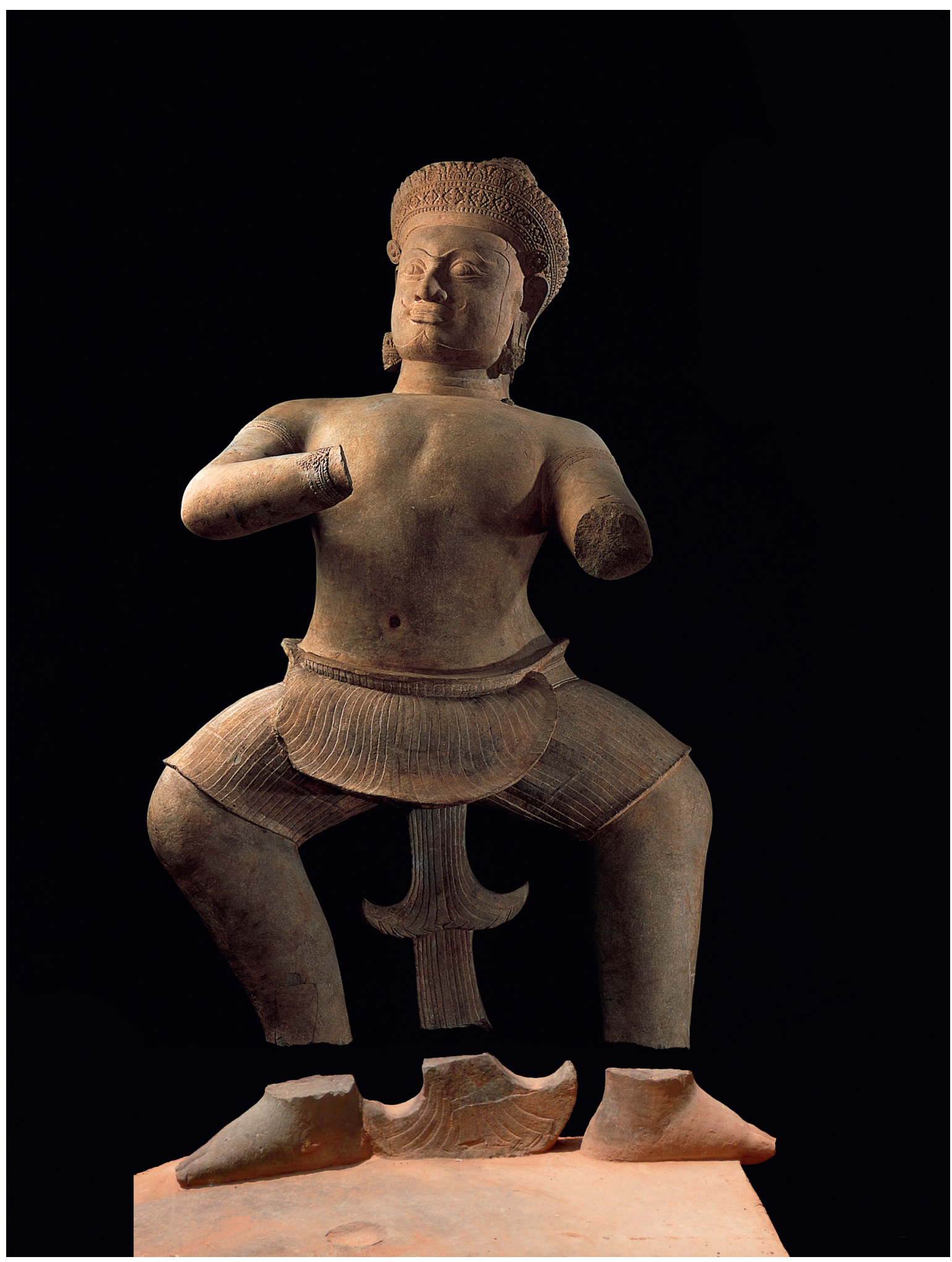

Fig. 10 Bhīma, gopura I Ouest du Prasat Chen (ph. auteur, 2009 et ph. Norton Simon Art Foundation [M198015S(1)]). 


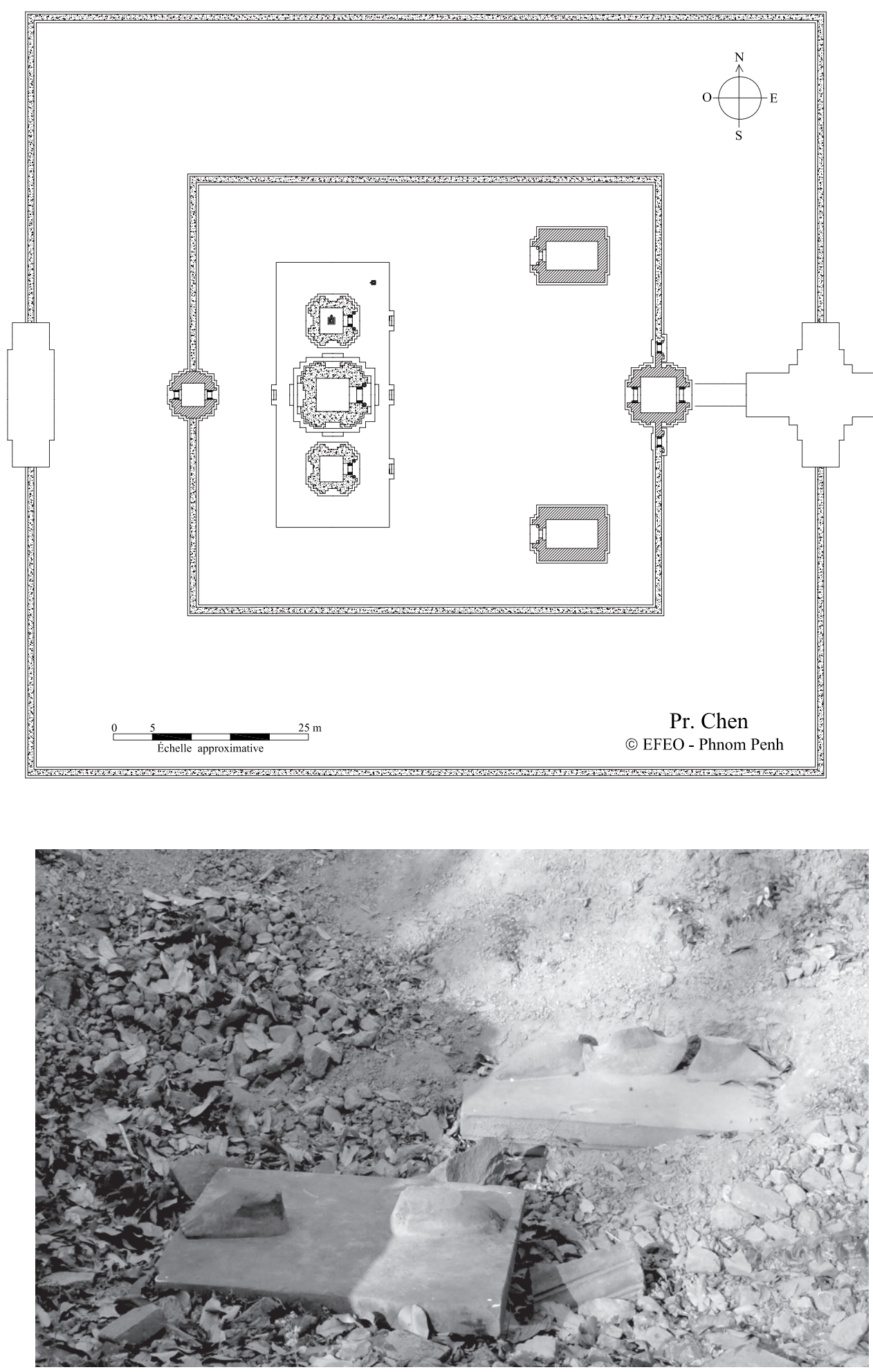

Fig. 12 Piédestaux du gopura I Ouest du Prasat Chen (ph. auteur, 2009). Parmen (source : Parmentier 1939, t. 1 , fig. 82 ; numérisation : Chrin Narong, sous la direction de Bruno Bruguier). 


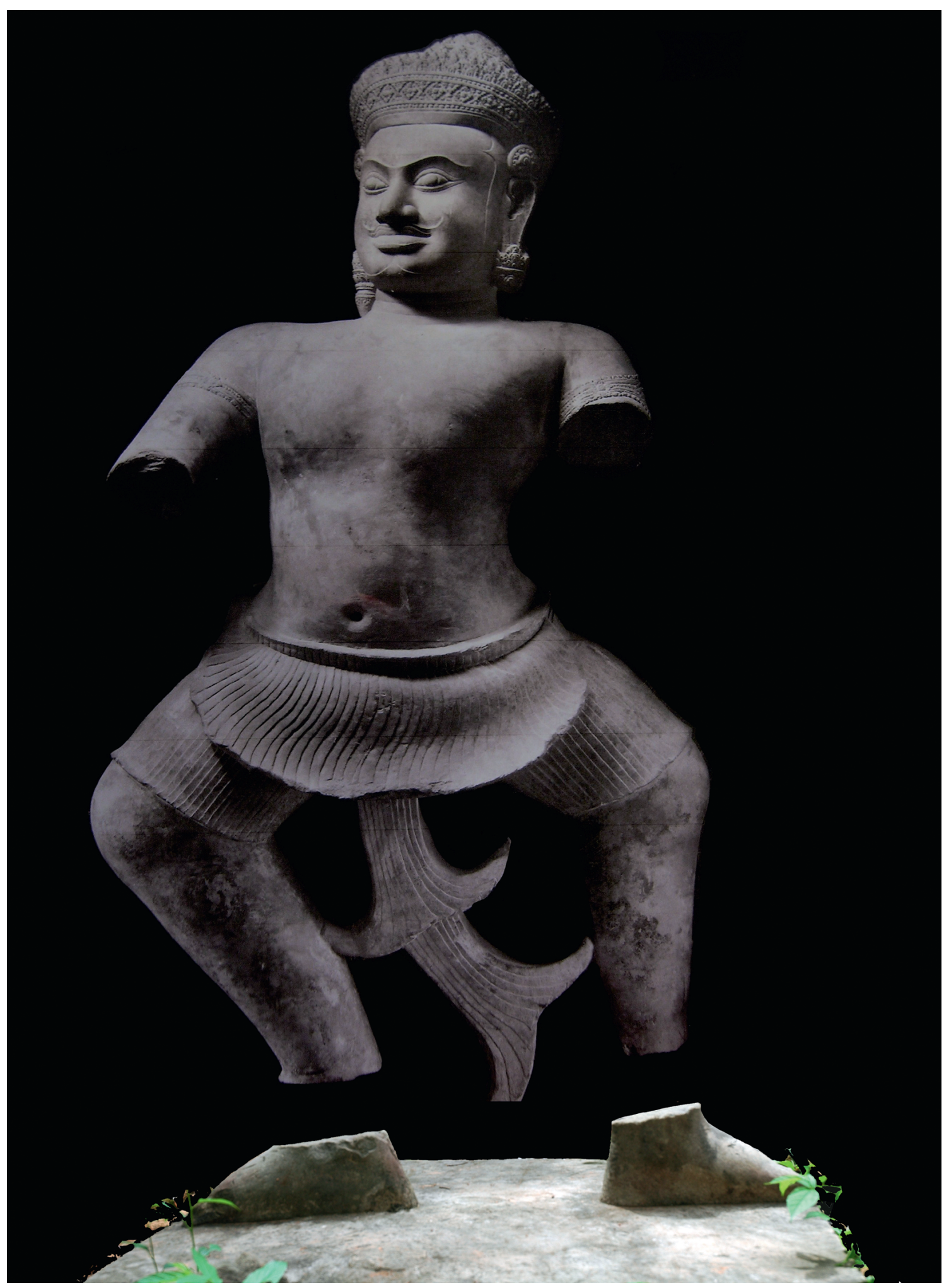

Fig. 13 Duryodhana, gopura I Ouest du Prasat Chen (ph. auteur, 2009 et Archives photographiques du musée Guimet). 
Le groupe sculpté du Prasat Chen est emblématique à bien des égards. Il dévoile tout d'abord un peu plus l'ampleur du pillage dont a souffert le site de Koh Ker, et laisse deviner, non sans un certain effroi, l'importance des moyens mobilisés par les pilleurs (comme pour le Ganeśa du Prasat Bak, ce sont chaque fois des pièces de dimensions imposantes). Il illustre ensuite, de manière un peu brutale, combien le site demeurait mal connu et les travaux de prospection très insuffisants. Il révèle enfin la très grande homogénéité de la statuaire répartie aujourd'hui entre les principales collections privées et les différents musées (nord-américains essentiellement). Une telle homogénéité suggère qu'une partie au moins de ces pièces est issue des mêmes réseaux de trafic d'antiquités.

De ce point de vue, la parution de l'ouvrage de Bunker et Latchford, qui suscite une certaine perplexité, a agi comme un révélateur et ne fut pas sans conséquence. En révélant, au moment même où le terrain est redevenu accessible à la recherche, un nombre significatif de pièces provenant, et sans que le doute soit permis, du site même de Koh Ker, on est là contraint de réviser sensiblement une position que l'on aurait pu penser de bonne méthode : il ne semble plus tout à fait possible, désormais, de s'en tenir à une réserve prudente à l'égard de ces pièces dont le lien avec les sites a été certes rompu, mais offrant toutes les chances d'être issues des mêmes opérations de pillage.

En revenant à l'analyse du dispositif culturel amorcée plus haut, nous aurons l'occasion de signaler quelques-unes de ces statues qui proviennent très probablement des temples de Koh Ker, sans que l'on dispose pour autant concrètement des indices d'une telle origine. L'ensemble des images du «style de Koh Ker » publiées dans l'ouvrage de Bunker et Latchford - et plus généralement acquises lors de ces quarante dernières années sur le marché de l'art - sont virtuellement concernées (a fortiori lorsque la mention « Koh Ker » apparaît explicitement comme le lieu de provenance). Si certaines des hypothèses de provenance émises ci-dessous paraissent hautement probables, d'autres le sont sans doute un peu moins, et d'autres encore ne sont juste que des possibilités. Toutes nous semblent utiles pour orienter les recherches à poursuivre sur le terrain.

Deux images extraordinaires de Skanda, conservées dans deux collections privées distinctes, retiennent l'attention à la suite du Ganeśa du Prasat Bak ${ }^{35}$. L'une représente le dieu monté sur son vāhana habituel, le paon, déployant le plumage de sa queue en une roue magnifique. Il s'agit là, en quelques sortes, de l'équivalent khmer du Skanda de Mỹ Sơn (au Campā), daté également $\mathrm{du} \mathrm{X}^{\mathrm{e}}$ siècle, et qui montre la même finesse de traitement dans la représentation des plumes du paon $^{36}$. Au Cambodge même, seules deux autres statues de Skanda sont connues; l'une et l'autre remontent cependant à l'époque préangkorienne ${ }^{37}$.

La seconde image de Skanda est plus exceptionnelle encore. Elle représente Skanda sous la forme d'un petit enfant, aux membres potelés, se tenant debout et tendant les bras vers un Śiva assis, les jambes repliées l'une sur l'autre. Les mains de Skanda sont posées sur celles de son divin père, jointes en añjali ; plus exactement, elles paraissent exercer une légère pression sur les mains de Śiva tandis que celui-ci semble hésiter dans l'exécution de son geste.

35 Bunker et Latchford 2004, p. 142-143 et 146-147.

36 Baptiste et Zéphir 2005, nº 34, p. 240-243. Le Skanda de Mỹ Sơn a été retrouvé à l'avant de la tour B 3, non loin d'une image de Ganeśa.
37 Baptiste et Zéphir 2008, n 16, p. 62-63, et Dupont 1955, pl. XIV B, p. 18. 
Une telle iconographie est inconnue au Cambodge et, sauf erreur, la remarque vaut pour l'ensemble de l'Asie du Sud-Est. La scène évoque l'un des nombreux récits sur l'enfance de Skanda-Murukan relatés dans le Kanta Purānam tamoul : Brahmā, dans l'incapacité de réciter les Veda, est incarcéré par Skanda qui assume dès lors le rôle du dieu créateur ; Śiva intervient, Brahmā est remis en liberté et c'est à cette occasion que Skanda expose à Śiva le sens du pranava, la syllabe sacrée $o^{38}$. Skanda est ainsi dit Takappan Cāmi le « maître du père » ou Cāmi nātar "seigneur ou guru du dieu »" Se prêtant au jeu de Skanda, Śiva adopte la position docile et humble qui convient à un étudiant devant son professeur. C'est cette attitude inhabituelle que l'on retrouve dans la statue de Koh Ker, où l'on voit également le jeune Skanda prendre très au sérieux son rôle d'enseignant en guidant le geste d'hommage esquissé par Śiva ${ }^{40}$.

Ces deux images de Skanda mesurent, en leur état actuel, un peu plus de 1 mètre de hauteur et sont donc de taille raisonnable, même si elles offrent des proportions un peu moins imposantes que celles du Ganeśa du Prasat Bak (ht 1,65 m, en son état actuel). Autant qu'il est possible d'en juger, nonobstant les restaurations abusives dont ces pièces ont fait l'objet, elles offrent rigoureusement le même traitement stylistique que les statues provenant du site même de Koh Ker. Les exemples de piédestaux décapités, de dimensions semblables et offrant une modénature nue (comme c'est le cas pour le Śiva et Skanda) ou bien richement décorée (comme pour le Ganeśa et Skanda sur le paon) sont relativement nombreux à Koh Ker ${ }^{41}$. Leur inventaire permettra peut-être de rétablir les liens perdus avec les images. La profonde originalité iconographique de ces deux images, sans équivalent dans le Cambodge angkorien, plaide aussi fortement en faveur d'une provenance du site de Koh Ker.

Il existait ainsi probablement, à l'échelle de l'ancienne capitale et distribuée entre un sanctuaire central et ses temples satellites, une représentation de la famille śivaiite : les images de Śiva et de la déesse, érigées en différents endroits du Prasat Thom, étant accompagnées des deux fils du couple divin, Ganeśa au Prasat Bak et Skanda dans un troisième sanctuaire qui reste à identifier.

Le Champa voisin fournit, à nouveau, d'intéressants points de comparaison. Un tel dispositif évoque en particulier deux frontons assez semblables provenant des tours A'1 et C1 de Mỹ Sơn : autour de Śiva-Rudra dansant, accompagné de l'ascète Bhrngin rythmant sa propre danse au son d'un petit tambour, sont regroupés Umā, Skanda-enfant, Ganeśa (ce dernier sur le fronton de la tour A'1 uniquement) et une petite troupe de musiciens et de gardiens, parmi lesquels il est possible de reconnaître Nandin et Mahākāla. Une telle comparaison permet de souligner que la « sainte famille śivaïte » n'est peut-être pas tant réunie, à Koh Ker, autour du couple divin qu'autour de la danse de Rudra telle que celle-ci est représentée, majestueuse, au gopura III Est du Prasat Thom.

38 Dessigane et Pattabiramin 1967, p. 23-24. Selon Françoise L'Hernault, l'enseignement à Brahmā, Śiva mais aussi Agastya, de la science du Brahman et de la connaissance des Veda, est " un des traits du Kanta Purānam dont on ne possède de traduction iconographique qu'au Tamilnad » (L'Hernault 1978, p. 117188). Si l'épisode de l'enseignement à Śiva y est en particulier bien connu, ses représentations, ajoute l'auteur, demeurent peu nombreuses. Notons enfin que le Kantapurānam est supposé ne pas être antérieur au XII ${ }^{e}$ siècle, soit deux siècles après le Skanda de Koh Ker.
39 Clothey 1978 , p. 82.

40 Sur la thématique du "fils qui fait le père » et le rôle de celleci dans la formation de l'iconographie divine en Inde, signalons les récentes réflexions de Charlotte Schmid qui propose d'établir un parallèle entre la relation de Viṣnu et $\mathrm{Kr}$ rșna et celle entre Śiva et Skanda (Schmid 2010, p. 394 sqq.).

41 L'université de Waseda a recensé 84 piédestaux dans 59 des 74 temples du groupe de Koh Ker (Nakagawa et Mizoguchi 2009, p. 18). 
En se tournant vers l'Inde, la comparaison s'impose avec les nombreuses représentations du tāṇạva, la danse terrible de Śiva, attestées notamment dans les grands temples royaux de Tanjavur et Gangaikondacholapuram (plus tardifs d'un siècle, rappelons-le, par rapport à Koh Ker). Autour du Națarāja sont regroupés là deux formes de la Déesse (Kālī et Pārvatī), Skanda et Ganeśa, les deux personnages squelettiques de Bhrngin et Kāraikkālammaiyār, Nandikeśvara à nouveau, le soleil et la lune et enfin toute une troupe de gnomes dansant au rythme de cymbales et de tambours ${ }^{42}$.

Nous pouvons songer également à la série des ganeśvara sur laquelle Alexis Sanderson a récemment attiré l'attention. Relevant les mentions (problématiques à nos yeux) de Canḍeśvara dans l'épigraphie khmère, l'auteur énumère la liste des huit « chefs des gana » qui font l'objet d'un culte dans les systèmes de certains Tantra śaiva " as the deity-circuit outside the Vidyeśvaras, between the latter and the Lokapālas » : Ambikā/Umā (ganamātā « la mère des gana »), Skanda, Ganeśa, Nandin, Mahākāla, Bhrnginin, le taureau de Śiva et Caṇdeśvara ${ }^{43}$. L'auteur cite également cette autre séquence de divinités invoquées dans le śāntyādhyāyah du Śivadharma : Śiva, Umā, Skanda, Nandin, Ganeśa, Mahākāla, Ambikā (Ganamātr), Mahișāsuramardin̄̄ (Durgā), Bhrngin et Caṇḍeśvara, suivis par Brahmā, Vișṇu et les Mères. L'examen détaillé du programme iconographique du Prasat Thom révèlera combien nous retrouvons assez précisément ce panthéon à Koh Ker. Retenons pour l'heure que, davantage que la famille śivaïte étroitement définie, ce sont plus largement les ganeśvara qui, à Koh Ker, étaient certainement représentés autour de la danse terrible de Śiva-Rudra. Les troupes démoniques des gana sont, en elles-mêmes, bien présentes également : elles apparaissent sur les échiffres des escaliers des gopura du Prasat Thom, sous la forme de gardiens à tête animale.

On ne saurait pour autant totalement renoncer à une lecture de la population divine de Koh Ker en termes de liens de filiation et d'alliance. L'une et l'autre interprétation - famille ou troupe de Śiva - s'excluent moins qu'elles ne soulignent deux « usages » complémentaires du panthéon śivaïte $^{44}$.

Les exemples sont nombreux, où la juxtaposition des images divines au sein d'un temple ou, comme c'était le cas peut-être à Koh Ker, d'un même groupe de temples liés entre eux, ne se comprend pas sans considérer la nature des relations qui existent entre les auteurs de ces fondations (ou entre ces derniers et ceux pour lesquels ils érigent ces divinités) ${ }^{45}$. De ce point de vue, les images sont à percevoir comme les nœuds de relations sociales. De manière plus générale, et pour reprendre ici une formule de Marcel Granet, dont les vertus ne s'arrêtent pas aux frontières du monde sinisé, on se gardera - tout réductionnisme sociologique mis à part - de considérer, dans le Cambodge ancien, la sphère religieuse comme « une fonction différenciée de l'activité sociale»(Granet 1968, p. 476).

42 L'Hernault 1994, p. 129.

43 Sanderson 2003-2004, p. 437, n. 317.

44 À cet égard, la définition de la série des huit Ganeśas, telle que celle-ci apparaît dans le corpus Śaiva Siddhānta, comme "Śiva's Paurānika household» nous semble éclairante. Cf. Brunner et alii 2004, s.v. ganapati, ganeśa, cité dans Bisschop 2010, p. 243. Voir également les propres observations de Peter Bisschop sur l'affirmation progressive des liens familiaux établis au sein du panthéon śivaïte. L'auteur traite en particulier de la désigna- tion, dans le Śivadharma, de Vināyaka/Ganeśa et de Bhrngiriți/ Bhrngin comme les fils de Śiva (ibid., p. 244)

45 Remarque qui vaut sous bien d'autres cieux : "Dans leur royaume méridional, les Pallava comparent explicitement, dans leurs représentations, le roi à Śiva, son fils à Skanda. Leur cellule dynastique est symbolisée par les représentations du trio que forme Umā, Śiva et leurs fils, renforçant le schéma symbolique de l'enfance comme représentation de la filiation » (Schmid 2010 , p. 506). 
Un bref exemple, emprunté à l'épigraphie du Bakong nous permettra d'illustrer cette dimension essentielle des temples. L'épigraphie de ce temple-montagne nous livre la liste des images « faites » par Indravarman (r. 877-889) et érigées dans la " cour » d'Indreśvara, c'est-àdire dans les tours construites au pied de la pyramide dominée par le linga royal (associant le nom du roi à celui du dieu) : un Vișnu au bénéfice du roi défunt Jayavarman III, prédécesseur d'Indravarman mais issu d'une lignée (matrilinéaire) distincte de celui-ci, un Harihara érigé par les fils d'Indravarman, une Indrāṇī au bénéfice de la reine du souverain défunt « qui réside dans l'Indraloka », une Mahișāsuramardanī érigée "par les nobles femmes du gynécée " ${ }^{46}$. S’y ajoute une image d'Umāgangāpatîśvara dont on a pu supposer que la célèbre triade, retrouvée in situ, représentait le souverain accompagné de ses épouses.

L'exemple du Harihara, en particulier, nous permet là d'introduire un autre aspect de la cartographie divine du règne de Jayavarman IV (comme de bien d'autres règnes) : la juxtaposition de fondations vișnuïtes et śivaïtes. Au sein du petit corpus de Harihara attestés dans l'épigraphie khmère, d'autres exemples assez semblables à celui du Bakong sont à relever. Ainsi, dans K. 22, l'érection d'un Harihara s'interprète à nouveau comme l'acte pieux d'un fils au bénéfice de ses parents ${ }^{47}$. Dans la stèle de Sdok Kak Thom, K. 235, l'identité des acteurs concernés est sensiblement différente : le nom de la divinité donne à voir l'association d'un guru et de l'aieul (le grand-oncle maternel) du disciple de ce $g u r u^{48}$. L'exemple est plus complexe mais la signification est la même : la réunion de Śiva et Viṣnu transpose au niveau divin une relation d'alliance alliance spirituelle entre un guru et le lignage de son disciple, alliance matrimoniale entre deux lignages - célébrée par le produit même de cette alliance (enfants et disciples spirituels).

\section{Fondations śivaïtes et viṣṇuïtes à Koh Ker et Banteay Srei. La naissance de l'iconographie narrative}

Étendre l'analyse au-delà du seul panthéon strictement śivaïte, c'est bien sûr être confronté à la question récurrente de la relation entre śivaïsme et vișnuiisme dans le Cambodge ancien. Le sujet est évidemment complexe et n'a pas manqué de susciter d'abondantes discussions au sein de la littérature ${ }^{49}$. Envisager les images comme les nouds de relations sociales impose en ce domaine une certaine prudence. Nous nous efforcerons autant que possible de raisonner non pas, d'emblée, en termes de śivaïsme et de vișnuïsme (y compris même pour évoquer un hindouisme peu sectaire), ou encore de bouddhisme, mais de fondations śivaites, vișnuïtes et bouddhiques "localisées ", c'est-à-dire engagées dans l'écheveau complexe des relations auxquelles nous avons déjà fait allusion : relations des divinités entre elles (et avec leurs images), relations entre celles-ci et les hommes eux-mêmes engagés dans des situations d'interactions sociales.

Un second détour, par le temple fameux de Banteay Srei (l'ancien sanctuaire d'Ī́śvarapura), va nous ramener directement au dispositif cultuel de Koh Ker (fig. 14). Deux des trois images de

46 K. 826-B, st. XXIX-XXXIII (Coedès IC I, pp. 33 et 35).

47 K. 22, st. IV : " (le muni Îsānadatta) a érigé cette image dans laquelle sont unis par moitié les corps de Çankara et d'Acyuta, pour le bénéfice de ses parents » (Cœdès, IC III, p. 144 et p. 145). 48 Śivasoma et Śivakaivalya, respectivement maître spirituel et aĩeul de Vāmaśiva. Le Harihara est érigé par un descendant de
Śivakaivalya et Vāmaśiva, nommé Sadaśiva (K. 235 st. CXXVII, stèle de Sdok Kak Thom, Cœdès et Dupont 1943, p. 87 et 103). 49 Parmi les derniers travaux en date sur le sujet, signalons la thèse de Julia Estève qui discute longuement de la notion de syncrétisme, telle qu'elle a été notamment adoptée par Kamaleswar Bhattacharya (dans Bhattacharya 1961, chap. V). 


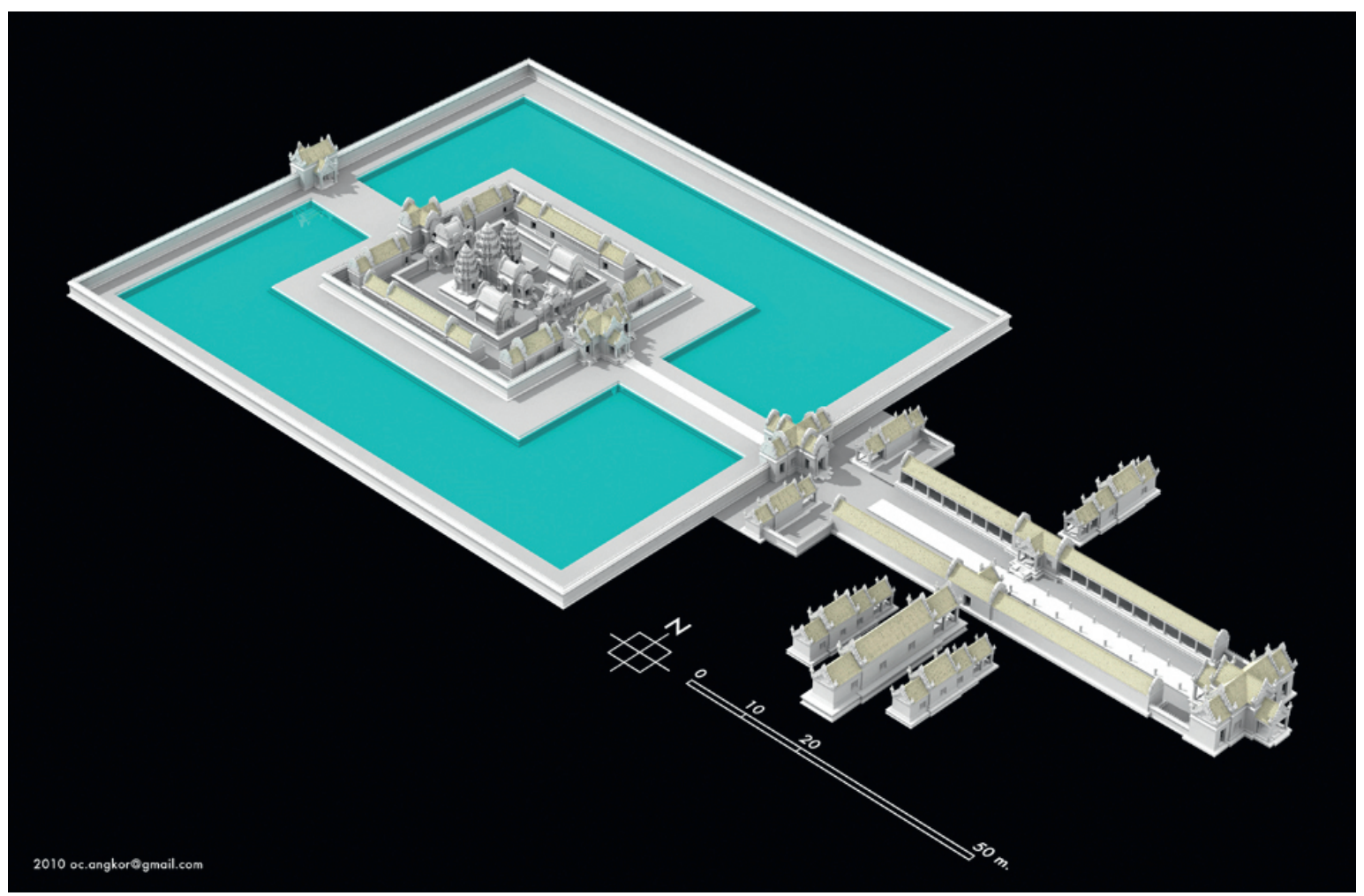

Fig. 14 Restitution du temple de Banteay Srei (O. Cunin).

culte abritées dans les tours centrales, sont des linga de Siva : celui de la tour principale, désigné comme Śiva Tribhuvanamaheśvara, est l'œuvre des deux co-fondateurs du temple, Yajñavarāha, vrah guru du roi Jayavarman V (968-1000), et son frère cadet Vișnukumāra ; le linga de la tour Sud fut érigé par Jāhnavī, sœur des deux précédents ${ }^{50}$. La troisième image, placée dans la tour Nord, est un Viṣnu consacré par un nommé Prothivīndrapaṇịita que les inscriptions désignent comme le « parent » de Yajñavarāha, ou plus exactement comme le "parent par alliance » (sambandhi $)^{51}$ : il y a là toutes les chances que Prọthivīndrapaṇịita soit ainsi l'époux de Jāhnavī. Śiva occupant la position centrale, Vișnu incarne ici la figure de l'allié (et du beau-frère en particulier) ${ }^{52}$.

Cette compréhension de Banteay Srei - qui s'ajoute à d'autres niveaux de lecture possibles -, comme la célébration de l'union terrestre et divine de deux moitiés complémentaires est confortée, en particulier, par l'examen de la genèse de son programme iconographique. Celui-ci se trouve en effet préfiguré dans les deux temples majeurs du groupe de Koh Ker, l'un śivaite, l'autre vișnuite : le Prasat Thom et le Prasat Chen.

50 K. 574 (Finot 1926, n 7, p. 92).

51 K. 573 (Finot 1926, n 8, p. 93).

52 Ajoutons brièvement, en illustration là encore de notre propos et pour compléter ce rapide survol de Banteay Srei, que Yajñavarāha érigea également, dans le gopura I Ouest, une image de Umāmaheśvara (aujourd'hui conservée au Musée national de Phnom Penh, inv. 1797), "pour l'augmentation des mérites de ses parents" (pitror ddharmmavivrddhaye, K. 783, cf. Cœè̀s, IC I, p. 143). 
Il s'agit là de prolonger les remarques qui ont déjà été faites par le passé, en particulier par Jean Boisselier (Boisselier 1992). Nous avons de bonnes raisons aujourd'hui de renouveler le constat des similitudes observées entre les deux sites, en adoptant une position plus tranchée encore : à bien des égards, Banteay Srei est l'authentique reproduction du dispositif mis en œuvre au Prasat Thom et complété par celui du Prasat $\mathrm{Chen}^{53}$. Nous reviendrons plus loin sur certains aspects majeurs de cette relation, en nous limitant dans l'immédiat à l'examen de l'iconographie narrative inspirée des épopées. Cinq épisodes du Mahābhārata et du Rāmāyana sont représentés sur les frontons et les linteaux de Banteay Srei. Trois sont extraits du Mahābhārata : le Kirātārjunīya, la lutte des démons Sunda et Upasunda pour la possession de l'apsaras Tilottamā, l'affrontement de Bhīma et Duryodhana. Deux autres le sont du Rāmāyana : l'enlèvement de Sìtā par le rākṣasa Virādha, le combat des deux singes Vālin et Sugrīiva ${ }^{54}$. Au Prasat Thom, nous retrouvons la lutte à mains nues de Śiva-kirāta et d'Arjuna au gopura II Ouest ${ }^{55}$, parmi un groupe sculpté composé de trois images : Umāmaheśvara sur le taureau, Śiva Trimūrti ${ }^{56}$ et un personnage d'ascète accroupi que nous proposons d'identifier comme une seconde représentation d'Arjuna (fig. 15-19) ${ }^{57}$. L'enlèvement de Sìtā a pu être représenté au Prasat Thom, sur les frontons des salles longues comprises entre la première et la seconde enceinte. Parmi le chaos des blocs amoncelés au sol, des fragments de tympans, sur lesquels on reconnait trois personnages principaux luttant (ou dansant ?), sont susceptibles d'être interprétés en ce sens (fig. 20). La même hypothèse peut certainement être formulée aussi à propos de la lutte de Sunda et Upasunda, mais il faut bien reconnaître que nous ne disposons là que d'éléments assez minces. Nous sommes à nouveau en terrain plus sûr en nous tournant vers les représentations de Bhīma et Duryodhana, et de Vālin et Sugrīva.

53 Une telle lecture n'invalide pas l'accent mis sur l'originalité de Banteay Srei telle que nous avons proposé de la redéfinir ailleurs sans omettre de se référer alors au dispositif du Prasat Thom (Bourdonneau 1999, p. 57). À l'évidence toutefois, le poids accordé à ce dernier (et au Prasat Chen) dans la compréhension de Banteay Srei doit être aujourd'hui réévalué. Si le constat de l'originalité de ces deux sanctuaires majeurs du $\mathrm{x}^{\mathrm{e}}$ siècle angkorien doit être maintenu, c'est en articulant étroitement, au sein de l'analyse, l'une et l'autre réalisation comme les deux moments d'une même phase d'innovations dans l'histoire cultuelle d'Angkor.

54 Cf. Bourdonneau 1999, pl. II-IV pour la localisation des frontons et des linteaux dans le temple. Rappelons l'une des caractéristiques du programme iconographique de Banteay Srei : la répétition des mêmes thèmes sur les tours centrales et sur les édifices périphériques. C'est le cas pour trois des thèmes énumérés ici - l'enlèvement de Sītā, le combat de Vālin et Sugrīiva et probablement aussi le Kirātārjunīya - distribués entre les linteaux de la tour centrale et les frontons des gopura III Est et II Ouest (ibid., p. 41-53).

55 Groupe conservé aujourd'hui au Musée national de Phnom Penh (inv. 1657).

56 Vișnu et Brahmā sortent des flancs du corps de Śiva assis. On peut songer là aux observations de Bhattacharya sur l'Ekapādamūrti qui " conçoit également Śiva comme un arbre dont les deux branches latérales sont Brahmā et Viṣnu » (Bhattacharya 1961, p 70)

57 Une telle hypothèse d'identification repose sur la comparaison avec les groupes sculptés rencontrés dans les autres pavillons d'entrée du Prasat Thom et du Prasat Chen. Les images n'y sont jamais juxtaposées isolément les unes à côté des autres mais participent toujours de la même "mise en scène ». Il est ainsi très probable que les quatre images de ce gopura II Ouest ont toutes partie liée à la représentation du Kirātārjunīya. On relèvera ainsi que la présence de Umā aux côtés de Śiva, l'affirmation de l'identité de Śiva et de Viṣnu sont des éléments importants du récit de cet épisode (Biardeau 2002, p. 452-453). Le personnage accroupi pourrait ainsi être Arjuna-ascète se prosternant devant Śiva à la suite du combat. Ce qui reste des bras de la statue suggère que les mains ont pu être jointes. Sa position exacte dans le gopura n'est pas connue mais, si l'on retient cette hypothèse d'identification, la statue devait logiquement être placée en face de celle de Śiva et Umā sur le taureau. Cette dernière se dressait dans le bras oriental de l'édifice, orientée vers l'ouest selon Parmentier (Parmentier 1939, p. 49). L'image d'Arjuna-ascète aurait donc été placée dans le bras oriental, tournée vers le couple divin. Parmentier précise par ailleurs que le corps-à-corps du héros et du dieu était placé dans le bras nord. La statue de Śiva Trimūrti, dont la localisation précise n'est pas non plus connue, serait dès lors à replacer dans le bras sud. Seul le dégagement du dallage permettra de confirmer, ou d'infirmer, ces hypothèses. La comparaison avec le groupe sculpté du gopura II Est suggère que l'emplacement de la statue de l'ascète devrait clairement être indiqué sur le dallage (délimité par une margelle), comme c'est le cas pour chacune des images qui ne sont pas monolithes avec leur piédestal et qui sont les seules à être posées sur une cuve à ablution. 


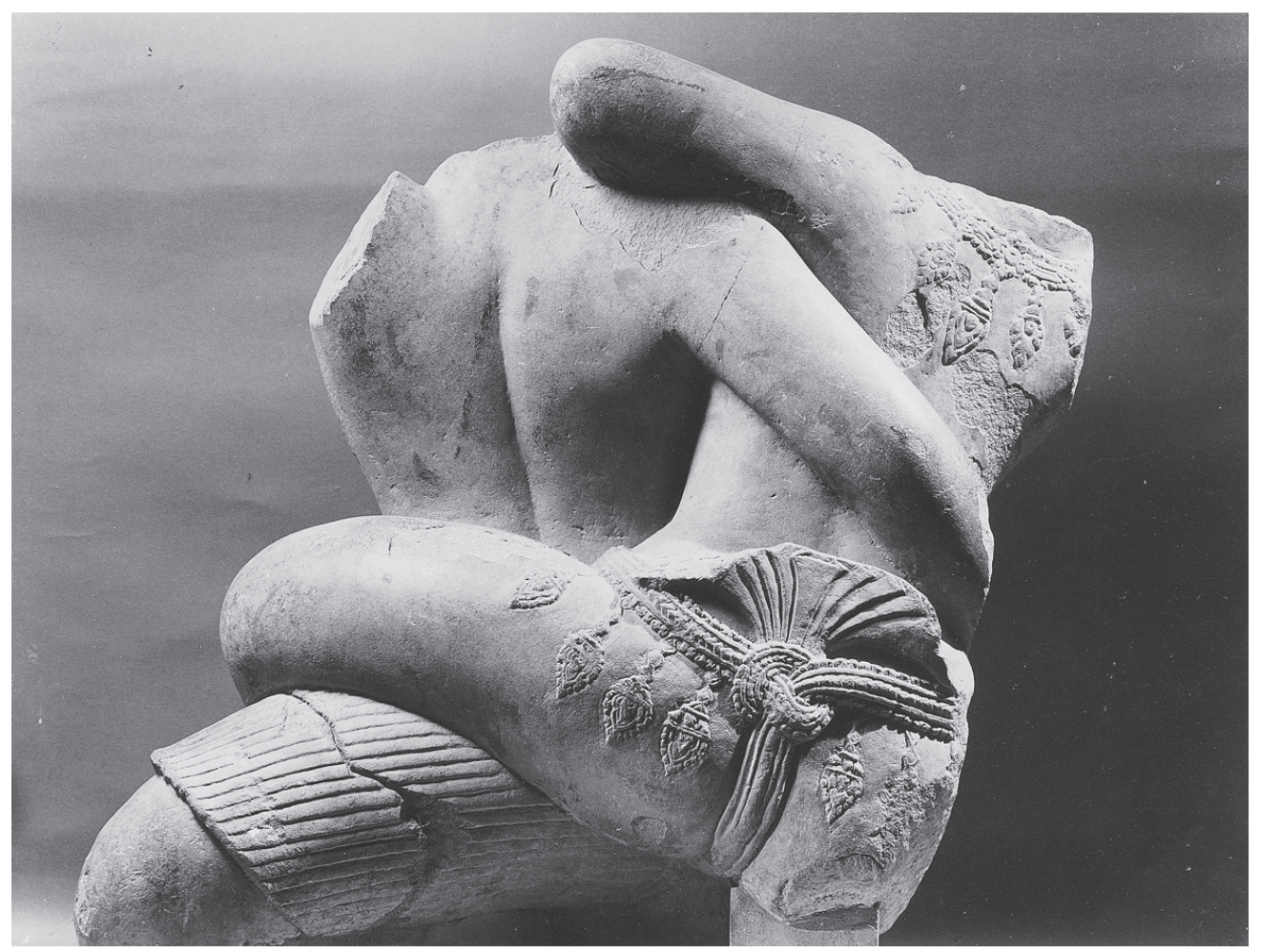

Fig. 15 Kirātārjunīya, gopura II Ouest du Prasat Thom (Archives photographiques de l’EFEO [03221]).

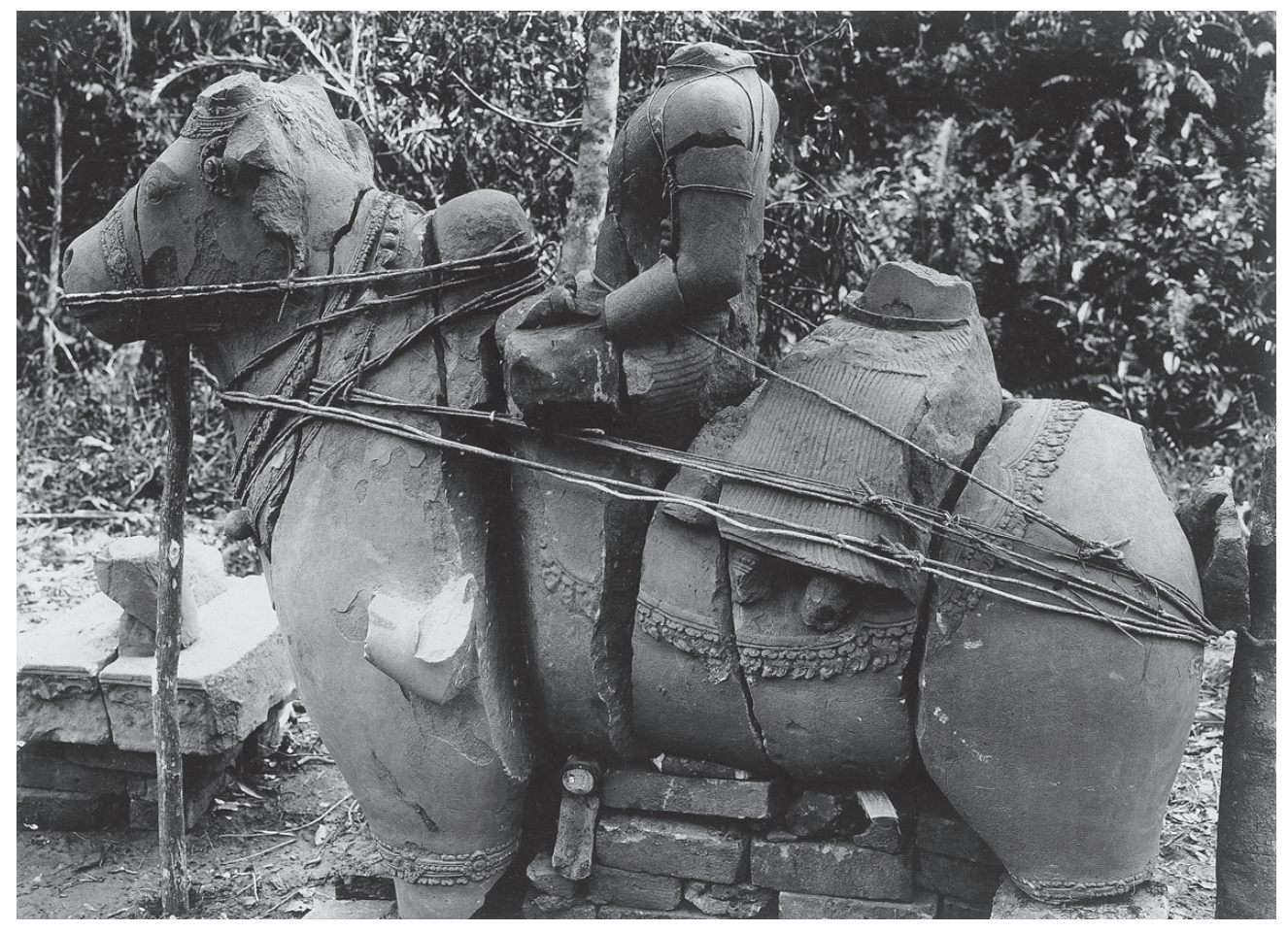

Fig. 16 Umāmaheśvara sur le taureau, gopura II Ouest du Prasat Thom (Archives photographiques de l'EFEO [11299]). 


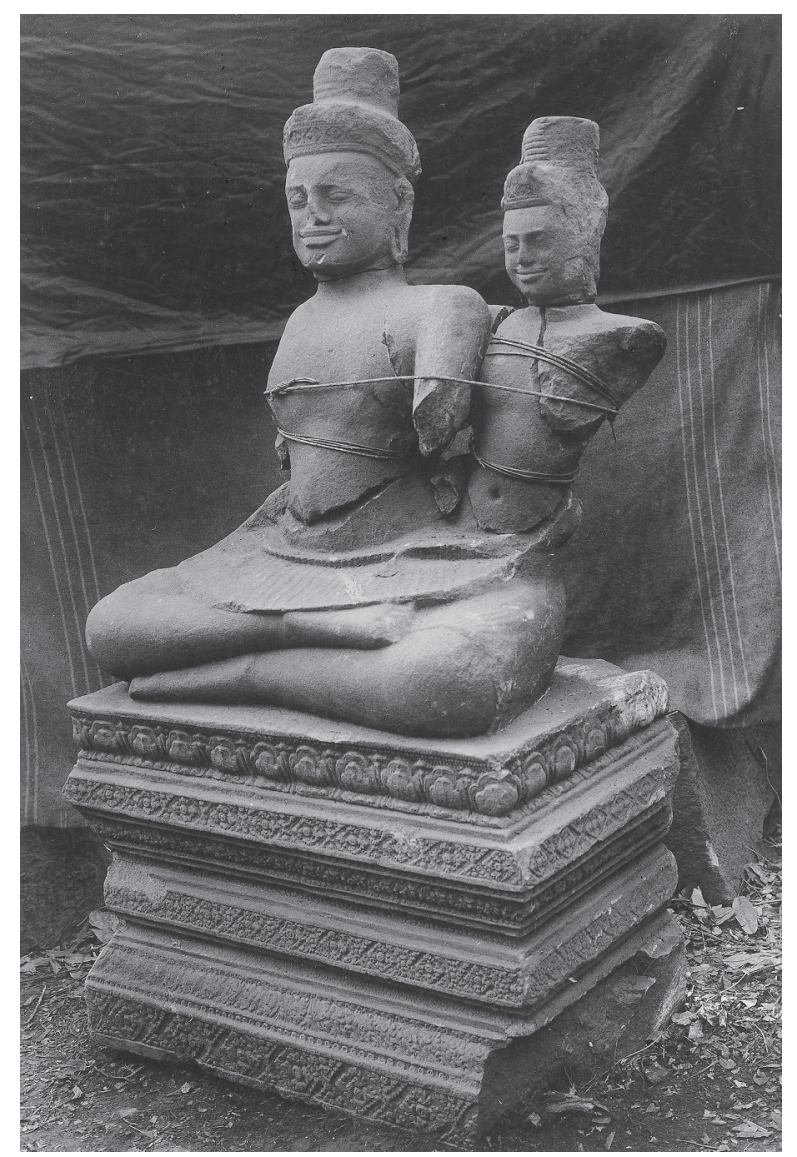

Fig. 17 Śiva Trimūrti, gopura II Ouest du Prasat Thom (Archives photographiques de l'EFEO [11280]).

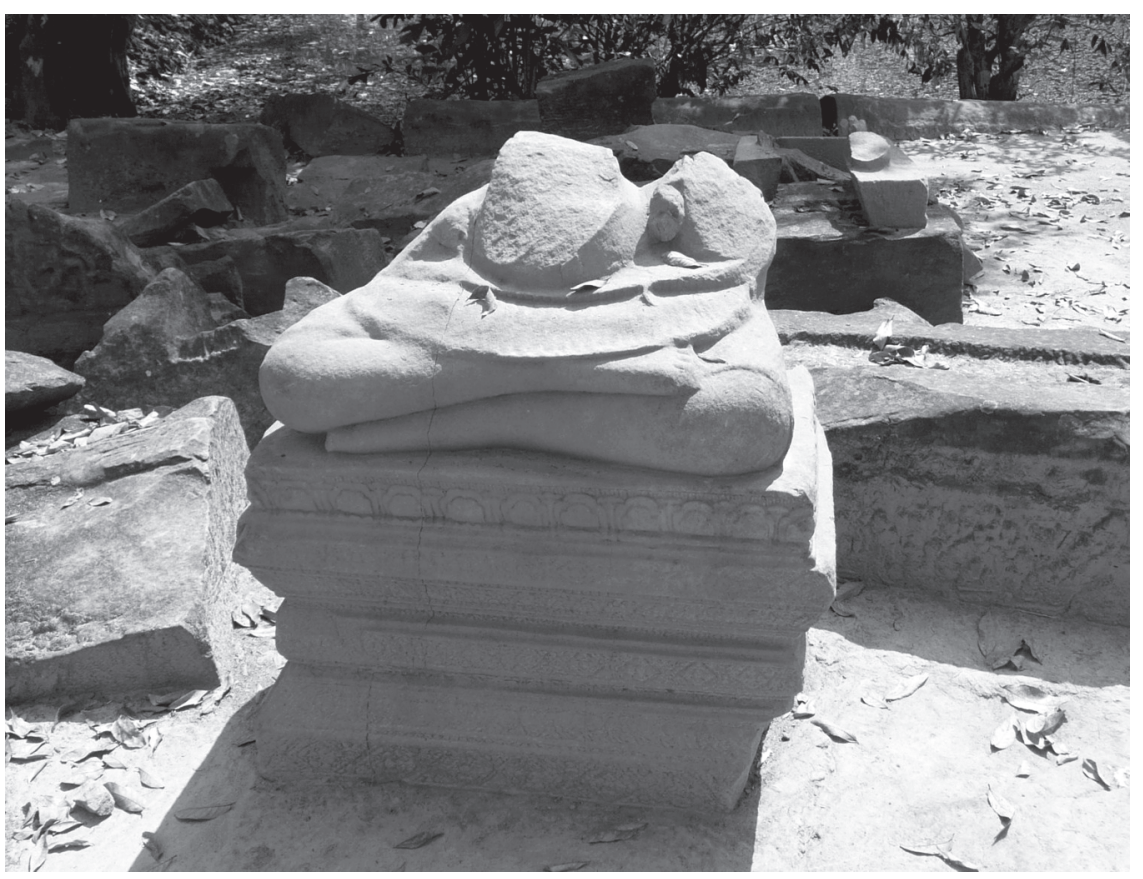

Fig. 18 Śiva Trimūrti, gopura II Ouest du Prasat Thom (ph. auteur, 2010). 


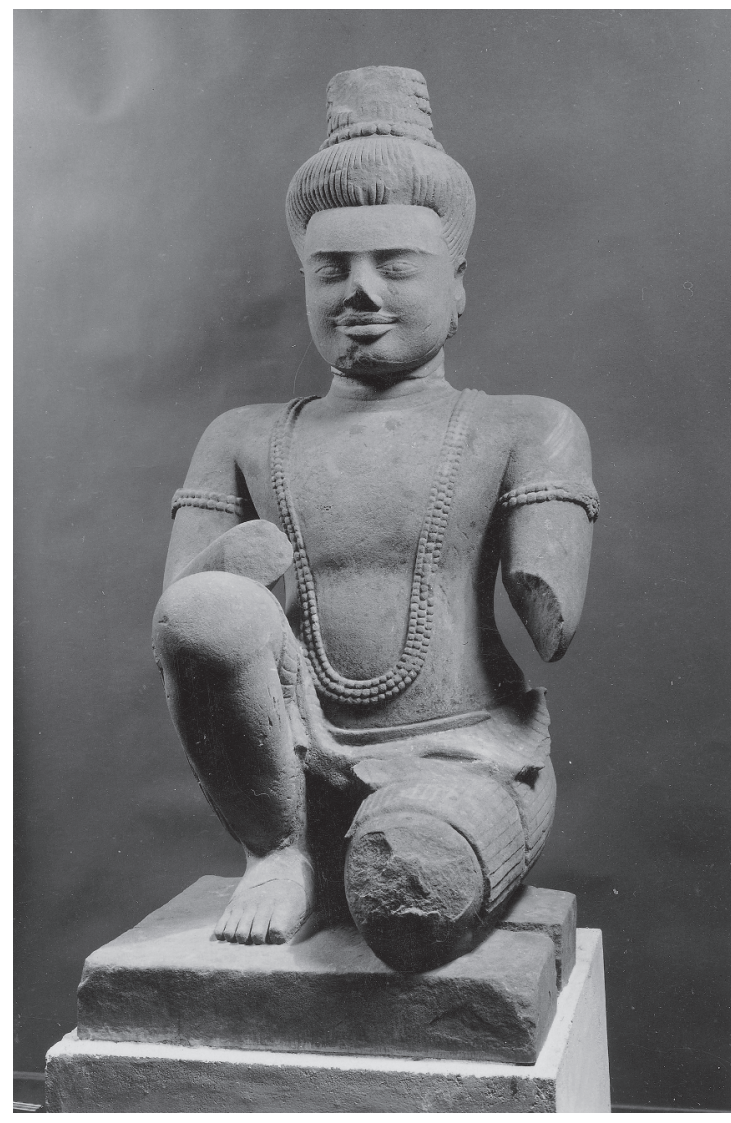

Fig. 19 Arjuna (?), gopura II Ouest du Prasat Thom (Archives photographiques de l'EFEO [03345-3]).

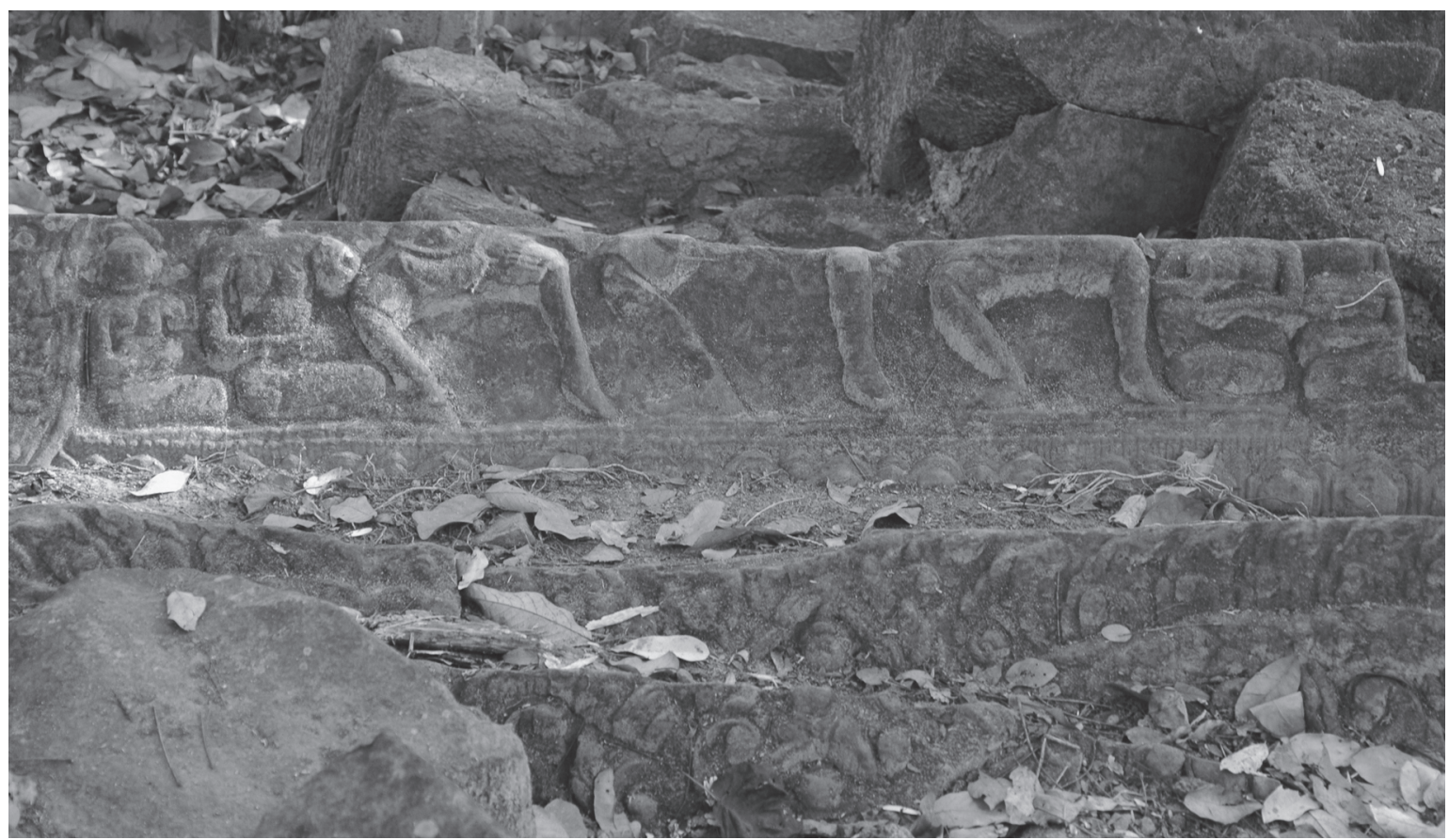

Fig. 20 Fronton au sol dans la partie ouest de la seconde enceinte du Prasat Thom (ph. auteur, 2010). 
Provenant du gopura I Est du Prasat Chen de Koh Ker, un imposant groupe sculpté figurant la lutte des deux singes, monolithe avec son piédestal, est connu de longue date et conservé au Musée national de Phnom Penh (inv. 1664, fig. 21). Des fragments de piédestaux (de dimensions plus réduites), visibles aujourd'hui dans ce même gopura, laissent à penser que d'autres images entouraient les deux lutteurs (fig. 22). Deux statues du style de Koh Ker, conservées l'une au musée de Cleveland (inv. 1982.46), l'autre au musée de Denver (inv. 1986.44), pourraient, de fait, venir de cet édifice ${ }^{58}$. La première est un singe agenouillé, au corps anthropomorphe et à tête animale, semblable en cela aux Vālin et Sugrīva du musée de Phnom Penh. La position des bras et des mains est celle d'une "fermeture du corps", caractéristique d'une attente passive qui ne saurait être confondue avec l'attitude plus ferme et menaçante des gardiens de porte ou d'échiffres. La seconde est une statue de Rāma debout, reconnaissable au carquois qu'il porte dans le dos. Si l'on retient l'hypothèse de provenance proposée, Rāma était représenté là s'apprêtant à décocher une flèche en direction de Vālin, à l'instar de ce que l'on observe sur le fronton de Banteay Srei.

Le combat de Bhīma et Duryodhana est, comme nous l'avons vu, le sujet du remarquable groupe sculpté placé dans le gopura I Ouest du Prasat Chen. Il est probable que deux autres pièces encore, conservées actuellement au Metropolitan Museum de New York, proviennent également de ce même édifice ${ }^{59}$. Il s'agit de deux personnages agenouillés, adoptant la même posture caractéristique que le singe du musée de Cleveland et présentant à hauteur des chevilles les mêmes stigmates des burins des pilleurs (fig. 23-24) ${ }^{60}$. Une statue identique est aujourd'hui conservée au dépôt de la conservation d'Angkor (DCA) à Siem Reap (fig. 25) ${ }^{61}$. On peut supposer que ce sont là trois des quatre Pāṇ̣ava qui assistent au combat de leur frère Bhīma.

La représentation de cet épisode du Mahābhārata est certainement celui qui illustre le mieux combien le programme iconographique de Koh Ker a pu servir de modèle à celui de Banteay Srei. Le fronton donne à voir ce moment précis du récit où le Kaurava s'élance vivement dans les airs tandis que Bhīma, prenant appui sur sa jambe arrière et esquissant un mouvement de torsion, s'apprête à lui briser les cuisses en lui jetant violemment sa massue (coup fatal mais déloyal, car contraire aux règles du combat) (fig. 26) ${ }^{62}$. Ce mouvement de Bhīma est très précisément celui rendu par le sculpteur du Prasat Chen (fig. 10). On retrouve, en ronde-bosse, la même courbe du drapé tombant au sol entre des jambes lourdement fléchies, la même tension qui parcourt le torse arqué et les bras pointant la massue vers le ciel $^{63}$, cette même expression du visage courroucé et légèrement relevé (Bhīma et Duryodhana étant semblable à deux Yama); mais surtout, et de façon plus remarquable encore, il y a ce petit pas en arrière, cette prise d'appui de la jambe du Pāṇ̣ava qui donne la mesure de la violence du coup qui se prépare : dans ces quelques centi-

58 Les deux sculptures sont publiées dans Bunker et Latchford 2004, p. 154-156 et 158-159. Les cassures sont visibles à hauteur des chevilles. Celles de la statue de Cleveland portent clairement la marque du pillage.

$59 \mathrm{~N}^{\text {os }} 1992.390 .1$ et 1992.390 .2

60 Nous retrouvons encore cette position représentée sur le fronton de Banteay Srei figurant la lutte de Sunda et Upasunda, conservé au musée Guimet (MG 18913, cf. Baptiste et Zéphir, op. cit., p. 172-177).
61 Je dois à Thierry Zéphir d'avoir attiré mon attention sur l'existence au DCA, d'une statue semblable à celles du Metropolitan Museum. La pièce (N 625) a été amenée au DCA en 1994. Elle présente de nombreux ajouts en ciment. La tête, en particulier, a été remplacée par une copie.

62 Cf. Alvares 1998, p. 41-44.

63 La trace d'arrachement visible sur la surface du piédestal, au pied de Bhīma, est, selon toute vraisemblance, celle d'un étai de section circulaire (bien différente de la trace d'arrachement de section octogonale laissée par la massue de Duryodhana, cf. infra). 


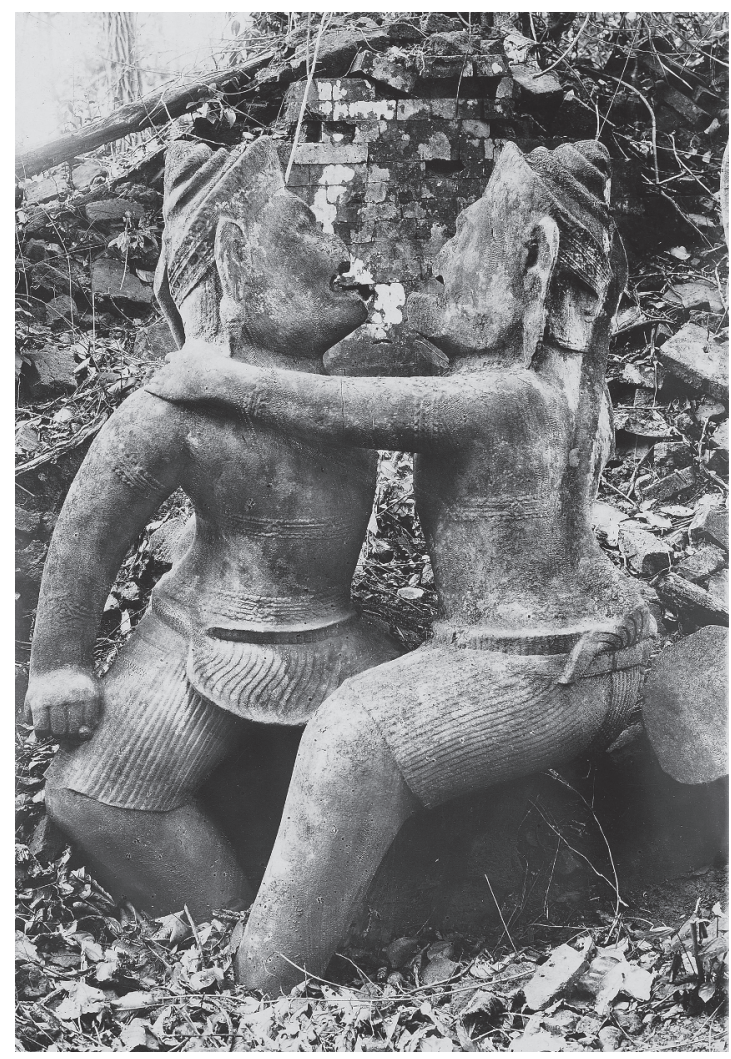

Fig. 21 Vālin et Sugrīva, gopura I Est du Prasat Chen (Archives photographiques de l'EFEO [11322]).

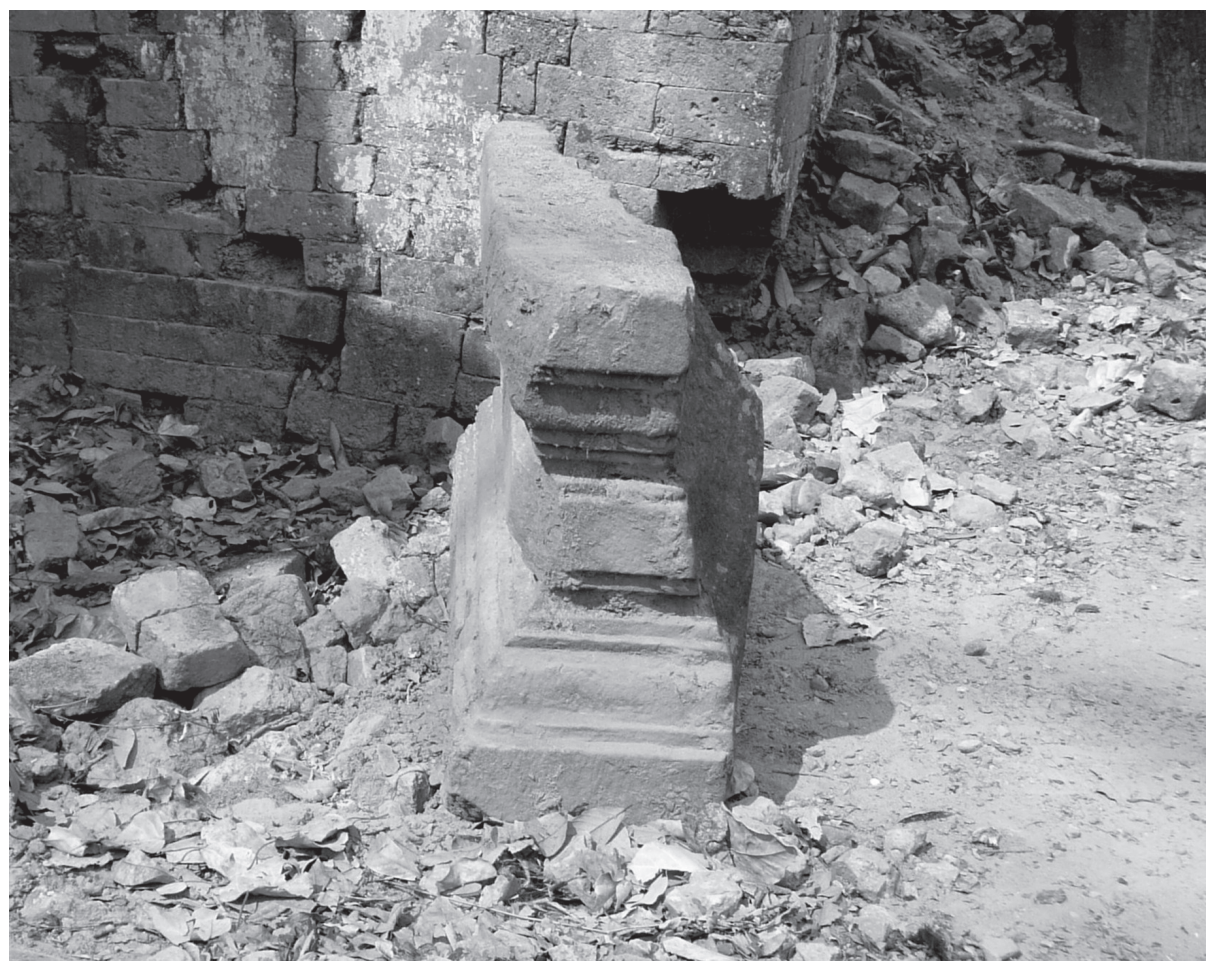

Fig. 22 Piédestal, gopura I Est du Prasat Chen (ph. auteur, 2009). 

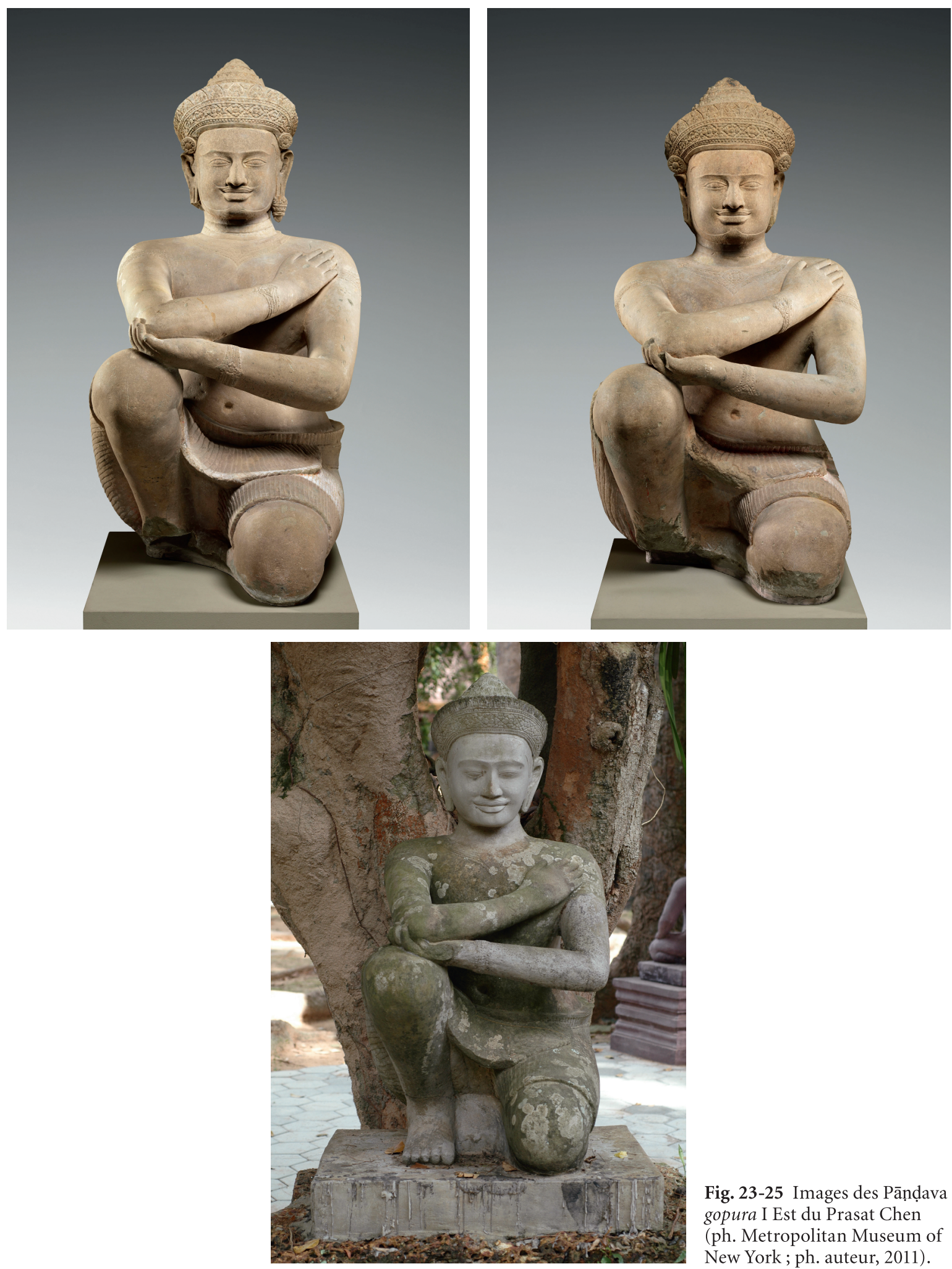

Fig. 23-25 Images des Pāṇḍava (?), gopura I Est du Prasat Chen (ph. Metropolitan Museum of New York ; ph. auteur, 2011). 


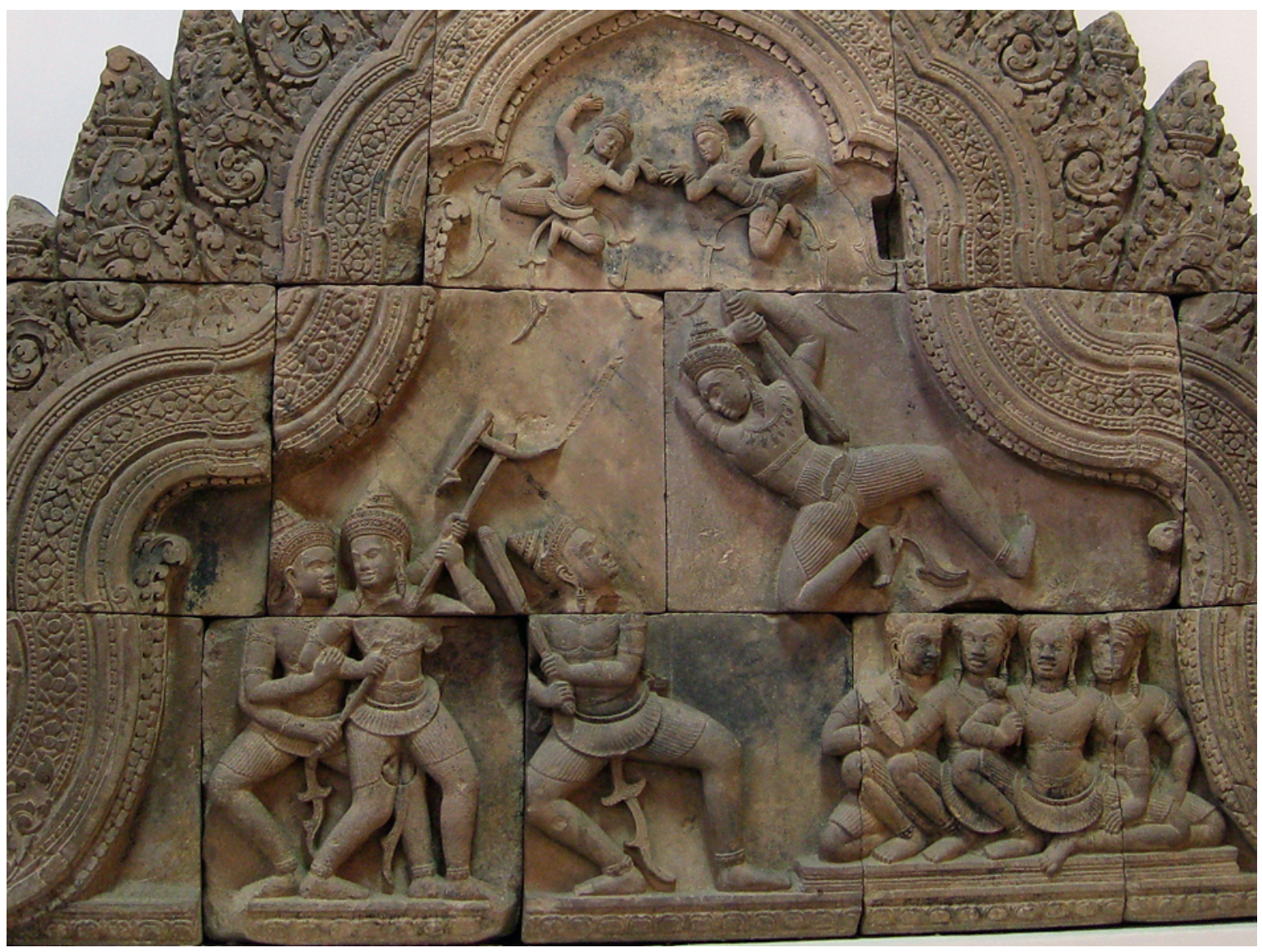

Fig. 26 Combat de Bhīma et Duryodhana, fronton ouest du gopura II Ouest de Banteay Srei (ph. Bertrand Porte, Atelier de restauration du Musée national de Phnom Penh).

mètres où les orteils de Bhīma dépassent de la surface du piédestal, se résume et se condense tout le dynamisme de la scène (fig. 27).

Ce tour de force, le ou les artistes du Prasat Chen, qui auront été les maîtres des bâtisseurs de Banteay Srei, ont su le renouveler en sculptant la statue du Duryodhana (fig. 13). Ils ont réalisé cette gageure inouie de donner l'illusion d'un être en suspension, s'arrachant du sol et semblant s'affranchir de la masse pesante du bloc de grès dans lequel il est taillé. Les pieds dûment posés à plat sur le piédestal, selon une constante de la statuaire khmère, Duryodhana n'en est pas moins «bondissant » grâce, une nouvelle fois, à un jeu subtil sur les lignes du drapé et l'équilibre du corps. Seule la confrontation avec l'image de Bhīma devrait permettre d'en apprécier pleinement l'effet : la chute en ancre du sampot dessine ici une courbe plus accentuée qui ne fait qu'effleurer la surface du piédestal ; le corps est à nouveau arqué et fléchi mais projette là nettement son centre de gravité vers l'avant ; la massue était pointée vers le bas (laissant une trace d'arrachement de section octogonale sur le piédestal) dans une position inversée par rapport à celle de Bhīma, qui suggère paradoxalement ce mouvement de jaillissement vers le haut (selon un procédé que l'on retrouve également à Banteay Srei) (fig. 28). 


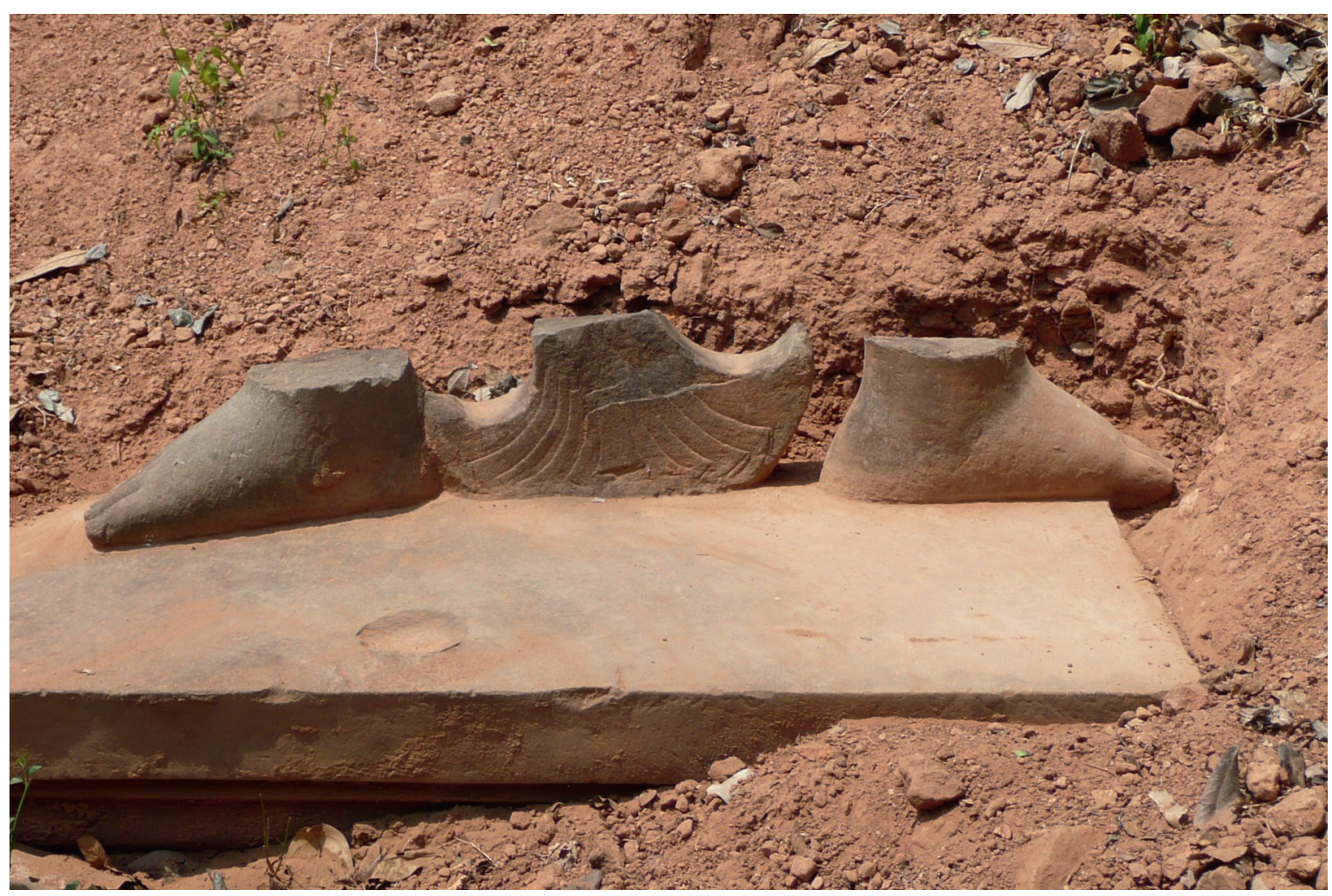

Fig. 27 Pieds de Bhīma, gopura I Ouest du Prasat Chen (ph. auteur, 2009).

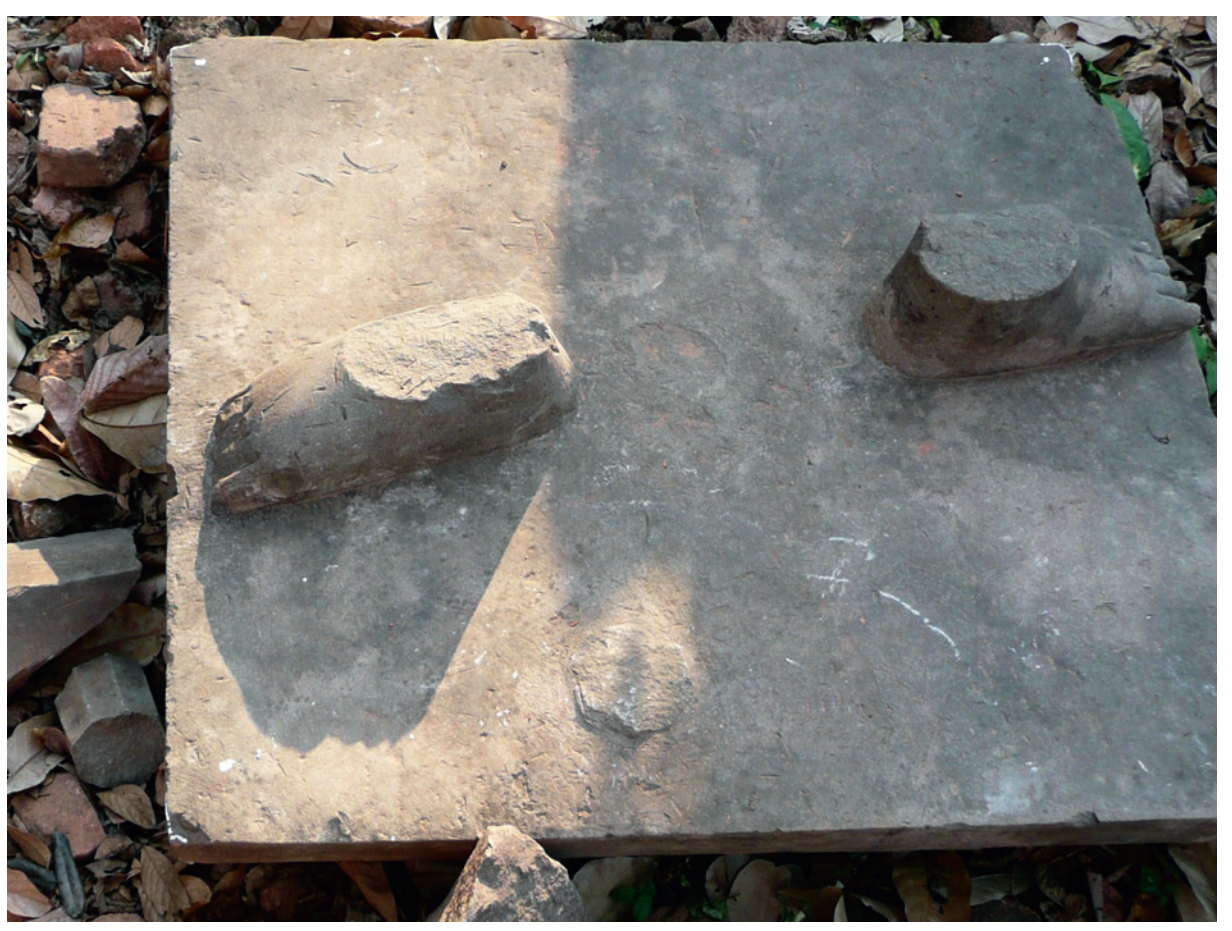

Fig. 28 Pieds et massue de Duryodhana, gopura I

Ouest du Prasat Chen (ph. auteur, 2009). 
Aucun autre groupe sculpté n'illustre sans doute de façon aussi spectaculaire la créativité des artistes de Koh Ker. Il n'est pas assez dire, on le voit, qu'ils ont introduit le mouvement dans la statuaire de l'époque. Nulle part ailleurs que dans cette représentation de Bhīma débordant du cadre de son piédestal, la prise de possession de l'espace par la statuaire n'est aussi marquée. Nulle part ailleurs les sculpteurs ne sont peut-être allés aussi loin dans la suggestion du mouvement que dans la représentation de Duryodhana s'élançant dans les airs. Nulle part ailleurs la statuaire angkorienne ne paraît avoir été aussi proche de ce qui lui fut peut-être un modèle : le théâtre.

De ces similitudes rigoureuses entre Banteay Srei et Koh Ker, il est plusieurs enseignements à tirer. Comme nous l'avons suggéré plus haut, elles permettent tout d'abord de mieux comprendre la genèse du programme iconographique de Banteay Srei. Les compositions élaborées de quelques-uns des plus beaux linteaux et frontons qui ont tant contribué à la renommée de son décor sculpté, ne sont pas nées ex nihilo. Le mérite des sculpteurs de Banteay Srei est là d'avoir su retranscrire en bas-reliefs ce que leurs prédécesseurs à Koh Ker avaient réalisé en rondebosse. Certes, sur de nombreux autres aspects, ils innoveront également, mais on ne saurait faire de Banteay Srei un point de départ unique et on ne saurait a fortiori s'étonner de la maîtrise " précoce » de ces compositions narratives pour soutenir, comme cela a pu être proposé récemment, une date beaucoup plus basse que celle retenue jusqu'à présent ${ }^{64}$.

Il reste bien sûr à s'interroger sur la genèse de l'iconographie narrative à Koh Ker même. Sans rentrer dans les détails d'une telle discussion, nous ferons ici deux remarques. On se souviendra tout d'abord qu'il existe un précédent remarquable, même si sa datation a pu aussi être contestée : la frise sculptée sur l'ensemble du pourtour du dernier gradin de la pyramide du Bakong. Quelle que soit la chronologie plus ou moins complexe de ce temple et quels que soient les ajouts tardifs, bien identifiés, dont il a fait l'objet, nous ne voyons guère de raisons de dater une telle frise au-delà de la fin du IX ${ }^{\mathrm{e}}$ siècle ${ }^{65}$. Une datation aussi haute n'est sans doute pas incongrue si on prête attention à l'évolution suivie par les autres royaumes sud-est asiatiques et le monde javanais en particulier. Il demeure qu'on ne saurait raisonner uniquement en termes d'influences ou, plus exactement, que celles-ci doivent elles-mêmes être expliquées, c'est-à-dire historicisées en s'interrogeant sur les conditions mêmes qui ont rendu possible leur réception. En d'autres termes, nous sommes ramenés à la caractérisation de " ce long $\mathrm{x}^{\mathrm{e}}$ siècle » que nous évoquions précédemment. C'est là, nous l'avons dit, un travail qui reste largement à mener. Nous ne pouvons ici que formuler, sur un mode par trop allusif, le constat d'une certaine congruence entre les évolutions que nous avons soulignées plus haut et ce processus remarquable d'expansion des images divines qui, au Cambodge, ne s'affirme véritablement qu'avec la fin du IX siècle. Au Bakong puis à Koh Ker et Banteay Srei, une visibilité nouvelle est accordée au principe divin abrité dans les temples, bien au-delà de leurs seules représentations, anthropomorphe ou non, dans l'isolement des cella : désormais, les images des dieux - et il s'agit là aussi bien de Śiva que

64 Contra Roveda 2002, p. 46 et Roveda 2005, p. 350.

65 Seuls quelques blocs de cette longue frise étaient encore lisibles lors des premières couvertures photographiques réalisées sur le Bakong. Mais ce qui subsiste s'interprète fort bien d'un point de vue stylistique et ne s'accorde en aucun cas à l'hypothèse d'un archaïsme plus tardif (comme on a pu le supposer pour certaines rondes-bosses du $\mathrm{XII}^{\mathrm{e}}$ siècle imitant le style du Bakheng). 
de Viṣnu - se projettent nettement en avant des tours-sanctuaires et cette projection donne à voir leurs « descentes » et leurs " prises de corps » dans le monde manifesté (dont ils sont eux-mêmes la source), c'est-à-dire leur action dans le triple monde ${ }^{66}$.

Un second enseignement à tirer des similitudes avec Banteay Srei intéresse directement - et c'était là notre point de départ-la compréhension de la relation entre fondations vișnuites et śivaites dans le Cambodge ancien. L'examen de l'iconographie narrative renforce l'interprétation du temple d'Î́sarapura comme l'union respectivement terrestre et divine de deux fondateurs et de deux fondations, autour d'une figure centrale et dominante (Yajñavarāha et Tribhuvanamaheśvara). De la même façon que les images placées dans les tours latérales juxtaposaient Vișnu et Śiva, les frontons des gopura juxtaposent, à l'ouest et à l'est de la première enceinte, les thèmes épiques issus du Prasat Chen (vișnuite) et ceux du Prasat Thom (śivaïte) ${ }^{67}$ : les premiers apparaissent sur les frontons du gopura II Ouest ${ }^{68}$, les seconds sur ceux du gopura III Est.

La comparaison est inversement susceptible de nous éclairer, à Koh Ker, sur la place du Prasat Chen aux côtés du Prasat Thom. Si ce dernier est bien identifié, par l'épigraphie, comme le grand sanctuaire royal śivaïte bâti par Jayavarman IV, les inscriptions du Prasat Chen, très mal conservées, sont, elles, plus difficiles d'utilisation. L'un des piédroits retrouvés sur le site porte néanmoins une inscription dont les premières lignes paraissent désigner le Viṣnu du temple sous le nom de Śrīpati ; la titulature du roi apparaît également, suggérant qu'une telle fondation fut l'œuvre du souverain, ce qui s'accorde naturellement avec la présence de groupes sculptés de la même importance (et de la même main ?) que ceux du Prasat Thom ${ }^{69}$. Il n'est donc pas trop hardi de définir le Prasat Chen comme le grand pôle viṣnuite de l'ancienne capitale, tandis que le Prasat Thom en constitue le cœur śivaite. Si, par ailleurs, l'on adopte bien cette lecture de l'inscription du Prasat Chen, proposée ici à la suite de Cœedès, une seconde observation peut être formulée dans le prolongement des réflexions qui précèdent : il n'est peut-être pas indifférent que le dieu érigé par Jayavarman IV dans le temple viṣnuite soit précisément désigné comme «l'époux de Śrī ». Nous retrouverions là l'association privilégiée des fondations vișnuïtes avec la célébration d'une alliance.

\section{Le « Seigneur des trois mondes»}

Il y eut toutefois une autre dimension du Prasat Chen qui, loin d'être contradictoire avec une telle hypothèse, nous semble en élargir la portée. Un buste de dimensions respectables, visible aujourd'hui au pied de la tour centrale, correspond très certainement à l'image de Vișnu, érigée autrefois à l'intérieur de celle-ci (fig. 29). Les fragments de quatre paires de bras retrouvés à proximité, peuvent lui être associés avec une quasi certitude (fig. 30). Il s'agit donc de la forme

66 Une telle évolution est naturellement à rapprocher avec celle observée en Inde, selon toutefois une périodisation et des modalités assez différentes. Nous renvoyons à ce sujet aux récents travaux de Charlotte Schmid et Valérie Gillet (Schmid 2010 et Gillet 2010)

67 C'est le cas, tout au moins, du Kirātārjunīya.

68 De façon remarquable, l'orientation des thèmes iconographiques est reproduite d'un temple à l'autre. Au Prasat Chen, la lutte de Vālin et Sugrīva est placée dans le pavillon d'entrée oriental tandis que le combat de Bhīma et Duryodhana est érigé dans le pavillon d'entrée occidental. De la même façon, sur les frontons du gopura de Banteay Srei, Vālin et Sugrīva apparaissent à l'est, Bhīma et Duryodhana à l'ouest.

69 K. 182, 1. 3-4 (Coedès, IC I, p. 55). Sur les six temples de Koh Ker renseignés par l'épigraphie, cinq d'entre eux apparaissent ainsi comme des fondations du souverain : le Prasat Thom, le Prasat Kracap, Banteay Pir Choan, le Prasat Damrei et le Prasat Chen. 


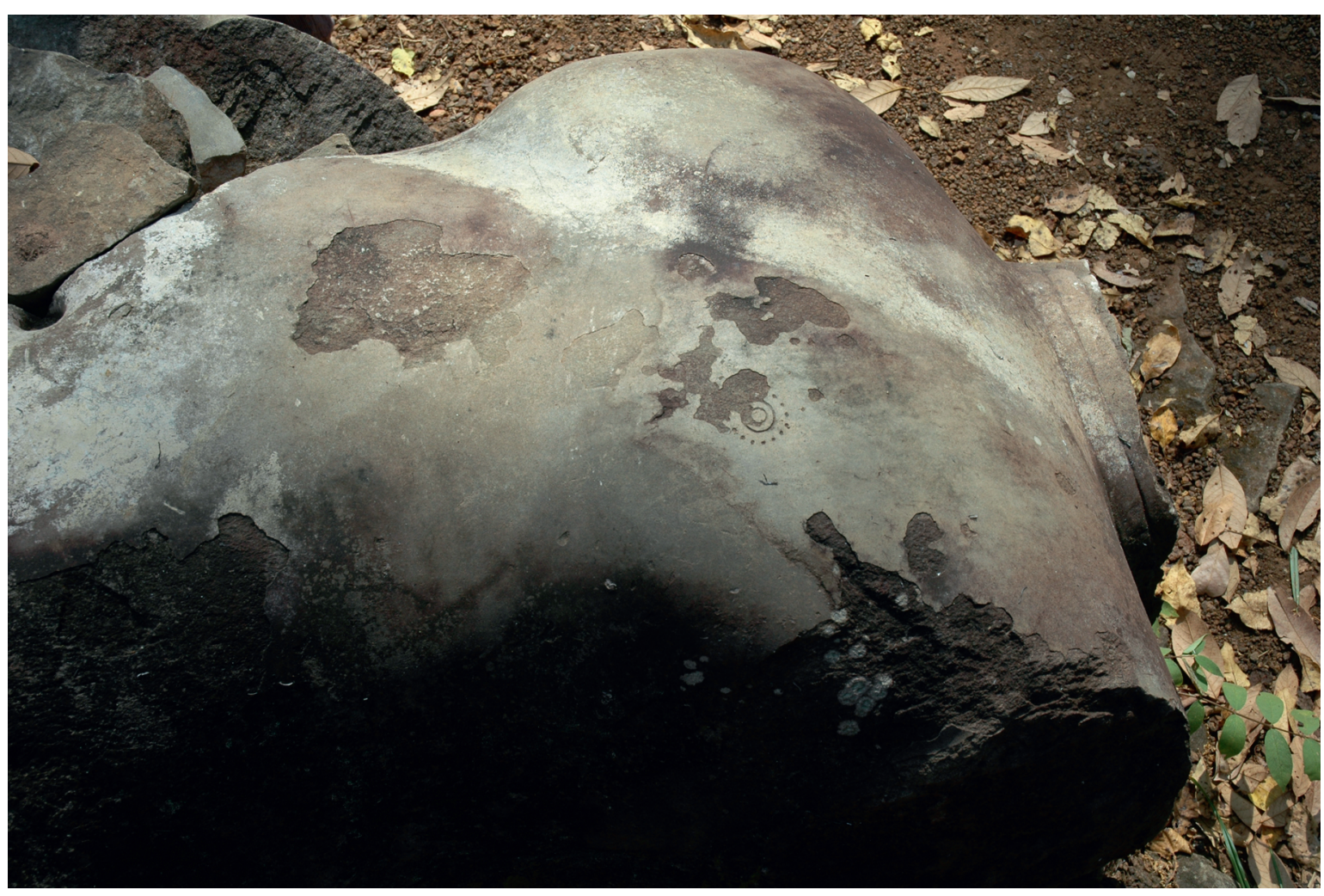

Fig. 29 Buste de Viṣnu, Prasat Chen (ph. auteur, 2009).

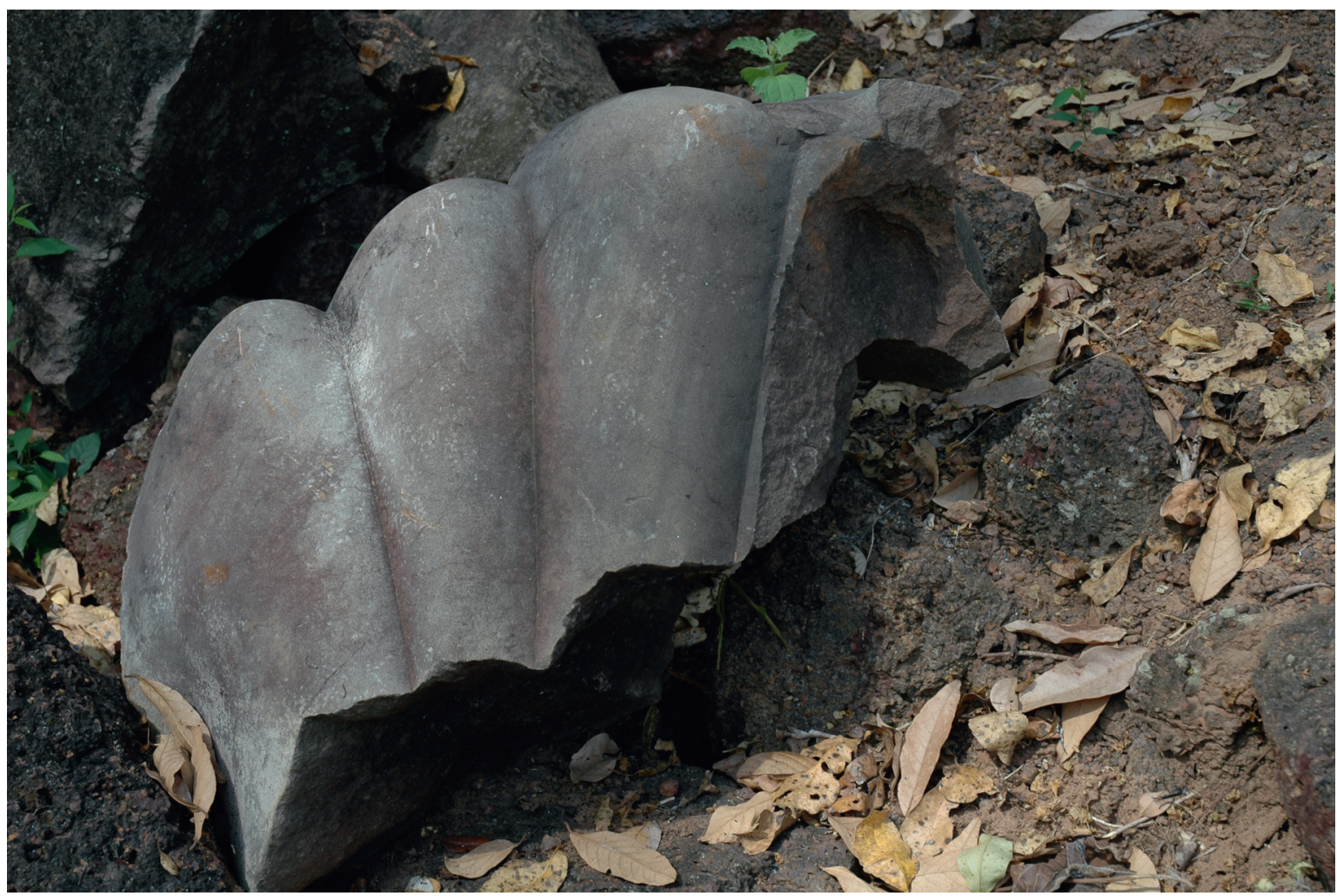

Fig. 30 Bras de Viṣnu, Prasat Chen (ph. auteur, 2009). 
cosmique de Viṣnu, telle que celle-ci apparaît très précisément dans les deux temples les plus fameux du règne de Jayavarman IV bâtis en dehors de Koh Ker : le Prasat Kravan et le Prasat Neang Khmau (fig. 31 et 32$)^{70}$. Nous avons déjà évoqué le premier des deux, fondé rigoureusement le même jour, « le jour de Yama », et aux mêmes heures que le Prasat Thom. Les inscriptions de la tour centrale et de la tour située au sud de celle-ci ont conservé les noms des deux images vișnuites qu'elles abritaient : Trailokyanātha et Tribhuvanasvāmin. Ces deux images furent érigées respectivement par deux hauts dignitaires : le Kamsten 'Añ Śrī Mahīdharavarman et le Mratāñ Khloñ Śrī Vīrendrādhipativarman ${ }^{71}$. L'inscription de la tour centrale du Prasat Neang Khmau (dans la province de Takéo), datée de 928, s'ouvre par une invocation à Viṣnu sous le nom de Lokanātha et sous l'aspect de Trivikrama (K. 35, stances I-II) ${ }^{72}$. Comme le souligne Coedès, une telle invocation est en accord avec le caractère des fresques peintes à l'intérieur des tours, fresques qui sont elles-mêmes à rapprocher des bas-reliefs intérieurs du Prasat Kravan. Dans ces deux temples, la forme cosmique de Vișnu à huit bras identifiée au Prasat Chen apparaît sur le mur du fond de la cella centrale. Dans le sillage de Coedès et de Bhattacharya, nous pouvons admettre l'hypothèse d'un lien direct entre cette forme iconographique de Vișnu et la «maitrise du ou des (trois) monde(s) » qui donne son nom au dieu dans les inscriptions.

À notre sens, rendre compte de la place du "vișnuïsme » dans le Cambodge ancien, et sous le règne de Jayavarman IV en particulier, consiste, pour une large part, à prendre la mesure de cette double connotation : Viṣnu comme figure de l'allié (position qui, dans le domaine de la parenté, est fondamentalement celle du beau-frère, mari de la sœur) et comme figure du protecteur des mondes manifestés. Ces deux dimensions se ramènent en réalité à une seule attribution : la prise en charge non pas tant de la pleine souveraineté - celle-ci demeurant incarnée par Śiva (au moins jusqu'à la fin du XI ${ }^{\mathrm{e}}$ siècle) ou, dans le domaine de la parenté, par le frère de la sœur - mais de ce que l'on pourrait désigner comme la mise en ouvre de cette souveraineté, c'est-à-dire son expansion ou son rayonnement (dans le ou les mondes manifestés précisément).

Disons tout de suite, néanmoins, que cette « distribution des rôles » entre les grandes divinités du panthéon peut se révéler sensiblement plus complexe puisque, à Koh Ker, Siva se voit lui aussi attribuer la maîtrise des mondes. Comme nous allons le voir, il s'agit d'un événement important ; mais pour en mesurer toute la portée, il est utile au préalable de faire brièvement l'inventaire des divinités qualifiées de « seigneur ou protecteur des trois mondes » avant et pendant l'épisode de Koh Ker.

Antérieurement au règne de Jayavarman IV, toutes périodes confondues, nous relevons les mentions suivantes : sept désignent des images de Viṣnu ${ }^{73}$; l'une est un Bouddha également dési-

70 Pour un premier examen de ces deux images de Vișnu, voir Bhattacharya 1961, p. 108-109. Une étude plus fouillée a été récemment consacrée au Prasat Kravan par T.S. Maxwell. L'auteur propose de reconnaître là plus spécifiquement la forme de Vișnu-Pradyumna à partir de laquelle se déploie l'univers selon la cosmogonie Pāñcarātra : "The (now) missing statue of Visnu as Trailokyanātha was worshipped in the Central Temple of Prasat Kravan as the source of Pradyumna, and hence as the source of the Purusa, creator of the world" (Maxwell 2010, p. 31).

71 K. 270, 1. 3-4 et K. 269, 1. 2-3 (Cœdès, IC IV, p. 69 et p. 74) L'inscription de la tour nord (K. 271, 1. 1-2), mentionne une donation à Śrī (ibid., p. 75).
72 Cœdès, IC II, p. 32

73 Trailokyasāra : K. 21, st. XII et XVII du texte sanskrit, 1. 2 du texte khmer (Barth, ISC n ${ }^{\circ}$ II, p. 24-25 et Cœè̀s, IC V, p. 5); K. 447, st. III (Cœdès, IC II, p. 193). Tribhuvanañjaya : K. 939, 1. 4-5 (Cœdès, IC V, p. 56) et K. 1254 (inscription inédite, communication personnelle de Gerdi Gerschheimer et Dominic Goodall). Trailokyanātha : K. 291, st. X (piédroit nord) et 1. 1-2 (piédroit sud), cf. Cœdès, IC III, p. 201. Tribhuvaneśvara : K. 1214, 1. 5 (Griffiths 2005, p. 20, n. 34). Lokanātha : K. 259, S 1. 22, 23 et $31, \mathrm{~N} 1.17$ et 28-29 (Codès, IC VII, p. 53-55). Il semble qu'une seule de ces images ait été érigée par un souverain (le roi Jayavarman I ${ }^{\text {er }}$ ), le Vișnu Tribhuvanañjaya de K. 1254. 


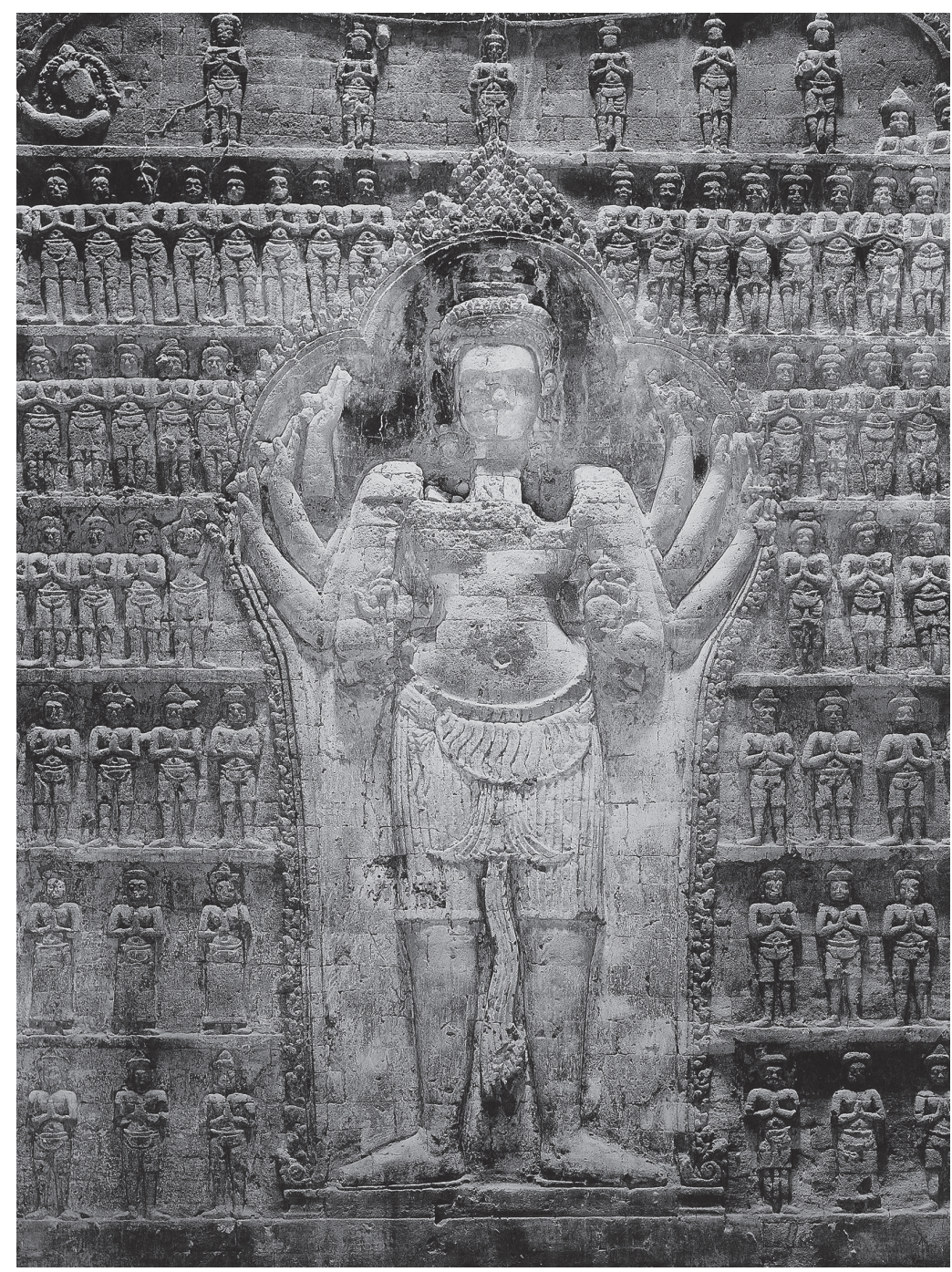

Fig. 31 Mur ouest de la tour centrale du Prasat Kravan (Archives photographiques de l'EFEO [11036]).
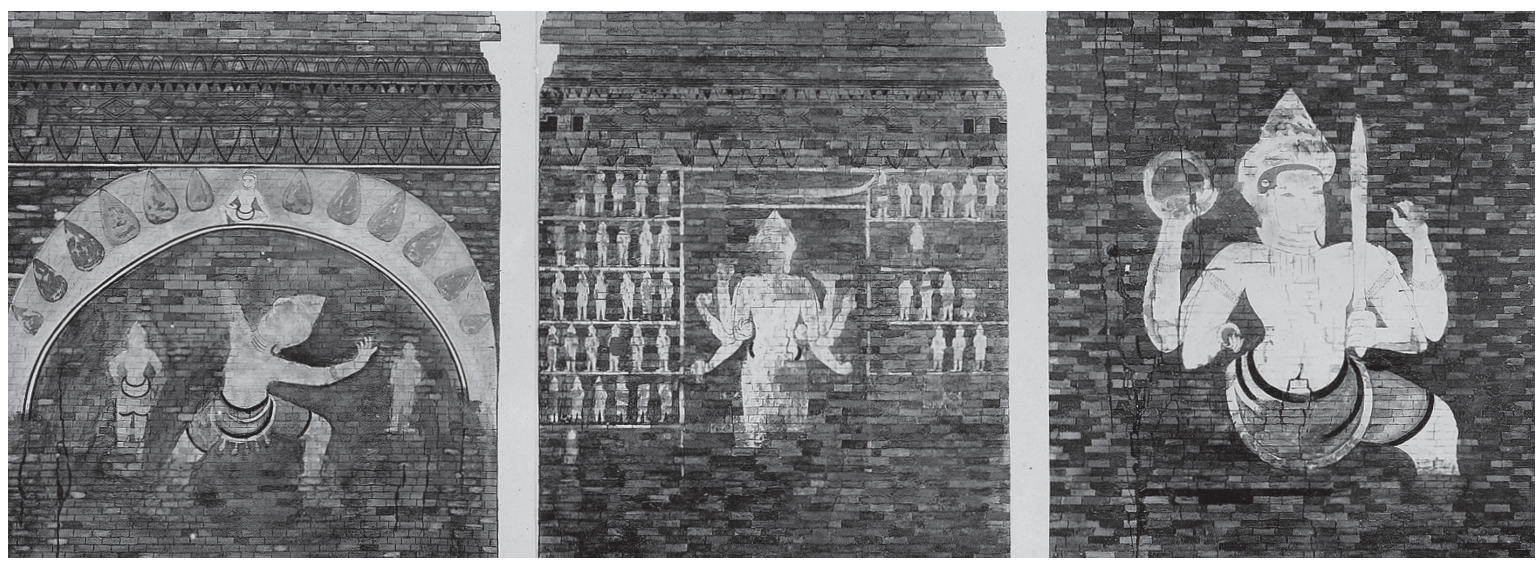

Fig. 32 Peintures du Prasat Neang Khmau (Archives photographiques de l'EFEO [12632]). 
gné comme le "Maître de tous les Munis» (sakalamunipati) ${ }^{74}$; une autre encore pourrait être soit un Vișnu, soit un Buddha ${ }^{75}$. Nous relevons enfin une dernière occurrence qui pourrait être soit un Viṣnu, soit un Śiva ${ }^{76}$. Sauf erreur, une seule image d'un Vișnu sous sa forme cosmique est alors connue ; il s'agit du grand Viṣnu du Phnom Da, qui remonte à l'époque funanaise et peut être daté de la première moitié du vi $\mathrm{v}^{\mathrm{e}}$ siècle ${ }^{77}$.

Sous le règne même de Jayavarman IV, l'évocation de la « maîtrise des mondes » est beaucoup plus fréquente, avec un nombre d'occurrences sensiblement identique au total réuni pour les trois siècles précédents. Sept divinités sont ainsi consacrées sous des vocables apparentés à la "maitrise des mondes »: à Koh Ker, ce sont Tribhuvaneśvara et Trailokyādhipatiśvara au Prasat Thom ${ }^{78}$ et (Viṣnu ?) Tribhuvanadeva au Prasat Kracap (également fondation royale) ; dans la région d'Angkor, nous avons déjà cité les Vișṇu Trailokyanātha et Tribhuvanasvāmin du Prasat Kravan ; dans la province de Kompong Cham, au Prasat Cheung Ang, la troupe (gana) d'un Viṣnu Tribhuvanaikanātha est réunie en 922, sur ordre de Jayavarman IV, à celle du Vișnu Cāmpeśvara ${ }^{79}$. Dans la province méridionale de Takéo, nous avons vu également qu'un Vișnu Lokanātha était consacré au Prasat Neang Khmau. Rappelons enfin que la tour centrale du Prasat Chen abritait une forme cosmique de Vișnu à huit bras semblables aux images du Prasat Kravan et du Prasat Neang Khmau.

À ces témoignages contemporains du règne de Jayavarman IV, il faut ajouter celui des inscriptions plus tardives. De façon remarquable, celles-ci ont conservé le souvenir précis de la fondation d'un culte de Śiva Tribhuvaneśvara par Jayavarman IV. Ainsi, la stèle de Baksei Chamkrong (datée de 948 de n. è./869 śaka) précise que Jayavarman IV «fonda une ville qui par son ampleur fut le siège de la puissance des Śrī des trois mondes ${ }^{80}$. Comme le souligne Coedès, il y a là une allusion évidente au nom de la divinité principale de Koh Ker. Nous retrouvons la même allusion dans une inscription du Prasat Ampil Rolum où le bâtisseur de Koh Ker est mentionné en ces termes : «le roi des rois Śrī Jayavarmadeva, fondateur du siège de Tribhuvana ${ }^{81}$. La stèle de Sdok Kak Thom (1053 de n. è./974 śaka) nous livre également un témoignage semblable : " ayant reçu une terre de la faveur de ce roi, ce sage [İsāanamūrti] illustre fonda la ville de Khmvā̃̃, par dévotion envers Tribhuvaneśvara $»^{82}$. Cette dernière stance retient en particulier l'attention car elle conserve, outre le souvenir du culte instauré par Jayavarman IV, celui des actes de « dévotion» (bhakti) des hauts dignitaires participant à la célébration de ce culte ${ }^{83}$.

74 Trailokyanātha : K. 495, 1. 4 (Cœdès cité dans Seidenfaden 1922, p. 64)

75 Trailokyanātha : K. 534, st. XIV (Finot 1925, p. 303).

76 Tribhuvaneśvara : K. 359, st. 3 (Barth, ISC n IV, p. 30-31). Selon Gerschheimer et Griffiths, une nouvelle traduction (à paraître) de cette inscription suggèrerait qu'il s'agit d'un Śiva (Griffiths 2005, p. 20-21, n. 34).

77 La statue est conservée au Musée national de Phnom Penh (Inv. 1639). Cf. Bhattacharya 1961, pl. XIII.

78 Tribhuvaneśvara : K. 184, st. I et III (Codès 1931, p. 13) Trailokyādhipatiśvara : K. 824, 1. 3-4 (Cœdès, IC I, p. 52 ; Pou 2001, p. 96).

79 K. 99, 1. 5-6 (Codès, IC VI, p. 108). L'ordre royal est daté de 922/844 śaka (la lecture de la date sur l'estampage n'est pas douteuse à nos yeux). On prêtera attention au fait que l'inscription ne mentionne pas l'érection du dieu, qui est naturellement anté rieure et dont on pourrait supposer qu'elle remonte, elle aussi, à 921. Il est intéressant, par ailleurs, de relever que l'autorité de
Jayavarman IV s'étendait au temple de Cāmpeśvara qui fut le principal lieu saint viṣnuite de la période angkorienne. 80 K. 286, st. XXXV : «śriyām vibhūtyā bhuvanatrayasya sthānam purī yena krtā mahimnā » (Codès, IC IV, p. 92 et 99).

81 K. 162-S, 1. 22 : "śrïjayavarmmadevendrādhirājena tribhubansthānanirmmikena " (Codès, IC VI, p. 104-105). L'inscription ne porte pas de date. Elle pourrait remonter, au plus tôt, au règne même de Jayavarman IV.

$82 \mathrm{~K} .235$ st. LV : « bhūmim prasādato labdhvā tasya rājñas sa paṇditah / khmvā̄ñ-puram krtavān mānyo bhaktyā tribhuvaneśvare " (Cœè̀s et Dupont 1943, p. 81 et 98).

83 Au Prasat Thom même, on signalera également les donations de deux mratāñ $m$ rateñ au vrah̆ kamratèn añ jagat ta rājya, c'està-dire à Śiva Tribuvaneśvara tel qu'il est désigné dans les inscriptions en vieux khmer (cf. infra). Précisons, toutefois, que l'un d'entre eux est désigné comme le " chef du sanctuaire " (khloñ vnam); de telles donations ne sont donc guère surprenantes (K. 682, Codès 1931, p. 15). 
Prises toutes ensemble, les données de l'épigraphie et de l'iconographie présentent ainsi une remarquable cohérence. L'accent mis sur la maîtrise divine des mondes apparaît de façon très claire comme l'une des caractéristiques distinctives du règne de Jayavarman IV. Le répertoire des expressions divines n'est pas en lui-même nouveau, mais son usage en est profondément renouvelé.

L'innovation majeure est bien sûr l'association désormais étroite entre un tel vocable et la royauté. Le "Seigneur des trois mondes » désigne désormais le dieu érigé au cœur du sanctuaire royal, lui-même bâti au cœur de la capitale et, partant, du royaume. Cette divinité centrale érigée au cœur du royaume est bien sûr Śiva, conformément à la préséance qui lui est accordée par les souverains successifs tout au long du demi-millénaire qui précède le XII siècle. C'est là, bien sûr, un autre aspect important de l'évolution observée dans l'évocation de la maîtrise divine des mondes. Jusqu'à présent, cette maîtrise était surtout le fait de Viṣnu, dans une moindre mesure celui du Buddha ${ }^{84}$, et assez peu celui de Śiva.

La dimension à la fois royale et śivaïte qui est désormais celle du «Seigneur des trois mondes», ne met pas fin, bien au contraire, à l'association de ce vocable avec Vișnu. Mais celle-ci se fait alors selon des modalités définies par l'usage śivaïte de l'expression. En l'état des connaissances, on observera tout d'abord qu'il ne semble plus y avoir de recouvrement possible dans l'emploi des différentes expressions disponibles : Tribhuvanasvāmin, Trailokyanātha, Tribhuvanaikanātha ou Lokanātha, Viṣnu n'est plus jamais qualifié comme Tribuvaneśvara ${ }^{85}$, expression que l'on retrouve en revanche quelques décennies plus tard, sous la forme Tribhuvanamaheśvara, bien associée à la figure souveraine de Śiva au temple de Banteay Srei (conformément à l'étroite relation qui lie ce temple au Prasat Thom).

Nous relèverons surtout que la "protection des mondes » attribuée à Vișnu prend place alors à la périphérie ou, disons, dans le sillage de la «maîtrise des mondes » reconnue au Śiva du Prasat Thom.

Au sein même de la capitale, nous avons vu que le Prasat Chen, par son implantation et par son iconographie, forme ainsi, sur un mode mineur, le pendant vișnuïte du Prasat Thom. Son image centrale, sans être désignée par un vocable du type Trailokyanātha, est une forme cosmique de Vișnu qui l'apparente aux images contemporaines associées à cette expression. Elle l'apparente également fortement à l'image colossale de Śiva-Rudra dansant érigée au Prasat Thom (dans le gopura III Est) (fig. 33). Nous aurons à revenir, dans une prochaine étude, sur la thématique complexe de cette danse. Mais nous pouvons faire observer dès à présent que dans le Cambodge des $\mathrm{x}^{\mathrm{e}}$ et $\mathrm{XI}^{\mathrm{e}}$ siècles, précisément à partir du règne de Jayavarman IV, la danse de Siva est, par excellence, la figuration du dieu se manifestant (et se donnant à voir) ici-bas et que cette manifestation est elle-même la représentation de l'expansion cosmique du divin. De ce point de vue, il y a bien une relation étroite à établir entre cette image de Śiva (à dix bras) et la forme cosmique (à huit bras) de Viṣnu au Prasat Chen.

À l'échelle plus globale du royaume, les mêmes remarques s'appliquent aux fondations viṣnuïtes que nous avons passées en revue : le Prasat Kravan, le Prasat Neang Khmau, et le Prasat

84 Aux occurrences de Trailokyanātha signalées, il faudrait en effet ajouter celles de Lokeśvara désigné comme Jagadīśvara : K. 244, 1. 2 (Coedès, IC III, p. 89), K. 214 st. V (Cœè̀s, IC II, p. 203, inscription de la fin du $x^{e}$ siècle mais rapportant une donation faite sous le règne d'Indravarman). 85 Voir également Griffiths 2005, p. 20-21, n. 34 


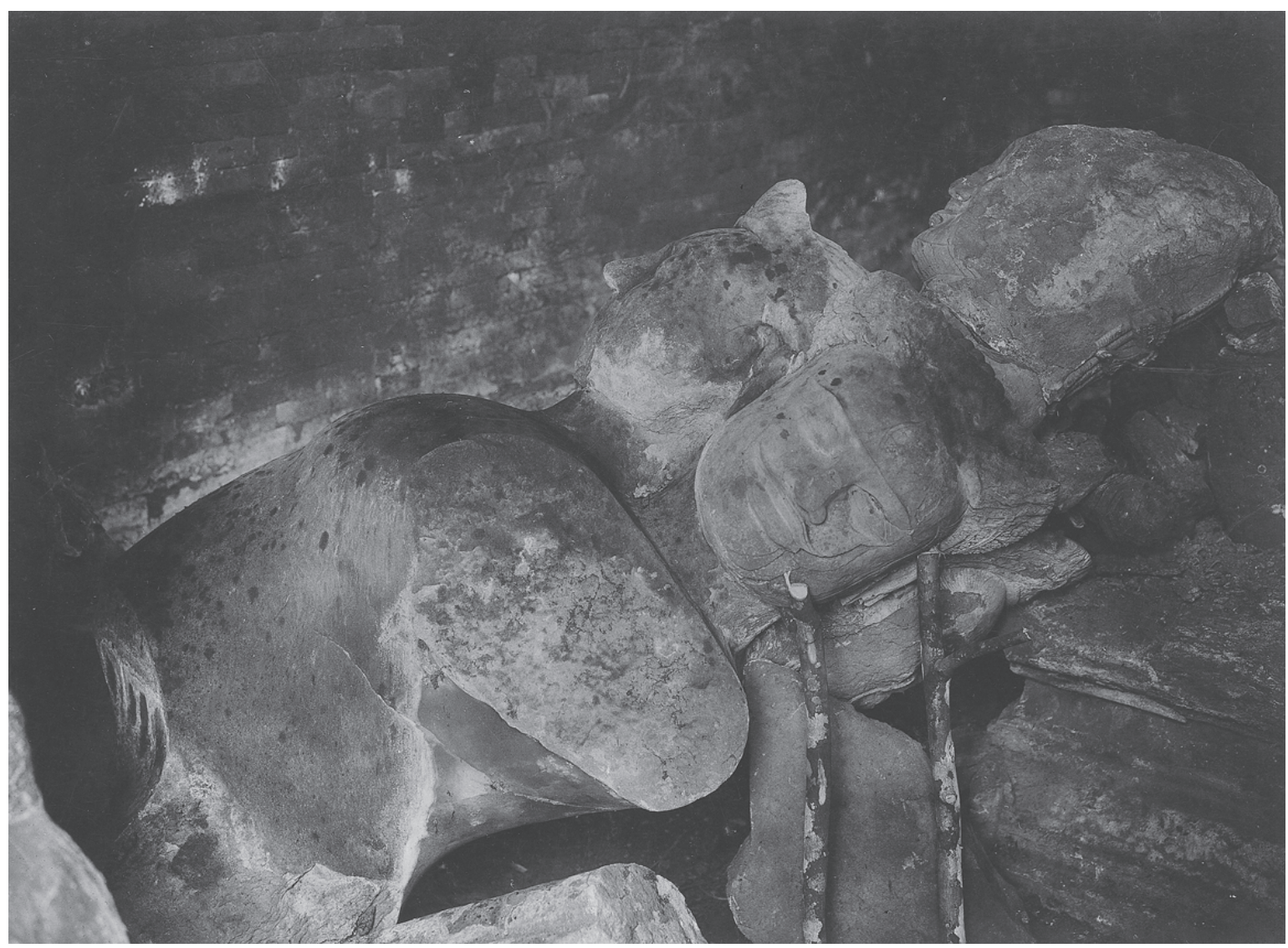

Fig. 33 Śiva-Rudra dansant, gopura III Est du Prasat Thom (Archives photographiques de l'EFEO [11303]).

Cheung Ang, fondations auxquelles il faut certainement ajouter le temple de Kôk O Chrung ${ }^{86}$. Tout se passe comme si, à leur tour, elles venaient dupliquer " à la périphérie ", c'est-à-dire ici dans les différentes provinces, et sur un mode mineur, la " maîtrise des mondes " assurée au centre, et dans le cadre monumental qui lui revient, par Śiva. Au grand sanctuaire royal et śivaïte de Jayavarman IV, répondent ainsi les fondations secondaires et viṣnuïtes des grands dignitaires provinciaux. Loin d'être des entreprises autonomes, ces dernières participent directement à la reconfiguration de la géographie sacrée initiée par le souverain en sa capitale. La similitude des dates de fondation avec celle du Prasat Thom ne saurait ici être un hasard (cf. supra). Certes, les inscriptions de Prasat Kravan (et du Kôk O Chrung) ne comportent aucun panégyrique royal qui placerait explicitement ces fondations sous l'autorité de Jayavarman IV. Coupée de son contexte, une telle similitude des dates pourrait sans doute s'interpréter comme relevant d'une simple coïncidence, en un jour considéré comme particulièrement propice par des acteurs indépen-

86 L'inscription de Kôk O Chrung qui nous livre une date strictement contemporaine de celles du Prasat Thom et du Prasat Kravan, ne précise pas l'identité de la divinité qui était érigée dans le temple. Il semble assez probable, toutefois, qu'il s'agissait bien d'un sanctuaire vișnuïte : les deux inscriptions plus tardives qui lui font suite, désignent clairement Vișnu, sous les noms de Nārāyaṇa et Acyuta, comme la divinité du lieu (Codès, IC IV : 173-174). 
dants. Mais, outre qu'une telle simultanéité entre trois fondations demeure exceptionnelle dans l'histoire angkorienne ${ }^{87}$, la dite " coïncidence » vient, répétons-le, s'ajouter à celles des formes et des vocables pris par les divinités.

Le scénario de fondations concurrentes, exprimant les rivalités entre les deux branches royales revendiquant le pouvoir suprême, nous semble moins crédible encore pour expliquer un tel événement ${ }^{88}$. Rappelons, si nécessaire, que les inscriptions du Prasat Kravan, si elles ne nomment pas Jayavarman IV, ne mentionnent pas davantage les fils de Yaśovarman. On peut s'étonner surtout des raisons pour lesquelles la fondation du Prasat Karvan - qui est l'œuvre sans aucun doute de dignitaires de haut rang mais sans aucun lien de parenté revendiqué avec la maison royale - aurait été perçue, aux yeux des contemporains, comme pouvant d'une quelconque façon « rivaliser » avec la fondation royale du Prasat Thom. L'hypothèse aurait plus de poids s'il pouvait être montré qu'une telle fondation relevait d'une décision royale (émanant en l'occurrence de Harșavarman I ${ }^{\text {er }}$; t tel n'est pas le cas. L'un et l'autre scénario n'ont pu être soutenus que parce que la thèse d'une partition du territoire, comme étant la traduction géographique des rivalités entre Jayavarman IV et les fils de Yaśovarman, a pu sembler aller de soi. Or, tout ce que l'on devine de l'organisation sociale et politique du Cambodge ancien - un écheveau complexe de relations de dépendance et d'alliance entre les grandes maisons aristocratiques du royaume nous semble vivement s'y opposer.

Sous le règne de Jayavarman IV, les fondations religieuses des hauts dignitaires se distribuent ainsi schématiquement en deux groupes : ce sont d'une part les donations faites au Siva Tribhuvaneśvara de la capitale (telles qu'elles sont documentées par l'épigraphie de ce temple et l'inscription, plus tardive, de Sdok Kak Thom) et, d'autre part, les fondations provinciales conçues comme les équivalents viṣnuïtes du Prasat Thom, érigé là en modèle à reproduire. En un double mouvement centripète et centrifuge, l'activité cultuelle du royaume (ou, tout au moins, de ceux reconnaissant l'autorité de Jayavarman IV) s'organise ainsi autour du śivalinga royal et de sa manifestation dansante ${ }^{89}$.

L’ambition de réorganiser la géographie sacrée du royaume, en plaçant au cour de celle-ci les fondations royales de la capitale n'est certes pas une spécificité de l'action de

87 Cf. supra. La date de consécration en elle-même retient l'attention. Le mercredi 12 décembre 921 est un « jour de Yama » (désigné comme tel dans les inscriptions). Il n'est pas indifférent de relever que, dans le petit groupe de fondations ayant eu lieu ce même « jour de Yama » (cf. Goodall 2011, p. 58, n. 10), l'on compte à nouveau le temple de Banteay Srei. Nous aurons à revenir dans l'étude du programme iconographique du Prasat Thom sur la signification d'une telle date de consécration et, de manière plus générale, sur la place de Yama dans les dispositifs cultuels des temples angkoriens (pour un premier aperçu, cf. Bourdonneau 2011)

88 Contra Maxwell 2010, p. 2.

89 L'épigraphie demeure silencieuse sur l'existence de fondations bouddhiques durant les deux décennies de ce règne. Aucune image bouddhique n'a été retrouvée, à notre connaissance, sur le site de Koh Ker. En revanche, le temple D du Phnom Trâp (Prasat Praeus Meas), dans la province de Kompong Cham, qui peut être daté stylistiquement de cette période, s'interprète sans ambiguité possible comme une fondation bouddhique. Les murs intérieurs ouest des trois tours du site encore debout ont conservé des bas-reliefs en brique parmi lesquels on reconnaît sans mal la figure de Vajrapāni (fig. 34). Ces bas-reliefs sont à mettre directement en relation avec la triade en ronde-bosse associant Buddha, Lokeśvara et Vajrapāṇi, retrouvée non loin de là et aujourd'hui conservée au musée Guimet (Baptiste et Zéphir $2008, n^{\circ} 48$, p. 166). Cette triade, datée du style de Banteay Srei, a pu être placée là en remplacement des images d'origine, comme cela est attesté pour bien d'autres temples (e.g. le Prasat Kravan). Ces bas-reliefs, tout à fait exceptionnels, ont été quelques peu négligés, voir omis dans la littérature, et méritent une étude spécifique. Retenons, pour l'heure, qu'ils font naturellement de ce temple l'équivalent bouddhique du Prasat Kravan et du Prasat Neang Khmau. L'information est précieuse car elle suggère que les fondations bouddhiques (a fortiori de ce bouddhisme tantrique qui s'affirme ici) ont pu jouer un rôle comparable aux fondations vișnuites dans l'affirmation de la maîtrise divine des mondes à l'époque de Koh Ker. Voir Aymonier 1900, p. 321 et Lajonquière 1902, p. 120, pour les premières descriptions du Phnom Trâp D. 


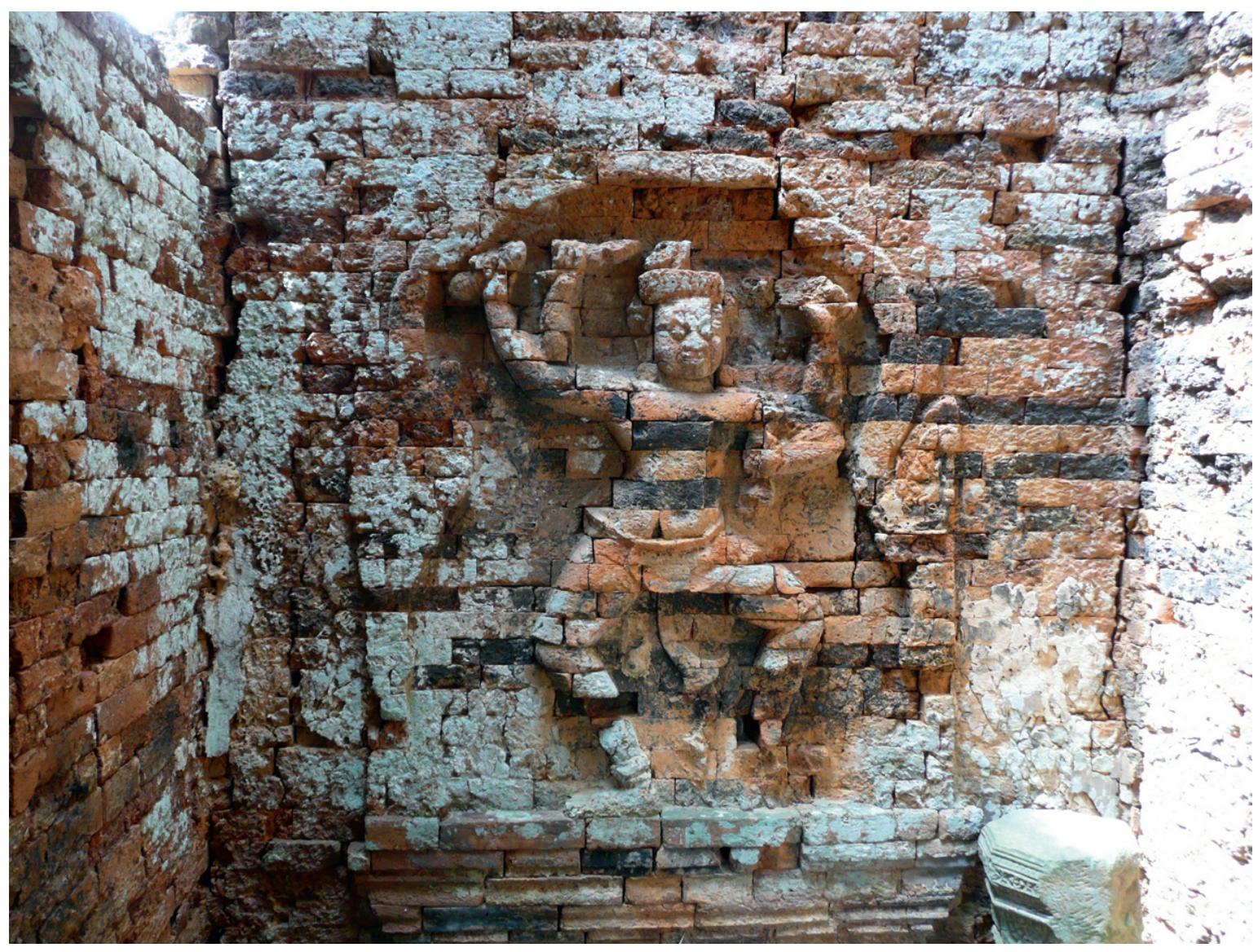

Fig. 34 Vajrapāni, tour nord du temple D du Phnom Trâp (ph. auteur, 2010).

Jayavarman IV. À l'époque préangkorienne, dès le début du viI ${ }^{\mathrm{e}}$ siècle, les fondations religieuses du règne de Íśānavarman (616/617-ca. 635) se prêtent à ce type de lecture. Nous renvoyons là à deux inscriptions, K. 441 et K. 90. La première, gravée sur le gopura II Ouest du groupe sud de Sambor Prei Kuk - l'un des trois grands sanctuaires royaux construits dans l'ancienne capitale İsānapura - fournit les dimensions de deux montagnes, séjours de Śiva ${ }^{90}$. L'une peut être identifiée avec le grand lieu saint de Lingapura, dans le Sud du Laos actuel. L'autre, située « dans la ville nommée Girīśa ", pourrait être le Phnom Bayang, autre lieu saint important du pays khmer, localisé dans l'extrême Sud du pays, à proximité de la frontière vietnamienne ${ }^{91}$. Mesurer les dimensions des lieux saints aux confins du royaume, graver les mesures ainsi prises au cour de la capitale : c'est à la fois rendre hommage au dieu présent en chacun de ces lieux et inscrire l'œuvre royale sous la protection de celui-ci ; mais c'est aussi, au cœur de la capitale, projeter l'autorité du souverain vers la périphérie du royaume. L'inscription K. 90 de Kuk Preak livre en quelques

90 Codès, IC IV, p. 16-17.

91 Un pada de Girî́a est en effet mentionné dans K. 13 (st. V), provenant du Phnom Bayang. La topographie du site s'accorde par ailleurs assez bien à celle décrite par l'auteur de K. 441. 
sortes le témoignage symétriquement inversé de cette relation entre le centre et sa périphérie. Elle relate une donation faite par un « serviteur de İsānavarman » à un Vișnu Cakratīrthasvāmin. Elle présente cette particularité d'être placée sous l'invocation de Śiva Prahasiteśvara ; or, comme Cœedès le fait observer, Śiva est précisément vénéré sous ce vocable dans le groupe sud de Sambor Prei Kuk ${ }^{92}$.

Plus proche du règne de Jayavarman IV, la fondation des áśrama par Yaśovarman forme également un précédent remarquable sur lequel nous allons revenir ci-dessous ${ }^{93}$. L'entreprise s'étend, là aussi, à l'ensemble du royaume, aussi bien dans la capitale que dans les provinces, et l'on peut relever que, comme à Koh Ker, elle réunit autour de Śiva un panthéon élargi : Skanda, Gaṇeśa, la Déesse mais aussi Viṣnu ou encore Buddha ${ }^{94}$.

\section{En guise de conclusion}

Ce qui demeure proprement spécifique à la cartographie divine sous le règne de Jayavarman IV est l'accent mis sur la maîtrise des trois mondes. Encore faut-il prendre garde aux modalités d'une telle innovation : le vocable "Seigneur ou Protecteur des trois mondes » était en usage à époque plus ancienne, mais non son association à la royauté et à Śiva. Dans le dispositif qui se met en place avec l'accession de Jayavarman IV au pouvoir, Siva fournit le modèle, central et royal, de la maîtrise des mondes, tandis que Viṣnu en livre la reproduction à la périphérie. Historiquement cependant, l'évolution s'est faite à l'inverse : Śiva s'est approprié les qualités qui étaient tout d'abord celles de Viṣnu. Mise ainsi en perspective, cette évolution peut se lire de deux façons : comme une extension des attributions de Siva (dont la préséance est par ailleurs acquise depuis la fin du Funan) et comme l'affirmation des valeurs associées à la figure de Viṣnu.

Si la caractérisation du "long $\mathrm{x}^{e}$ siècle » évoqué ci-dessus a quelque validité, il y a là une nouvelle conjonction remarquable entre une telle appropriation du rôle de Viṣnu par Śiva et les grands processus qui nous paraissent alors à l'œuvre : figure par excellence de la souveraineté, Śiva s'attribue la maîtrise du monde manifesté précisément à une époque d'« affermissement de la surface d'en-bas », selon la formulée adoptée plus haut, et tandis que parait se mettre en place un monde plus " plein socialement ». Rappelons que participe de cette même évolution l'expansion des images divines donnant une visibilité nouvelle au principe divin abrité dans les temples. Au Prasat Thom de Koh Ker, l'expression tribhuvaneśvara désigne le linga érigé dans la (petite) tour centrale du sanctuaire mais c'est la représentation monumentale de la danse de Śiva dans le gopura III Est qui donnait à voir au dévot le dieu agissant et se manifestant ici-bas : elle est l'image visible de Śiva « Seigneur des trois mondes».

Nous retrouvons là la position exprimée au départ de cette étude : au sein de ce mouvement d'ensemble du monde angkorien, l'épisode de Koh Ker représente à la fois une étape parmi d'autres et un moment singulier. Une étape parmi d'autres car une telle évolution prend

92 Coedès, IC V, p. 26.

93 K. 280-B, st. 6 : «Il a entretenu sur la terre cent āśramas chers à ses ancêtres, aux dieux et aux hôtes, pleins des subsistances et des ustensiles nécessaires, vases de prospérité » (yenāśramaśatam śastam pitrdevātithipriyam / bhogopabhogabhāg bhüti-bhäjanam bhāvitam bhuvi). Cf. Bergaigne et Barth, ISCC n LVII, p. 442.
94 Cf. Cœdès 1932, p. 108, n. 2 ; Estève 2009 : 350. Signalons, à ce sujet, la mission dite "Yaśodharāśrama ", récemment mise en place par Dominique Soutif et Julia Estève, qui comporte un volet épigraphique (édition synoptique des inscriptions récemment découvertes relatives à ces āśrama) et un volet archéologique (la prospection et la fouille des sites d'áśrama à proximité du baray oriental). 
certainement naissance dès le $\mathrm{IX}^{\mathrm{e}}$ siècle. La création d'une centaine d'āśrama par Yaśovarman est fondatrice à bien des égards, non pas seulement comme une entreprise du pouvoir royal pour imprimer son autorité sur les lieux saints à une large échelle, mais car elle fixe sans doute une première fois la géographie sacrée du royaume telle que celle-ci va perdurer à travers la période angkorienne.

Lactivité de bâtisseur de Yaśovarman sur ces sites semble être demeurée assez limitée. La grande phase de construction interviendra plus tard, au XI ${ }^{\mathrm{e}}$ siècle et, comme nous y reviendrons ailleurs, il est alors remarquable qu'elle reprenne une bonne part du vocabulaire iconographique et architectural mis en place au Prasat Thom de Koh Ker. De ce point de vue, le règne de Jayavarman IV marque bien également un tournant. Certes, ses successeurs n'érigeront, pour leur part, aucun Śiva Tribhuvaneśvara dans leurs «temples d'État». Il est vrai également que le vocable "seigneur des trois mondes", s'il est par la suite bien attesté (comme à Banteay Srei), ne fera plus l'objet d'un usage aussi systématique avant longtemps (c'est-à-dire avant la fin du $\mathrm{XII}^{\mathrm{e}}$ siècle). À l'instar de ce que montre l'analyse iconographique et architecturale, il n'en existe pas moins une réelle postérité des pratiques théonymiques de la période de Koh Ker, à la fois au cœur de la capitale et dans l'ensemble du royaume. Au cœur de la capitale : ce sera le culte du kamraten jagat ta rāja, le devarāja de la stèle de Sdok Kak Thom ${ }^{95}$. Dans l'ensemble du royaume : ce seront les divinités désignées désormais par ce même titre de kamraten jagat, une titulature par ailleurs bien spécifique des lieux saints du royaume, ceux-là mêmes où Yaśovarman érigea quelques décennies plus tôt ses āśrama et où seront reprises les formules architecturales et iconographiques fixées au Prasat Thom.

Il s'agit donc là d'une postérité considérable ou qui apparaît, à tout le moins, comme telle dès lors que l'on s'accorde sur ce point essentiel : l'équivalence, proposée autrefois par Codès mais contestée plus récemment ${ }^{96}$, entre le titre kamraten jagat et le vocable sanskrit tribhuvaneśvara. En concentrant, dans une prochaine étude, l'analyse sur le Prasat Thom (où l'une et l'autre expression apparaissent simultanément), il importera naturellement d'en refaire la démonstration, une démonstration qui détermine pour une bonne part la compréhension du culte du devarāja.

95 Rappelons que, lorsqu'elle fait son apparition, l'expression est construite d'au moins trois différentes façons : vrah kamraten añ jagat ta rājya, vraḥ kamraten añ ta rājya, vrah kamraten jagat ta rājya. 


\section{- ABRÉVIATIONS, BIBLIOGRAPHIE -}

EFEO : École française d'Extrême-Orient.

BEFEO : Bulletin de l'EFEO.

PEFEO : Publications de l'EFEO.

IC : Inscriptions du Cambodge, 8 vol. (Cœdès 1937-1966).

ISC : Inscriptions sanscrites du Cambodge (Barth 1885).

ISCC : Inscriptions sanscrites de Campā et du Cambodge (Barth et Bergaigne 1893).

ALVARES $1998=$ S. Alvares, «Images de l'idéologie royale khmère aux frontons du temple d'Íśvarapura (967 ap. J.-C.). Nouvelles hypothèses (II) ", Histoire de l'art 42-43, p. 41-48.

Aymonier 1900 = É. Aymonier, Le Cambodge. I. Le royaume actuel, Paris.

BAptiste et ZéPHIR $2004=$ P. Baptiste et Th. Zéphir, "Compte rendu : Emma C. Bunker, Douglas Latchford, Adoration and Glory. The Golden Age of Khmer Art ", Arts asiatiques, 59/1, p. 182-184.

BAPTISTe et ZÉPHIR $2005=$ P. Baptiste et Th. Zéphir dir., Trésors d'art du Vietnam. La sculpture du Champa $V^{e}-X V^{e}$ siècles, Paris (Réunion des musées nationaux).

BAPTISTE et ZéPHIR $2008=$ P. Baptiste et Th. Zéphir, L'Art khmer dans les collections du musée Guimet, Paris (Réunion des musées nationaux).

BARTH 1885 = A. Barth, "Inscriptions sanscrites du Cambodge ", dans Notices et extraits des manuscrits de la Bibliothèque nationale et autres bibliothèques 27/1, $2^{\mathrm{e}}$ fasc., Paris, p. 1-180.

Bergaigne et BARTh $1893=$ A. Bergaigne et A. Barth, "Inscriptions sanscrites de Campā et du Cambodge », dans Notices et extraits des manuscrits de la Bibliothèque nationale et autres bibliothèques 27/1, $2^{\mathrm{e}}$ fasc., Paris, p. 181-632.
BHATTACHARYA $1961=\mathrm{K}$. Bhattacharya, Les Religions brahmaniques dans l'ancien Cambodge d'après l'épigraphie et l'iconographie, Paris (PEFEO 49).

BiARDEAU 2002 = M. Biardeau, Le Mahābhārata. Un récit fondateur du brahmanisme et son interprétation, 2 t., Paris.

BIllard $2006=$ R. Billard, " Dates des inscriptions du pays khmer » (travail revu et augmenté par J.C. Eade), BEFEO 93, p. 395-428.

Bisschop $2010=$ P. Bisschop, "Once Again on the Identity of Candeśvara in Early Śaivism: A rare Candeśvara in the British Museum? ", Indo-Iranian Journal 53, p. 233-249.

BoIsSelier $1992=\mathrm{J}$. Boisselier, « 1. La signification d'Angkor Thom. 2. Prasat Thom de Koh Ker et Banteay Srei. 3. Oc-èo ", Renaissance culturelle du Cambodge 6, p. 259-284.

BOURDONNEAU $1999=$ E. Bourdonneau «Redéfinir l'originalité de Banteay Srei. La relation entre iconographie et architecture ", Aséanie 3, p. 27-65.

BOURDONNEAU $2003=$ E. Bourdonneau, " Culturalisme et historiographie du Cambodge ancien. À propos de la hiérarchie des sources de l'histoire khmère ", Moussons 7 (2003), p. 39-70.

BOURDONNEAU $2007=$ E. Bourdonneau, «Réhabiliter le Funan. 1. Óc Eo ou la première Angkor ", BEFEO 94, p. 111-158.

BOURDONNEAU $2011=$ E. Bourdonneau, « Mort, royauté et lieu saint dans le Cambodge ancien. Mission archéologique à Koh Ker ", dans Un siècle d'histoire. L'École française d'Extrême-Orient et le Cambodge, Paris, p. 84-93. 
BRUNNER et alii $2004=\mathrm{H}$. Brunner, G. Oberhammer et A. Padoux éd., Tāntrikābhidhānakośa II. Dictionnaire des termes techniques de la littérature hindoue tantrique (Beiträge zur Kultur-und Geistesgeschichte Asiens 44), Vienne.

BUNKER et LATCHFORD $2004=$ E.C. Bunker et D. Latchford, Adoration and Glory, The Golden Age of Khmer Art, Chicago (Art Media Resources).

Clothey 1978 = F.W. Clothey, The Many Faces of Murukan. The History and Meaning of South Indian God, La Haye, Paris, New York.

CEDDÈs 1908 = G. Coedès, « Les inscriptions de Bàt Čum (Cambodge) ", Journal asiatique 10 (12), p. 226-252.

CÉDÈs 1931 = G. Coedès, « Études cambodgiennes. XXVI - La date de Kọ̀ Ker », BEFEO 31, p. 12-18.

CEDÈs 1937-1966 = G. Cœedès, Inscriptions $d u$ Cambodge, 8 vol., Collection de textes et documents sur l'Indochine III, Hanoi, Paris (EFEO).

CCedÈs 1940 = G. Coedès, "Études cambodgiennes. XXXIII - La destination funéraire des grands monuments khmèrs ", BEFEO 40, p. 315-343.

CÉDÈs $1965=$ G. Coedès, « Le rôle de la pyramide de Koh Ker dans l'évolution du temple-montagne khmèr ", Paranavitana Felicitation Volume, Colombo, p. 61-66.

CEedès $1970=$ G. Coedès, « Le véritable fondateur de la royauté divine au Cambodge ", Himansu Bhusan Sarkar, R. C. Majumdar Felicitation Volume, Calcutta (H. B. Sarkar, K. L. Mukhopadhyay), p. 55-56.

Cédès et Dupont $1943=$ G. Coedès et P. Dupont, «Les stèles de Sdŏ̀k Kăk Thom, Phnom Sandak et Práh Vihãr », BEFEO 43, p. 56-154.
Dessigane et Pattabiramin $1967=$ R. Dessigane et P. Z. Pattabiramin, La Légende de Skanda selon le Kantapurānam tamoul et l'iconographie, Pondichéry (Publications de l'Institut français d'indologie 31).

Dumont 1966=L. Dumont, Homo Hierarchicus. Le système des castes et ses implications, Paris (rééd. 1979).

Dupont $1955=$ P. Dupont, La Statuaire préangkorienne, Ascona, Artibus Asiae (Supplementum XV).

Evans $2009=$ D. Evans, «Towards a Landscape Archaeology of Koh Ker: Methods, Issues and Recent research ", dans János Jelen éd., Jaya Koh Ker Project. Annual Report 2009, Budapest (Royal Angkor Foundation), p. 25-63.

FinOT $1925=$ L. Finot, «Inscriptions d'Ańkor. I- Pràsàt Tà Kèo », BEFEO 25/1, p. 297-304.

FinOT 1926 = L. Finot (avec V. Goloubew et H. Parmentier), Le Temple d'I̧çvarapura, Paris (G. Van Oest, Mémoires archéologiques de l'EFEO I).

GILLET $2010=$ V. Gillet, La Création d'une iconographie sivaïte narrative. Incarnations du dieu dans les temples pallava construits, Pondichéry (collection Indologie 113).

GolzIO 2006 = K.-H. Golzio, Chronologie der Inschriften Kambojas: Verifizierung und Umrechnung von Datumsangaben der Śaka-Ära, Wiesbaden.

Granet 1968 = M. Granet, La Pensée chinoise,

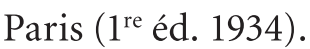

Griffiths 2005 = A. Griffiths (en coll. avec J.C. Eade et G. Gerschheimer), « La stèle d'installation de Śrī Tribhuvaneśvara : une nouvelle inscription préangkorienne du Musée national de Phnom Penh (K. 1214) », Journal asiatique 293/1, p. 11-43.

JACQUES $1994=$ C. Jacques, « Les Kamraten jagat dans l'ancien Cambodge ", dans 
F. Bizot dir., Recherches nouvelles sur le Cambodge, Paris (EFEO, Études thématiques 1), p. 213-225.

JACQUeS 2009 = C. Jacques, " The opening phase of the Khmer Empire: the Koh Ker adventure ", dans János Jelen éd., Jaya Koh Ker Project. Annual Report 2009, Budapest (Royal Angkor Foundation), p. 11-24.

Kyōraku 2001 = Kyōraku, Mahoko, « Le 'discours de la capitale' : le cas de Heian", dans J.-P. Berthon, A. Bouchy et P. F. Souyri dir., Identités, marges, médiations. Regards croisés sur la société japonaise (Actes des trois tables rondes franco-japonaises 19971998), Paris (EFEO, Études thématiques 10), p. 13-24.

LAJONQUIÈRE 1902 = E. Lunet de Lajonquière, Inventaire descriptif des monuments $d u$ Cambodge I, Paris (Imprimerie nationale, PEFEO IV).

L'HernaUlt 1978 = Fr. L'Hernault, L'iconographie de Subrahmanya au Tamilnad, Pondichéry (Publications de l'Institut français d'tndologie 59).

L'Hernault 1994 = Fr. L'Hernault, " Annexe 1 : L'iconographie ", dans P. Pichard et alii, Vingt ans après Tanjavur, Gangaikondacholapuram, 2 vol., Paris (Mémoires archéologiques de l'EFEO 20), p. 123-156.

Maxwell $2010=$ T.S. Maxwell, « 1. Prasat Kravan Central Temple - K. 270[1] and Iconography ", dans The A.I.S. Annual Report for 2010-2011, Technical Report to the $19^{\text {th }}$ UNESCO ICC-Angkor.
Nakagawa et Mizoguchi $2009=$ T. Nakagawa et A. Mizoguchi dir., Preliminary Report on the Ancient Khmer City Chok Gargyar [Koh Ker] (angl. et jap.), Laboratory of Architectural History, Waseda University.

PARMENTIER $1939=\mathrm{H}$. Parmentier, L'Art khmèr classique. Monuments du quadrant NordEst, 2 vol., Paris (PEFEO 29 bis).

Pollock $2006=$ S. Pollock, The Language of the Gods in the World of Men : Sanskrit, Culture and Power in the Premodern India, Berkeley (University of California Press).

Porte $2004=$ B. Porte, « Curieuses sculptures khmères », Arts asiatiques 59, p. 173-177.

Pou $2001=$ S. Pou, Nouvelles inscriptions $d u$ Cambodge. II et III (traduites et éditées), Paris (EFEO).

RovedA 2002 = V. Roveda, "Khmer Visual Narrative. La narration visuelle dans l'art khmer ", Museum international 213-214, p. 44-49.

RovEDA $2005=$ V. Roveda, Images of the Gods. Khmer mythology in Cambodia, Thailand and Laos, Bangkok (River Books).

SANDERSON 2003-2004 = A. Sanderson, " The Śaiva Religion among the Khmers (part I) », BEFEO 90-91, p. 349-462.

SCHMID $2010=$ Ch. Schmid, Le don de voir, premières représentations krishnaïtes de la région de Mathura, Paris (EFEO, Monographie 193).

SeIdenfaden $1922=$ E. Seidenfaden, "Complément à l'Inventaire descriptif des monuments du Cambodge pour les quatre provinces du Siam Oriental ", BEFEO 22, p. 55-99. 